\title{
Properties of $1 \mathrm{D}$ metal-induced structures on semiconductor suriaces
}

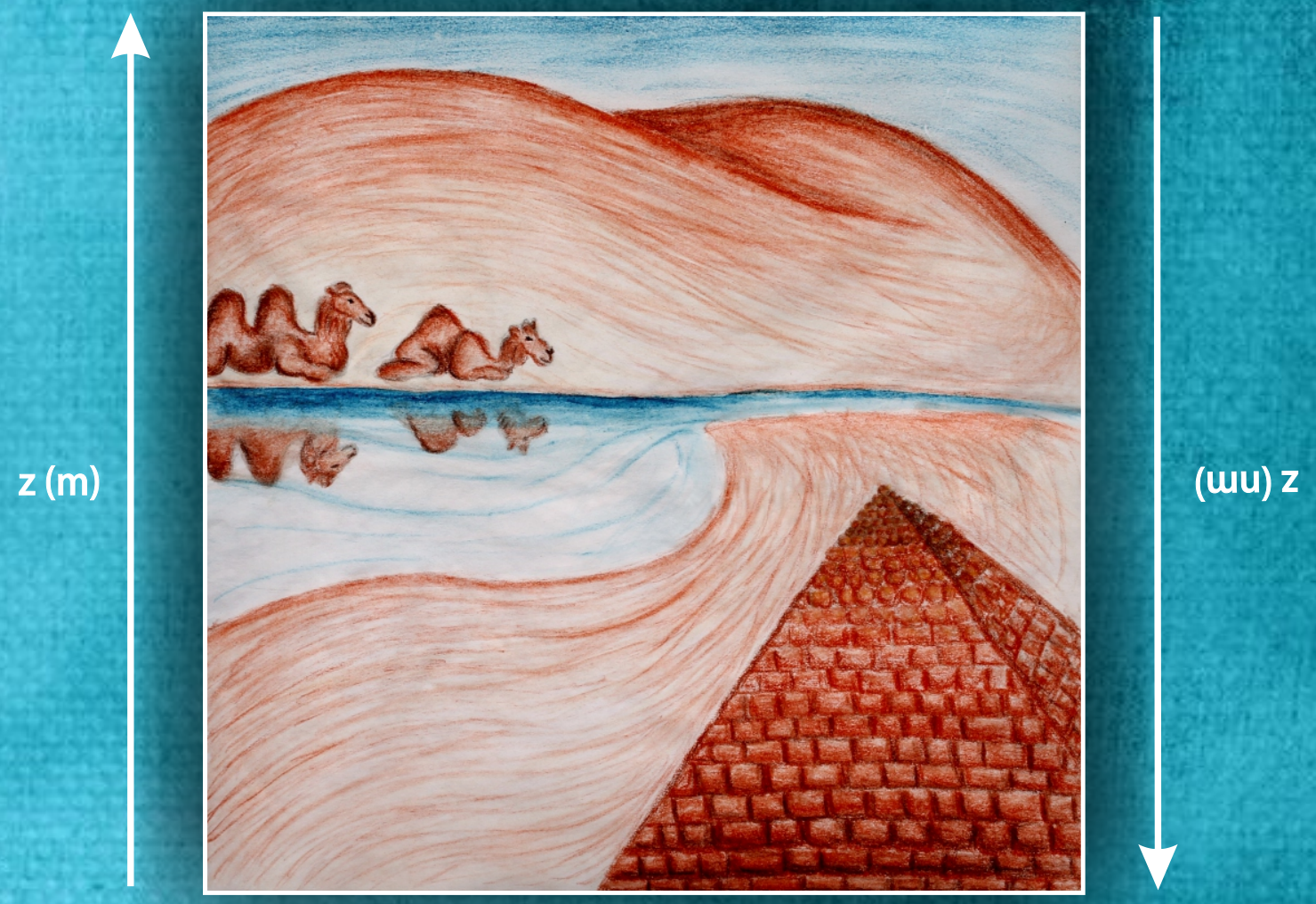

Tijs Mocking 


\section{Properties of 1D metal-induced structures on semiconductor surfaces}

Tijs Mocking 


\section{Composition of graduationcommittee:}

$\begin{array}{ll}\text { Chairman and secretary: } & \text { Prof. Dr. P. J. Kelly } \\ \text { Promotor: } & \text { Prof. Dr. Ir. H. J. W. Zandvliet } \\ \text { Members: } & \text { Prof. Dr. Ir. B. Poelsema } \\ & \text { Prof. Dr. Ir. W. G. van der Wiel } \\ & \text { Prof. Dr. D. C. Tegenkamp } \\ & \text { Prof. Dr. P. M. Koenraad } \\ & \text { Prof. Dr. D. van der Meer } \\ & \text { Dr. Ir. A. van Houselt } \\ \text { Referent: } & \end{array}$

The work described in this thesis was carried out in the Physics of Interfaces and Nanomaterials group, MESA+ Institute for Nanotechnology, University of Twente, The Netherlands.

This research was funded by the University of Twente.

T.F. Mocking

Properties of 1D metal-induced structures on semiconductor surfaces ISBN: 978-90-365-0179-8

DOI: $10.3990 / 1.9789036501798$

Published by Physics of Interfaces and Nanomaterials, University of Twente Printed by: Gildeprint drukkerijen

(C)T.F. Mocking, 2013, Enschede, The Netherlands

No part of this publication may be stored in a retrieval system, transmitted or reproduced in any way, including but not limited to photocopy, photograph, magnetic or other record, without prior agreement and written permission of the publisher.

Cover design: Eliane Nieuwenhuis

Author email: tfmocking@gmail.com 


\title{
PROPERTIES OF 1D \\ METAL-INDUCED STRUCTURES \\ ON SEMICONDUCTOR SURFACES
}

\author{
PROEFSCHRIFT
}

\author{
ter verkrijging van \\ de graad van doctor aan de Universiteit Twente, \\ op gezag van de rector magnificus, \\ prof. dr. H. Brinksma, \\ volgens besluit van het College voor Promoties \\ in het openbaar te verdedigen \\ op donderdag 19 september 2013 om 12:45 uur
}

door

Tijs Floor Mocking

geboren op 9 november 1984

te Utrecht 
Dit proefschrift is goedgekeurd door de promotor: prof. dr. ir. H.J.W. Zandvliet 


\section{Contents}

1 Introduction $\quad 7$

1.1 General . . . . . . . . . . . . . . . . 8

1.2 Germanium as a substrate . . . . . . . . . . 8

1.2.1 The Ge(001) surface - Short and long range interaction 9

1.2.2 The Ge(111) surface - $\mathrm{c}(2 \times 8)$ reconstruction . . . . 11

1.3 Why (1D metal-induced) nanostructures? . . . . . . . . . . 12

1.4 Outline of this thesis . . . . . . . . . . . . . . . 12

2 Experimental techniques and procedures $\quad 15$

2.1 Room temperature STM . . . . . . . . . . . . . . 16

2.2 Low temperature STM . . . . . . . . . . . . . . . 18

2.3 Helium-Ion Microscope . . . . . . . . . . . . . . . . 20

2.4 Cleaning and preparing the samples . . . . . . . . . 21

3 Au-induced nanowires on the $\mathrm{Ge}(001)$ surface 23

3.1 Introduction . . . . . . . . . . . . . . . 24

3.2 Experimental . . . . . . . . . . . . . . . . . . 25

3.3 Results and discussion . . . . . . . . . . . . . . 26

3.3.1 Structural properties of Au-induced nanowires _ . . . 26

3.3.2 Electronic properties of Au-induced nanowires . . . . 33

3.4 Conclusions . . . . . . . . . . . . . . . . . . 36

4 Dynamics of Au-induced nanowires and molecular bridges 37

4.1 Introduction . . . . . . . . . . . . . . . . 38

4.1.1 Further examination of Au-induced nanowires . . . . . 38

4.1.2 Au-induced nanowires as a template for molecules . . 39

4.2 Experimental methods . . . . . . . . . . . . . . . . . 40

4.3 Dynamics of Au-induced nanowires on $\mathrm{Ge}(001) \ldots \ldots$

4.4 Molecular bridges . . . . . . . . . . . . . . . . . 45 
4.5 Conclusions . . . . . . . . . . . . . . . . . 50

5 Co containing nano-islands on $\mathrm{Ge}(111)-\mathrm{c}(2 \times 8)$

5.1 Introduction . . . . . . . . . . . . . . 56

5.2 Experimental aspects . . . . . . . . . . . . . . 56

5.3 Results and discussion . . . . . . . . . . . . . 57

5.3 .1 Co on Ge(111) - Low coverage . . . . . . . . . 57

5.3.2 Co on Ge(111) - High coverage . . . . . . . . . . 65

5.4 Conclusions . . . . . . . . . . . . . . . . . 70

6 Co-induced nanocrystals on $\mathrm{Ge}(001)$ and $\mathrm{Ge}(111)$ surfaces 71

6.1 Introduction . . . . . . . . . . . . . . 72

6.2 Experimental aspects . . . . . . . . . . . . . . . . 73

6.3 Results and discussion . . . . . . . . . . . . . . . 74

6.3.1 Bistability of Co-induced nanocrystals on $\mathrm{Ge}(001)$. . 74

6.3.2 1D nanostructures on FNCs . . . . . . . . . . . . 78

6.3.3 Co-induced nanocrystals on $\mathrm{Ge}(111) \ldots \ldots$. . . . 80

6.4 Conclusions . . . . . . . . . . . . . . . . 86

7 Electronic growth of Ir nanowires on $\mathrm{Ge}(\mathbf{0 0 1}) \quad 87$

7.1 Introduction . . . . . . . . . . . . . . 88

7.2 Experimental aspects . . . . . . . . . . . . . . . 88

7.3 Results and discussion . . . . . . . . . . . . . . . . 89

7.4 Conclusions . . . . . . . . . . . . . . . . . 95

$\begin{array}{ll}\text { References } & 97\end{array}$

$\begin{array}{ll}\text { Summary } & 107\end{array}$

$\begin{array}{ll}\text { Samenvatting } & 111\end{array}$

$\begin{array}{ll}\text { Publicationlist } & 115\end{array}$

$\begin{array}{ll}\text { Dankwoord } & 117\end{array}$ 


\section{Introduction}

"Not only is the Universe stranger than we think, it is stranger than we can think."

- Werner Heisenberg 


\subsection{General}

In 1965 Gordon Moore stated that every 12 months a doubling of the number density of transistors placed on an integrated circuit will take place [1]. Up to now this law still holds, however, a limit to this law will be reached soon. When using the conventional 'top-down' approach for fabrication of electronic circuits and devices we are limited in scaling down the lateral size of electronic devices. With optical lithography the resolution is limited by the wavelength of the light. This thesis deals mainly with the creation of 1D (but also 2D and 3D) nanostructures, produced via the 'bottum-up' approach. With the term 'bottom-up' approach we mean a self-organization approach to nanofabrication using chemical or physical forces. Nature is capable of harnessing chemical forces for the creation of all the structures that are needed for life. And we like to take this example of nature's ability and let atoms and small clusters of atoms self-organize into nanosized structures. Three different metals deposited on semiconductor surfaces form the bulk of this thesis. Firstly, the gold (Au) on germanium $(\mathrm{Ge})(001)$ system, where $\mathrm{Au}$ atoms together with Ge atoms self-organize into very narrow and long nanowires. These Au-induced nanowires have the potential to serve as a model system for a 1D electron system. Secondly, cobalt- (Co) induced nanostuctures on $\mathrm{Ge}(001)$ and $\mathrm{Ge}(111)$ are studied. Nanosized crystals and islands are observed of which some show metallic behavior. Finally, iridium (Ir) nanowires are studied, showing a growth behavior that is stabilized by quantum confinement of Friedel oscillations.

\subsection{Germanium as a substrate}

While the first point-contact transistor was made of germanium (Ge), these days silicon $(\mathrm{Si})$ is widely used in semiconductor electronics. Si is used in virtually all integrated circuits and thus forms a basis for a large part of our modern technology. A Si substrate, slightly doped with small concentrations of other elements in order to tailor the electrical properties, is an excellent starting point for the realization of a large variety of electronic devices. Also the material can withstand very high temperatures and electrical powers and has a stable natural oxide.

Nowadays there is a renewed interest in Ge. But why are we using Ge as a substrate for our research? There are several reasons why Ge could be 


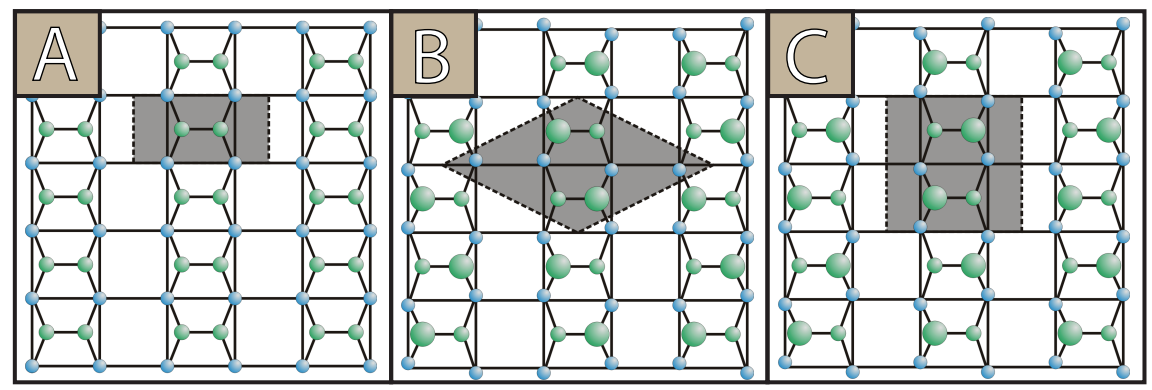

Figure 1.1: Ball and stick model of the different reconstructions that can be found on the $\mathrm{Ge}(001)$ surface. $(\mathrm{A})$ the $(2 \times 1)$ reconstruction with symmetric dimers. (B) and (C) asymmetric buckled dimers form the $\mathrm{c}(4 \times 2)$ and $\mathrm{p}(2 \times 2)$ reconstructions respectively.

chosen over $\mathrm{Si}$ : 1) compared to $\mathrm{Si}$, Ge crystal growth can take place at lower temperatures. 2) Ge has a smaller band gap than Si and it has substantially higher electron and hole mobilities. This can leed to higher-speed devices, for instance MOSFETs [2]. Furthermore, Ge can achieve higher switching speeds which will enable faster chips containing smaller transistors.

\subsubsection{The $\mathrm{Ge}(001)$ surface - Short and long range interaction}

Ge has a diamond crystal structure, which is composed of two interpenetrating $f c c$ sublattices. Large wafers with a particular lattice orientation are cut from pure intrinsic or doped Ge crystals. When a crystal is cut along the (001) plane all the surface atoms have two dangling bonds. These atoms move closer to each other, forming dimers to reduce the surface free energy. This way symmetric and asymmetric (buckled) dimers are created. Together they form long dimer rows in which the dimer bonds are oriented perpendicularly to the dimer row direction. In Fig. 1.1(A) the symmetric dimers form a $(2 \times 1)$ reconstruction. When the dimers buckle, an anti-phase $\mathrm{c}(4 \times 2)$ reconstruction (Fig. 1.1(B)) and an in-phase $\mathrm{p}(2 \times 2)$ reconstruction (Fig. 1.1(C)) can be formed. A topographic scan of the Ge(001) surface is shown in Fig. 1.2 where all three reconstructions are higlighted. 


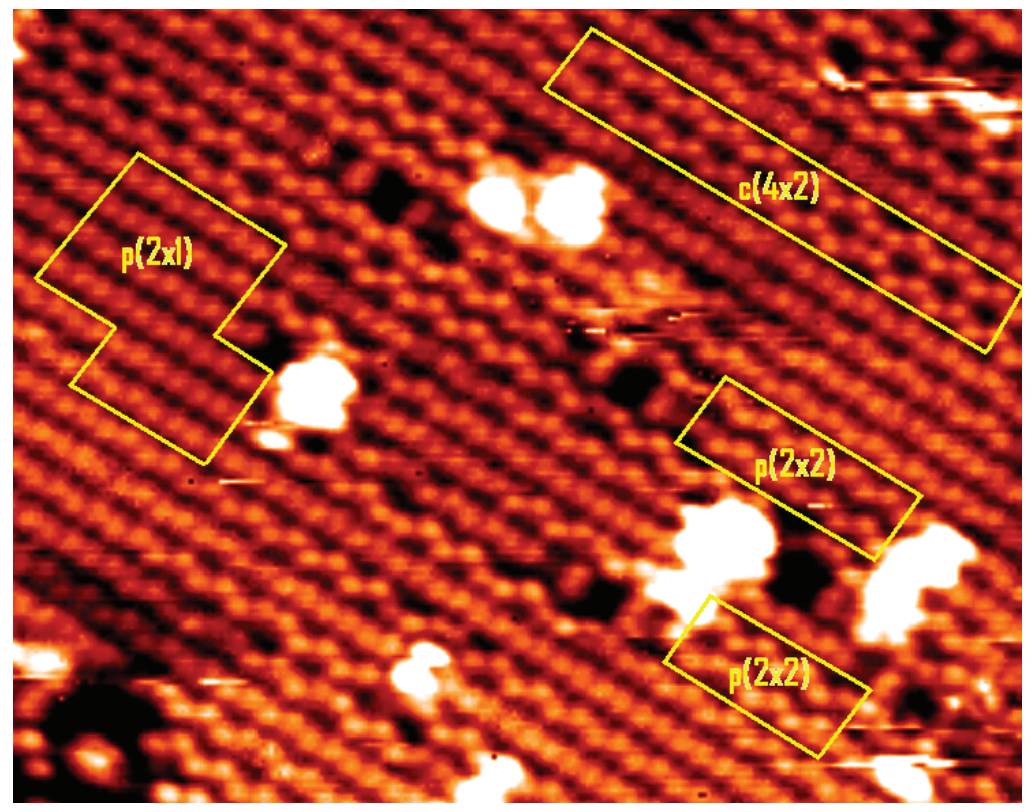

Figure 1.2: Ge(001) terrace showing all different reconstructions, highlighted in yellow. 


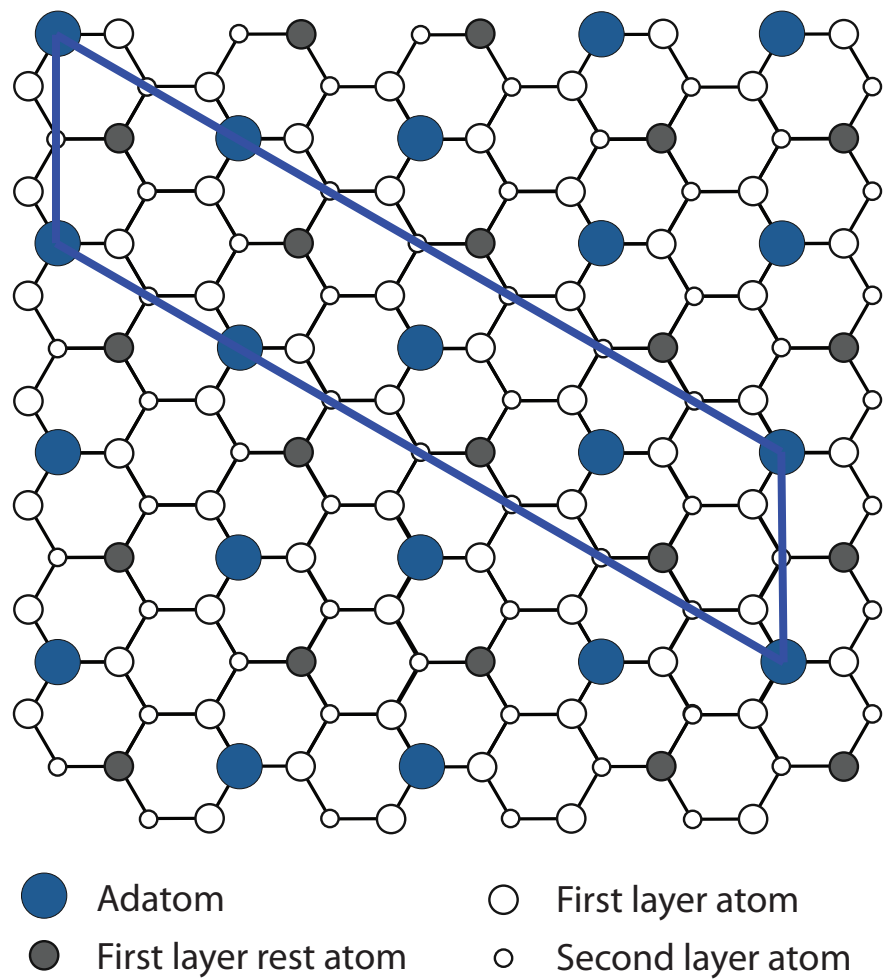

Figure 1.3: Ball and stick model of the Ge(111) surface. The $\mathrm{c}(2 \times 8)$ unit cell is highlighted with a paralellogram.

\subsubsection{The $\mathrm{Ge}(111)$ surface $-\mathrm{c}(2 \times 8)$ reconstruction}

When a Ge crystal is cut along the low energetic (111) plane the terraces are normally much larger than in the $\mathrm{Ge}(001)$ case. The reason is due to the fact that the (111) steps are of bilayer height or multiples thereof. Furthermore, a different reconstruction appears. As can be observed in Fig. 1.3 the Ge(111) surface has adatoms and rest atoms. These adatoms transfer some of their charge to the rest atoms. When the surface is scanned at negative bias we will observe mostly the rest atoms. If we scan the empty states of this surface the adatoms will be the dominant features. Both the adatoms and the rest atoms show a $\mathrm{c}(2 \times 8)$ reconstruction. 


\subsection{Why (1D metal-induced) nanostructures?}

A semiconductor surface can be modified by evaporating small amounts of metal atoms, such as $\mathrm{Pt}, \mathrm{Au}$ and $\mathrm{Ir}$, on them, after which an annealing step will trigger the self-organization of (sometimes 1D) nanostructures. We can list several reasons why there is a massive interest for these nanostructured surfaces. Of course there is a fundamental reason to study the behaviour and physics of atoms, clusters of atoms and of molecules at interfaces and in reduced dimensions. Theoretical calculations become seemingly more easy when one lowers the dimensions. However, experimentally it is very difficult to create a completely decoupled and stable $1 \mathrm{D}$ electron system. When atomic wires are created by applying the mechanical break junction (MBJ) technique $[3,4]$ the wires are only a few atoms long and often only stable for miliseconds. The 'bottom-up' approach makes it possible to build stable and long atomic wires on semiconductors of which the Fermi electrons are, at least in a naïve picture, decoupled from the semiconductor substrate.

Furthermore, the scaling down of electronic components is of great importance for industry. As mentioned before: the size of transistors should decrease following Moore's law, so that calculating power per unit area of transistors can increase. We are very interested in using the 'bottom-up' approach to create, tailor and functionalize, for example, nanowires, -switches and other electronic components, or to create possibilities for efficient data storage on the nanoscale.

\subsection{Outline of this thesis}

Imaging atoms and structures that have a size of several nanometers cannot be done using standard optical techniques. A scanning tunneling microscope uses small tunneling currents to make a topographic image of a surface and is also well capable of doing spectroscopic measurements. The experimental setup and the procedure of preparing the samples will be discussed in Chapter 2 .

Au-induced nanowires are the reason of an intense discussion between several research groups all over the world. Both the structural and electronic properties can easily be misinterpreted. In Chapter 3 we show our results on this topic.

In Chapter 4 we study the properties of a dynamic dimer on top of the 
Au-induced nanowire. Furthermore, the nanowires are an ideal template for the deposition of copper-phtalocyanine molecules. This chapter also deals with these 'molecular bridges'.

In Chapter 5 the Co-modified Ge(111) surface is studied. The deposition of $\mathrm{Co}$ on $\mathrm{Ge}(111)$ leads to the formation of two different types of nano islands that were examined in great detail. Furthermore, at higher coverage these islands show several types of domain boundaries and a faint superstructure.

Co has also been deposited on the Ge(001) sample. When the amount of Co and the annealing temperature are high enough we observe the formation of nanocrystals. In Chapter 6 one can find a bistability of nanocrystals, namely peaked nanocrystals, and flat-topped nanocrystals. Similar nanocrystals can be created on Ge(111). It becomes clear that steps on the surface, but also domain boundaries can act as a nucleation site for the formation of nanocrystals.

Finally, in Chapter $7 \mathrm{Ir}$ is deposited on a Ge(001) surface, resulting into well-defined nanowires. The length and density of these nanowires can be controlled by the deposited amount and the annealing temperatures. The wires consist of long rows of atom pairs and are metallic. The growth is strongly influenced by quantum confinement of Friedel oscillations. 

The invention and development of the scanning tunneling microscope (STM) by Gerd Binnig and Heinrich Rohrer in 1981 resulted in a Nobel Prize in Physics in 1986. The STM is a very powerful tool for imaging surfaces at the atomic level: with a lateral resolution of about $0.1 \mathrm{~nm}$ and a $z$-resolution in the pm range this instrument is capable of imaging atoms. Furthermore, besides the topographic possibilities, the STM can also be used for spectroscopic measurements, providing information on chemical, electronical and dynamical properties of a surface. In this chapter the STM-setups used in this research will be introduced. Finally, the helium-ion microscope (HIM) as well as the preparation method of the samples will be briefly described. 


\subsection{Room temperature STM}

A large fraction of the results that are obtained in this project are collected with a room temperature STM from Omicron: the STM-1. An image of this setup is shown in Fig. 2.1. The STM-1 can be divided into three parts:

- STM Chamber (containing the STM)

- Preparation Chamber (for preparing and cleaning samples)

- Load Lock (for insertion and removal of samples and tips)

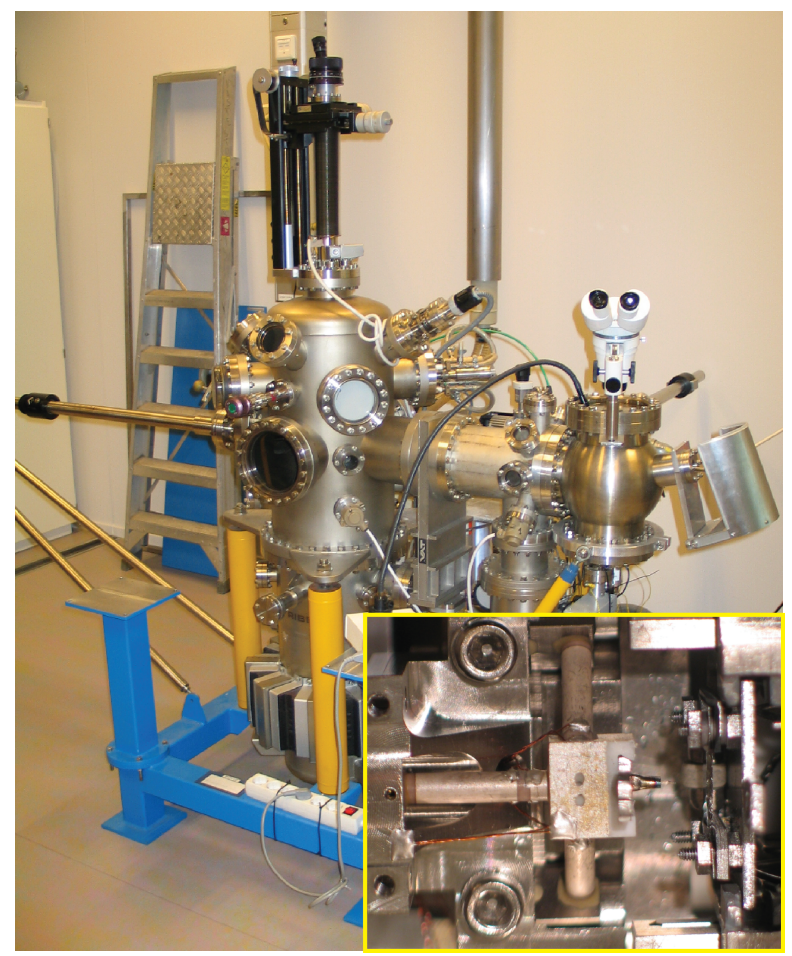

Figure 2.1: Photo of the STM-1 UHV system, located in the MESA+ nanolab. The inset shows the STM-tip (middle) in front of the sample (right). 


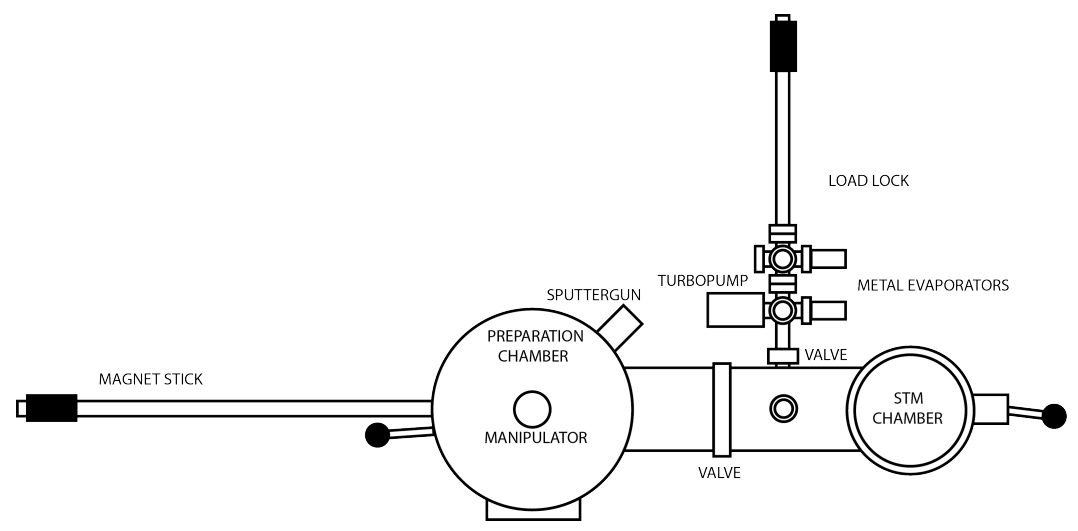

Figure 2.2: A schematic top view on the room temperature STM. The STM chamber, the preparation chamber, the load lock, the wobble sticks and the magnet sticks are outlined.

The STM chamber is connected to the load lock and the preparation chamber. The chambers are seperated by UHV valves and the transfer of samples between the UHV chambers is realized with the help of magnet sticks. The STM chamber together with the preparation chamber are pumped by a 340 $\mathrm{l} / \mathrm{s}$ turbo-molecular pump and a $200 \mathrm{l} / \mathrm{s}$ ion getter pump. The ion pump is integrated with a $1600 \mathrm{l} / \mathrm{s}$ Ti sublimation pump. The turbo pump is located in the main chamber, while the ion and Ti sublimation pump are located in the preparation chamber. These pumps are used to keep the system at a typical background pressure of $5 \cdot 10^{-11}$ mbar. The load lock is seperately pumped using a $70 \mathrm{l} / \mathrm{s}$ turbo-molecular pump maintaining a background pressure in the load lock of about $1 \cdot 10^{-8}$ mbar. The valve in between the load lock and the STM chamber is only opened for tip and sample transfers in order to keep a good background pressure in the main chambers. A schematic topview on the STM-1 is shown in Fig. 2.2. The three chambers, the valves and the magnet sticks are shown in this schematic view. 
In the preparation chamber we have the following facilities:

- a heating stage (273 $\mathrm{K}$ to $1500 \mathrm{~K})$

- a five degrees of freedom sample manipulator

- a sputter gun

- a leak valve

- several metal evaporators (Pt, $\mathrm{Au}, \mathrm{Ir}, \mathrm{Cu}, \mathrm{Co})$

- a quadrupole mass spectrometer

The sample is put into the sample manipulator in order to clean it by $\mathrm{Ar}^{+}$-bombardment and annealing via a DC current. The Ar gas can be introduced via the leak valve, while the sputter gun will ionize and accelerate the $\mathrm{Ar}^{+}$ion beam. Metal atoms can be evaporated onto the sample using the various metal evaporators. More metal evaporators are located in the load lock. The mass spectrometer can analyze the gas content of both the preparation chamber and the STM chamber. The commercially available room temperature STM-1 is operated using SCALA software. Both the STM and the software are provided by Omicron Nanotechnology GmbH. The STM can operate at biases from -10 to $+10 \mathrm{~V}$ and tunneling currents in the range from $10 \mathrm{pA}$ to $50 \mathrm{nA}$. The STM is isolated by an internal spring suspension system and (permanent) magnets for eddy current damping. A carrousel is positioned within the STM chamber which can store up to 8 samples and/or tips. STM-1 tips are electrochemically etched from a tungsten (W) wire with a diameter of $0.375 \mathrm{~mm}$.

\subsection{Low temperature STM}

The configuration of the LT-STM (shown in Fig. 2.3) is very similar to that of the STM-1. It also consists of a load lock, a preparation chamber and an STM chamber. The small difference lies in the fact that the load lock is connected via a UHV valve to the preparation chamber, which enables us to keep an even lower background pressure in the STM chamber, which is seperated from the preparation chamber by another UHV valve that is always closed during measurements. The preparation chamber is pumped by a 170 l/s turbo-molecular pump, while the STM chamber is pumped by a $400 \mathrm{l} / \mathrm{s}$ ion getter pump, which is integrated with a $1600 \mathrm{l} / \mathrm{s}$ Ti sublimation pump. This way the background pressure can be easily kept well below $3 \cdot 10^{-11}$ mbar. 
New samples and tips are introduced via the load lock which is pumped by a $70 \mathrm{l} / \mathrm{s}$ turbo-molecular pump.

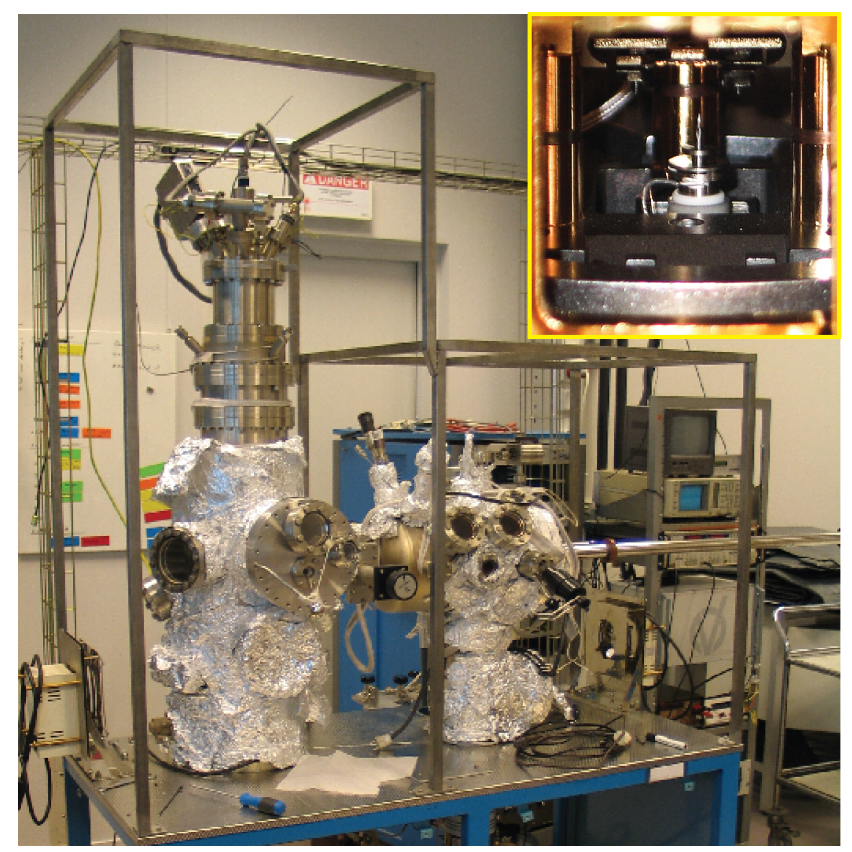

Figure 2.3: Photo of the LT-STM UHV system, located in the same MESA+ nanolab. The inset shows the STM-tip (bottom) and the sample (top). 
In the preparation chamber we have the following facilities:

- a heating stage (273 to $1500 \mathrm{~K}$ )

- a sputter gun

- a leak valve

- a platinum evaporator

- a Knudsen cell equipped with a quartz crucible

- a quadrupole mass spectrometer

The samples are cleaned in the heating stage by $\mathrm{Ar}^{+}$-bombardment and annealing via a DC current. Ar atoms are introduced via the leak valve, ionized and accelerated towards the sample by the sputter gun. The platinum $(\mathrm{Pt})$ evaporator (for deposition of atoms) is located in the preparation chamber, while the gold $(\mathrm{Au})$ evaporator is located in the load lock. A Knudsen cell is available for depositing organic molecules with low vapor pressures on the sample. The mass spectrometer can analyze the gas content of both the preparation chamber and the STM chamber.

The LT-STM is commercially available and can be operated using SCALA software. Both the STM and the software are provided by Omicron Nanotechnology GmbH. Another advantage of this STM is that it can operate at temperatures ranging from $4.7 \mathrm{~K}$ to $300 \mathrm{~K}$. The STM is located in a double cryostate. Measurements can be performed at 4.7 and $77 \mathrm{~K}$ if the cryostates are filled with liquid helium $(\mathrm{He})$ or liquid nitrogen $(\mathrm{N})$, respectively. Intermediate temperatures are reached using a counter heater. The STM operates at biases ranging from -10 to $+10 \mathrm{~V}$ and tunneling currents in the range from $1 \mathrm{pA}$ to $50 \mathrm{nA}$. The LT-STM is isolated by an internal spring suspension system and (permanent) magnets for eddy current damping. A carrousel is positioned in both the STM chamber and the preparation chamber. They can each store up to 6 samples and/or tips. LT-STM tips are electrochemically etched from a $\mathrm{W}$ wire with a diameter of $0.375 \mathrm{~mm}$.

\subsection{Helium-Ion Microscope}

The HIM is a powerful microscope and its functionality is in some aspects similar to that of a scanning electron microscope (SEM). It uses a focused beam of He ions instead of electrons. He ions can be focused into a smaller probe size and this gives a better resolution than electrons. A He ion source 
is stable and, if maintained under cryogenic condictions, will provide beam currents between $1 \mathrm{fA}$ and $25 \mathrm{pA}$. The ion source can be described as a sharp needle and is located in a UHV system with a background pressure of $5 \cdot 10^{-9}$ mbar. When a high voltage is applied to this tip a strong electric field will be created ionizing nearby He atoms. These He ions are then accelerated towards the sample and focussed on a surface area with a diameter as small as $0.75 \mathrm{~nm}$. Here they can collide with a surface atom or penetrate into the bulk. This ion bundle is then rastered across the sample. The primary energy of the He beam can be varied from $10 \mathrm{kV}$ to $35 \mathrm{kV}$.

There are several ways of imaging with this technique of which two are used in this thesis: secondary electron detection and backscattered ion detection. When surface atoms are hit by a He ion there is a chance that an electron is scattered from this atom. These secondary electrons are detected providing information of material composition and shape of the measured pixel. After the collision with a surface atom the He ion can also be backscattered and then detected. The amount of backscattered ions per pixel can give information about elemental and structural properties, but also about differences in crystal structure or crystal orientation.

\subsection{Cleaning and preparing the samples}

Ge substrates were cut from nominally flat 3 in. single-side-polished and lightly $\mathrm{Sb}$ doped n-type wafers with a resistivity of less than $0.01 \Omega \cdot \mathrm{cm}$. The samples were mounted on Mo holders and contact with any metal was avoided during the preparation. In order to grow nanometer sized ordered metal structures on semiconductor surfaces, these surfaces first have to be atomically clean. After inserting the samples into the UHV system they are degassed for at least 12 hours by sending a DC current through the sample, resistively heating it to $500-600 \mathrm{~K}$. This is followed by cycles of $\mathrm{Ar}^{+}$-sputtering and flash-annealing. Sputtering conditions: $800 \mathrm{eV} \mathrm{Ar}^{+}$ions induce a sputtering current of $6 \mu \mathrm{A}$ at a pressure of $3 \cdot 10^{-5}$ mbar. After 20 minutes of sputtering the sample is flash-annealed at a temperature of 1100 K. Typically this cycle needs to be repeated 5-7 times before an atomically clean surface is obtained. This can be checked by imaging the surface using the STM.

When the sample is atomically clean, it can be exposed to metal (Pt, Au, Ir or $\mathrm{Co}$ ) atoms after which an annealing procedure is performed to allow the 
surface atoms to self-organize into nanosized structures. During annealing temperatures were measured using a pyrometer (Wahl Heatspy). Metals were evaporated by heating a $0.375 \mathrm{~mm}$ diameter tungsten wire wrapped with high purity metals (99.9\%-99.995\% pure). For organic molecule adsorption experiments copper-phtalocyanine molecules were deposited onto the sample using the Knudsen cell. 


\section{III \\ Au-induced nanowires on the $\mathrm{Ge}(001)$ surface}

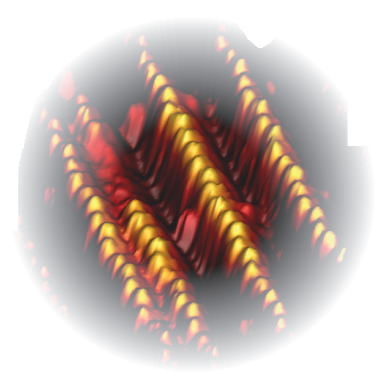

In this chapter we investigate the structural and electronic properties of $\mathrm{Au}$-induced self-organized nanowires on $\mathrm{Ge}(001)$, prepared by two different procedures, at room temperature and $77 \mathrm{~K}$. We find that the Au-induced nanostructures are identical for the different preparation procedures. The Au-induced nanowires are comprised of dimers that have their bond aligned in a direction perpendicular to the nanowire. The dimers are buckled, leading to a $2 \times$ periodicity along the nanowires. The troughs between the nanowires have a depth of several atomic layers. Furthermore, we measure the differential conductivities of the nanowires and the troughs and found that the troughs are slightly more metallic than the nanowires. 


\subsection{Introduction}

The properties of electron systems become increasingly exotic as one progresses from the three-dimensional (3D) case into lower dimensions. In $2 \mathrm{D}$ electron systems novel and intriguing physical phenomena, such as the integer [5] and fractional quantum Hall effect [6,7] have been found. More recently, the realization of a single layer of graphite (graphene) has resulted in a wealth of unexpected and exciting physical phenomena [8]. For instance, the electron transport in graphene is governed by the relativistic Dirac equation rather than by the Schrödinger equation [9]. The predictions for 1D electron gases lead to even more exotic properties. The Fermi liquid approach breaks down spectacularly in one dimension $[10,11]$. It has been predicted that the 1D electron gas is much better described by the Luttinger liquid formalism. One of the intriguing predictions of a Luttinger liquid is that the electron loses its identity and separates into two collective excitations of the quantum mechanical many body systems: a spinon that carries spin without charge, and a holon that carries the positive charge of a hole without its spin. The major problem with 1D electron systems is that they are much harder to realize than their $2 \mathrm{D}$ and $3 \mathrm{D}$ counterparts. The ideal $1 \mathrm{D}$ system would be a freely suspended atomic chain. Using the quantum mechanical break junction approach such freely suspended atomic chains can indeed be made [12]. However, the maximum length of these atomic chains is limited to only a few atoms and the lifetime is often very short. As an alternative, atomic chains can be created on surfaces either via self-organization, $[13,14]$ step decoration, [15] or atom-by-atom manipulation [16] using scanning tunneling microscopy (STM). In order to electronically decouple the electrons near the Fermi level from the underlying substrate often a material with a band gap is chosen [17-19]. Examples that fall in this category are $\mathrm{Pt}$ and Au-induced one-dimensional structures on Ge(001) surfaces [20-24]. Wang and co-workers $[21,22]$ reported the formation of a zigzag Au dimer row upon deposition of $\mathrm{Au}$ on $\mathrm{Ge}(001)$. Recently, Schäfer and co-workers [23] reported that the deposition of $\mathrm{Au}$ on $\mathrm{Ge}(001)$ leads to the formation of Au chains with a diameter of only a single atom, which represent an outstandingly close approach to a one-dimensional electron liquid. These authors report a change of the tunneling conductivity by two orders of magnitude when comparing the ridges of the self-organized nanowires with the troughs in between the nanowires. Their preparation method is, however, somewhat different from 
the one used by Wang et al. [21,22] and van Houselt et al. [24] Since there is some controversy regarding the exact structural and electronic properties of the Au-induced nanowires prepared by the different research groups we have revisited this system by comparing the Au-induced nanowires that have been prepared by the different preparation procedures. In this Chapter, we compare two preparation procedures, namely (1) deposition of $\mathrm{Au}$ at 775 $\mathrm{K}$ and (2) deposition of $\mathrm{Au}$ at room temperature followed by an anneal at $650 \mathrm{~K}$. The first method is applied by Schäfer et al., [23] whereas Wang et al. $[21,22]$ and van Houselt et al. [24] used the second method. On the basis of STM and scanning tunnelling spectroscopy (STS) measurements, we found that the resulting structures are in both cases electronically and structurally identical. In agreement with both Wang et al. [21,22] and Schäfer et al. [23] the $\mathrm{Au}$-induced nanowires are $1.6 \mathrm{~nm}$ separated apart. However, the height of these structures turns out to be at least $5 \AA$, i.e., several atomic layers, rather than the one layer $(1.5 \AA)$ reported by Schäfer et al. [23] and Wang et al. [21] Furthermore, in agreement with Wang et al. we found that the $\mathrm{Au}$-induced nanowires are two atoms wide, rather than one atom. Finally, our experiments reveal that the differential conductivities of the nanowires and the regions in between the nanowires are very comparable in magnitude.

\subsection{Experimental}

Experiments were performed with a low-temperature and a room temperature STM from Omicron, both operating in ultrahigh vacuum. $\mathrm{Ge}(001)$ substrates were cut from nominally at $3 \mathrm{in}$. by $0.5 \mathrm{~mm}$, about $25 \Omega \cdot \mathrm{cm}$ resistance, single-side-polished n-type wafers. Samples were mounted on Mo holders and contact of the samples to any other metal during preparation and experiment has been carefully avoided. The Ge(001) samples were cleaned by prolonged $800 \mathrm{eV} \mathrm{Ar}^{+}$ion sputtering and annealing via resistive heating at $1100( \pm 25) \mathrm{K}$. The temperature was measured with a pyrometer. After several cleaning cycles the $\mathrm{Ge}(001)$ samples were atomically clean and exhibited a well ordered $(2 \times 1) / \mathrm{c}(4 \times 2)$ domain pattern $[24,25]$. We have applied two methods to prepare the Au-induced self-organizing one-dimensional structures. In the first method an equivalent of 0.5 monolayers of $\mathrm{Au}$ was deposited onto the surface at $775( \pm 25) \mathrm{K}$. Au was evaporated by resistively heating a $\mathrm{W}$ wire wrapped with high purity $\mathrm{Au}$ (99.995\%). In the second method an equivalent of 0.5 monolayers of $\mathrm{Au}$ was deposited at room tem- 
perature. After Au deposition the sample was annealed at $650( \pm 25) \mathrm{K}$ for 2 minutes and then cooled down to room temperature by radiation quenching before placing it into the STM for observation.

\subsection{Results and discussion}

\subsubsection{Structural properties of Au-induced nanowires}

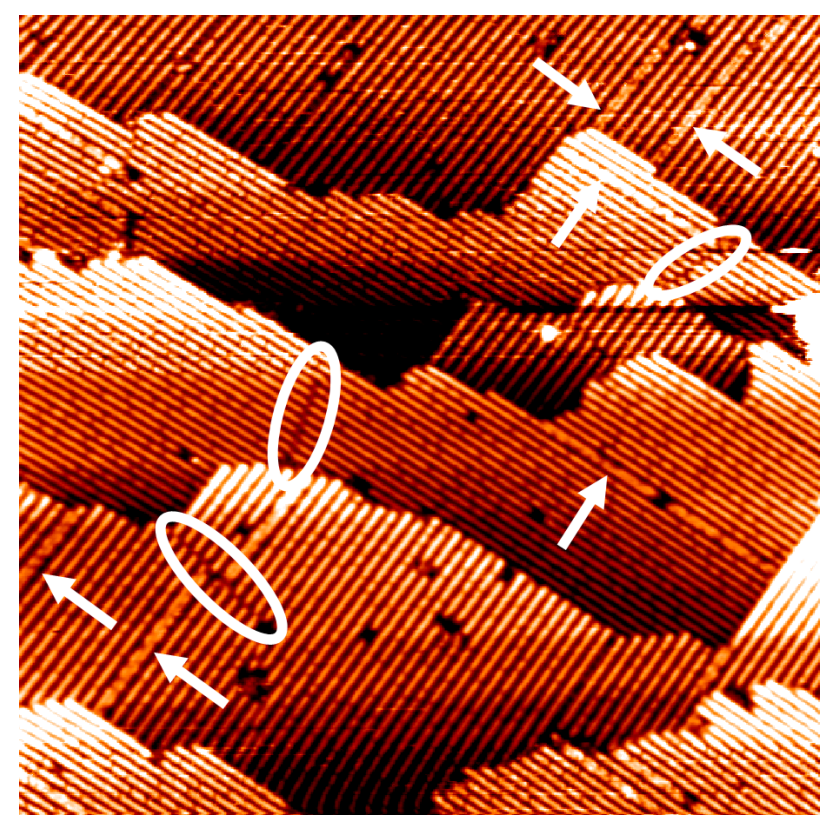

Figure 3.1: Overview of a $\mathrm{Ge}(001)$ surface covered with Au-induced nanowires. The arrows indicate double wires while the ellipses highlight phase defects. The sample bias is $-1.5 \mathrm{~V}$, the tunnel current is $0.5 \mathrm{nA}$ and the image size is $100 \mathrm{~nm}$ by $100 \mathrm{~nm}$

In Fig. 3.1 an overview of the Au-induced nanowires is shown. The wires run in two distinct directions, rotated $90^{\circ}$ with respect to each other. These directions are identified as the [110] and [110] directions of the underlying substrate. The wire direction changes with each monatomic step of the underlying $\mathrm{Ge}(001)$ surface. Although most of the wires are spaced $1.6 \mathrm{~nm}$ apart, there are several instances, marked with arrows, where they are only spaced $0.8 \mathrm{~nm}$. There are phase defects in the wire arrays, marked with 


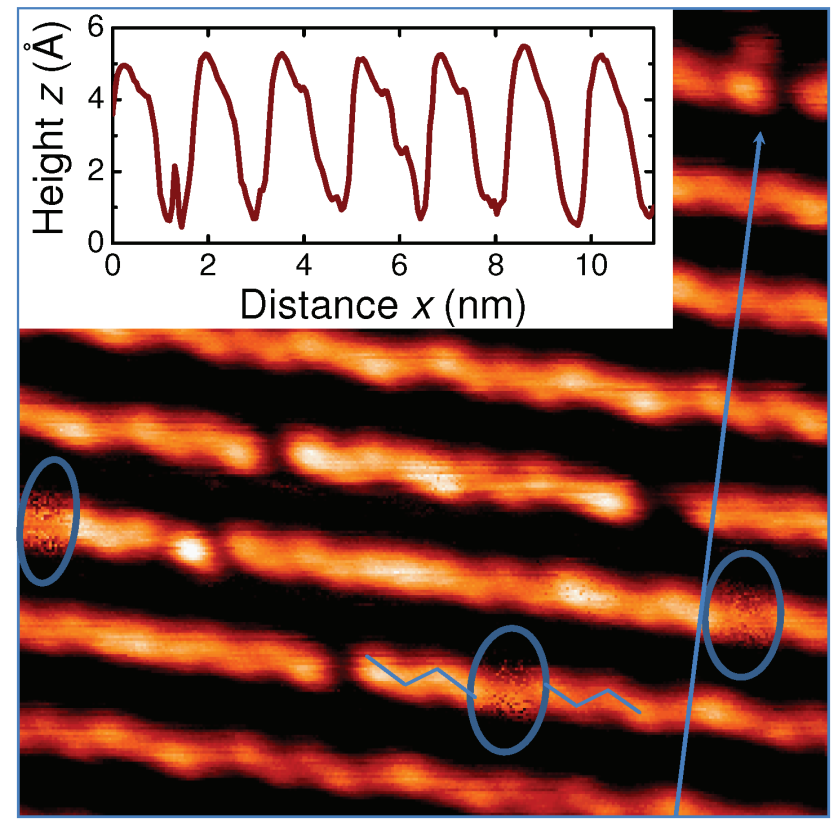

Figure 3.2: Scanning tunneling microscopy image of an array of Au-induced nanowires on a Ge(001) surface taken at room temperature. The Au-induced nanowires are prepared by deposition of $\mathrm{Au}$ at $775 \mathrm{~K}$. The ellipses mark dimers that exhibit flip-flop motion during imaging. Sample bias is $-0.5 \mathrm{~V}$, tunneling current is $0.4 \mathrm{nA}$ and the image size is $12.5 \mathrm{~nm}$ by $12.5 \mathrm{~nm}$. Inset: Line scan taken across the Au-induced nanowires. The depth of the troughs is about 4-5 $\AA$ and thus involves several atomic layers. 
white ellipses. Here the patches of wires are displaced approximately $4 \AA$ with respect to each other. This distance corresponds with the length of one unit cell of the unreconstructed Ge crystal lattice.

In Fig. 3.2 an STM image of an array of Au-induced nanowires on a $\mathrm{Ge}(001)$ surface is depicted. An equivalent of 0.5 monolayers of $\mathrm{Au}$ was deposited on a $\mathrm{Ge}(001)$ sample kept at a temperature of $775 \mathrm{~K}$. After cooling down to room temperature the sample was imaged with STM. A line profile recorded in a direction perpendicular to the nanowire direction is shown in the inset of Fig. 3.2. The depth of the troughs is about $4-5 \AA$ and thus involves several atomic layers. It should be pointed out here that one needs a very sharp STM tip in order to measure the depth of the troughs between the densely packed nanowires. With a blunt tip the extracted trough depth will be significantly smaller. Interestingly, using the same growth procedure and sample treatment Schäfer et al. [23] found that the depth of the troughs is only one atomic layer.

A depth of $5 \AA$ of the trenches implies that the observed Au-induced nanowires can not just be explained by chains of $\mathrm{Au}$ atoms on top of the Ge surface. It took about four years after their discovery, until a model was introduced that was able to explain the basic structural and electronic features $[24,26]$. Based on the alignment of the zigzag structures along the [110] directions and considering the $5 \AA$ deep trenches, the Au-induced surface structure is composed of alternating $\mathrm{Ge}(\overline{1} 11)$ and $\mathrm{Ge}(1 \overline{1} 1)$ micro-facets with buckled Ge dimers at the edges of the micro-facets [24]. The deposition of $\mathrm{Au}$ on $\mathrm{Ge}(111)$ surfaces, which are identical to the micro-facets, had been studied in earlier research [27]. A $(\sqrt{3} \times \sqrt{3}) \mathrm{R} 30^{\circ} \mathrm{Au}$ structure was found, in which the $\mathrm{Au}$ atoms are embedded into the top layer of the Ge(111) surface. Furthermore, the Au atoms form trimers. The zigzag structure is made out of buckled Ge dimer rows, which have striking similarities with the buckled dimer rows of the $\mathrm{c}(4 \times 2)$ and $\mathrm{p}(2 \times 2)$ reconstructed $\mathrm{Ge}(001)$ surface. Hence, the zigzag appearance of the dimer rows is due to the fact that adjacent dimers prefer to buckle in opposite directions. Connecting the alternating $\mathrm{Au} / \mathrm{Ge}$ facets with the $\mathrm{Ge}(001)$ surface reconstruction, one gets the presently accepted, but still incomplete, model for the trenches. Fig. 3.3 shows a schematic of the described model.

Subsequently we deposited 0.5 monolayer of $\mathrm{Au}$ on a fresh $\mathrm{Ge}(001)$ sample kept at room temperature. After the deposition process the sample was annealed at $650 \mathrm{~K}$ for two minutes. In Fig. 3.4 an STM image of the Au- 


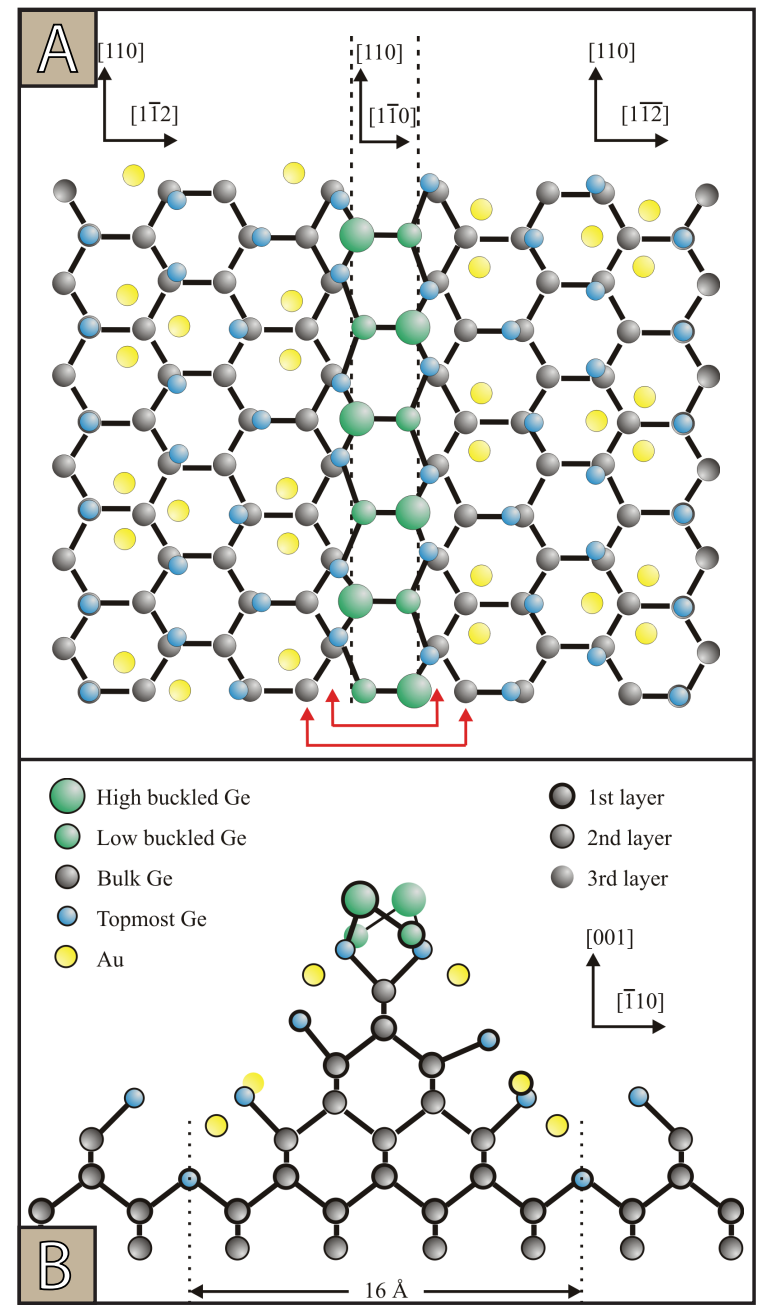

Figure 3.3: Ball and stick model of Au-induced nanowires. Schematic top view (A) and side view (B) of the (111) and (1111) facets. Au atoms form trimers and are embedded in the topmost $\mathrm{Ge}(111)$ plane. The blue Ge atoms are the topmost Ge atoms in the $(\sqrt{3} \times \sqrt{3}) \mathrm{R} 30^{\circ} \mathrm{Au}$ overlayer. Note that the Ge dimers on top (green) are buckled, the larger atoms are the higher atoms of the dimers. The atom rows connected by the red arrows are the same. They appear in the topview of both facets. 
induced nanowires is depicted. A line scan taken in a direction perpendicular to the nanowires is shown in the inset of Fig. 3.4. The image has the same characteristics as mentioned for Fig. 3.2: The Au-induced nanowires appear as bright zigzag rows in the image, occasionally interrupted by defects and noisy appearing dimers (marked by ellipses). A line scan taken in a direction perpendicular to the nanowires is shown in the inset of Fig. 3.4. The height is calibrated at a monatomic step of the bare $\mathrm{Ge}(001)$ surface which has a height of $1.4 \AA$. Again the depth of the troughs is about $4-5 \AA$ and thus involves several atomic layers.

The deposition of 0.3 monolayer Au leads for both preparation procedures to a surface containing nanowire and nanowire-free regions, whereas the deposition of more than 1-1.5 monolayer of Au results in the coexistence of nanowire regions and rectangular-shaped 3D clusters [22]. For growth or anneal temperatures that exceed $1000 \mathrm{~K}$ no nanowires are found.

First we discuss the structure of Au-induced nanowires. The STM images shown in Figs. 3.2 and 3.4 are very comparable and thus provide strong evidence for the fact that the structure of the $\mathrm{Au}$-induced nanowires is independent of the preparation method. The idea that the Au-induced nanowires are comprised of buckled dimers, leading to a $2 \times$ periodicity along the nanowire direction, has already been put forward in the first paper on the $\mathrm{Au} / \mathrm{Ge}(001)$ system by Wang et al. [21] In Figs. 3.2 and 3.4 zigzag lines that refer to the buckling registry in the $\mathrm{Au}$-induced nanowires are shown. Occasionally antiphase boundaries in the buckling registry are observed, leading to a single dimer that flips back and forth between the two buckled states, since this dimer does not know whether to align with its left or right neighbor. These flip-flopping dimers have a frizzy appearance and are present in Figs. 1(B) and 4 of ref [24], as well as Figs. 3.2 and 3.4 of the current work (they are marked by ellipses). Moreover, they are also observable in Fig. 2(A) of Ref. [21]. A detailed analysis of the distribution of the residence times in the two buckled states is discussed in Chapter 4 and shows that the flip-flop process is a stochastic process. The Ge dimers of the pristine Ge(001) surface are also known to exhibit such a stochastic flip-flop motion [28]. The buckling of the dimers leads to a periodicity of $0.8 \mathrm{~nm}$ along the nanowires. Schäfer et al. [23] observed the same periodicity along the nanowire direction. However, on the basis of an analysis of the Full Width at Half-Maximum (FWHM) of the Au-induced nanowires, which was measured to be $0.72 \pm 0.03 \mathrm{~nm}$, they concluded that the nanowires have a width of only one atom. In Fig. 3.5 STM 


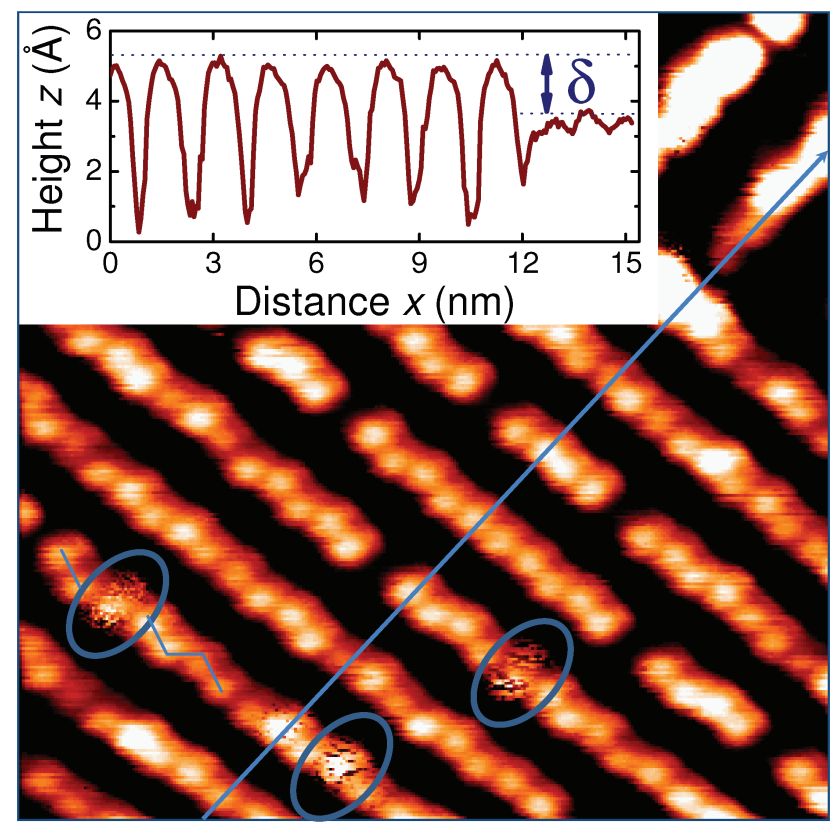

Figure 3.4: Scanning tunneling microscopy image of an array of Au-induced nanowires on a Ge(001) surface taken at room temperature. The Au-induced nanowires are prepared by deposition of $\mathrm{Au}$ at room temperature followed by annealing at $650 \mathrm{~K}$. The ellipses mark dimers that exhibit flip-flop motion during imaging. Sample bias is $-1.0 \mathrm{~V}$, tunnel current is $0.6 \mathrm{nA}$ and the image size is $12.5 \mathrm{~nm}$ by $12.5 \mathrm{~nm}$. Inset: Line scan taken across the Au-induced nanowires. The depth of the troughs is about $4 \AA$ and thus involves several atomic layers. The monatomic step height, $\delta(=1.4 \AA)$, is also indicated. 


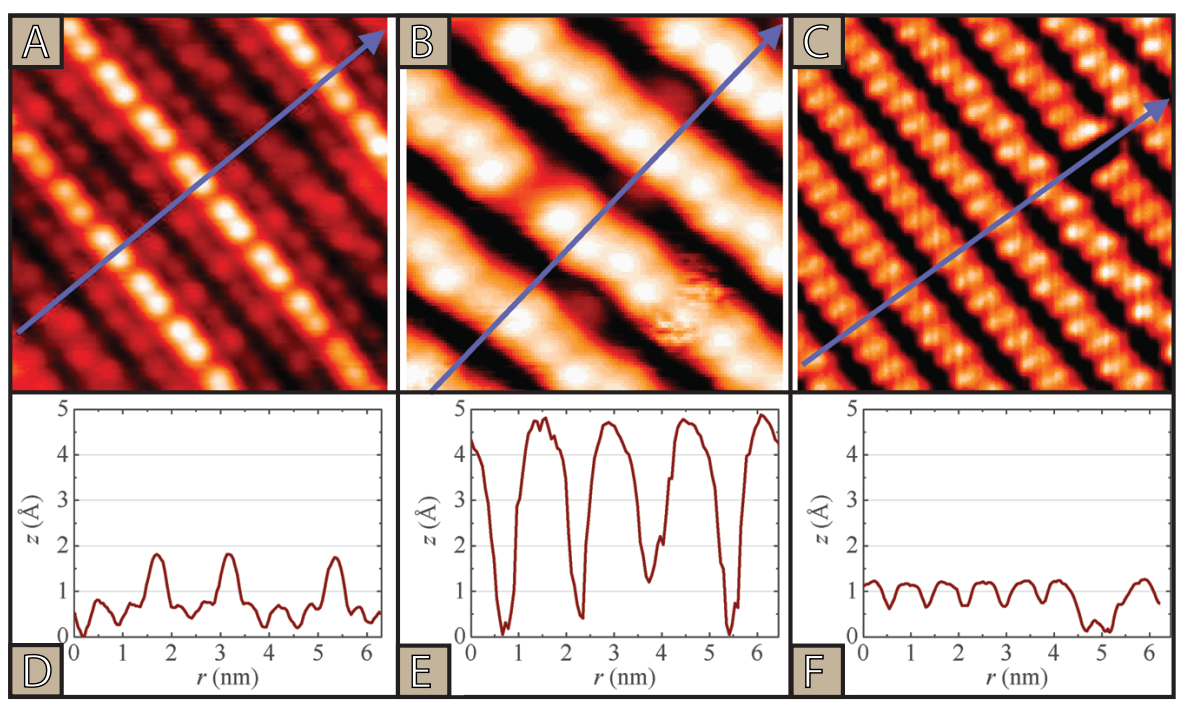

Figure 3.5: STM images of Pt-induced (A) and Au-induced (B) nanowires and of a pristine $\mathrm{Ge}(001)$ surface $(\mathrm{C})$. The images are $5 \mathrm{~nm} \times 5 \mathrm{~nm}$, sample biases are $-1.0 \mathrm{~V}$ for $(\mathrm{A})$ and $(\mathrm{C})$ and $-1.5 \mathrm{~V}$ for $(\mathrm{B})$. Tunneling currents are $0.4 \mathrm{nA}$ for $(\mathrm{A})$ and $(\mathrm{C})$ and $0.6 \mathrm{nA}$ for $(\mathrm{B})$. Line scans along the indicated arrows are shown in $(\mathrm{D}),(\mathrm{E})$, and $(\mathrm{F})$. 
images of the Pt-induced, see Refs. [13,20,29], (A) and Au-induced nanowires (B) and of the pristine $\mathrm{Ge}(001)$ surface $(\mathrm{C})$ are shown for comparison. The spacing between neighboring $\mathrm{Pt}$ and $\mathrm{Au}$-induced nanowires is in both cases $1.6 \mathrm{~nm}$. The FWHM differs substantially, from only $0.45 \mathrm{~nm}$ for the single atom wide Pt nanowires (Fig. 3.5(D)) to $0.75 \mathrm{~nm}$ for the $\mathrm{Au}$-induced nanowires (Fig. 3.5(E)). The latter value is very similar to the FWHM of the Ge dimers of the pristine Ge(001) surface (Fig. 3.5(F)). On the basis of the data shown above, we arrive at the conclusion that the Au-induced nanowires are not one atom wide, but two atoms (i.e., a dimer). In addition, in Fig. 3.5(B) an additional atomic structure within the troughs is visible, located at the side of the nanowires. These small blobs are, in most cases, $3.2 \mathrm{~nm}$ separated apart and alternately located at left and right sides of the trough. As detailed in Ref. [24], we suggested that these structures arise at the antiphase-boundaries in the Au-covered Ge(111) facets.

As can be concluded from the STM data presented in Figs. 3.2 and 3.4 the structural properties of the Au-induced structures for both growth methods are identical. The STM images of the Au-induced structures in Refs. [21-24] show nevertheless some variation in appearance. How to account for these differences? From Figs. 3.2 and 3.4 it is evident that the Au-induced nanowires can actually be considered as a comb of sharp ridges. The obtained STM images of such a surface will certainly be convoluted with the shape of the STM tip. The latter will lead to a variety of STM images, since the exact tip shape is in general not known and cannot be precisely controlled. By taking many STM images with different STM tips on a Ge(001) surfaces with Au-induced nanowires we have been able to reproduce figures which closely resemble the images shown in Fig. 2(A) of Ref. [21] (see Figs. 3.6(A)) and Fig. 1(B) of Ref. [23]. These findings support the idea that the structural properties of the $\mathrm{Au}$-induced nanowires prepared by the two different preperation methods are indeed similar.

\subsubsection{Electronic properties of Au-induced nanowires}

Next, we focus on the electronic properties of the Au-induced structures. In their Letter, Schäfer et al. [23] show dI/dV curves recorded on the wires and in the troughs without providing current and voltage setpoints. By integrating these $\mathrm{dI} / \mathrm{dV}$ curves, we have reconstructed their $\mathrm{I}(\mathrm{V})$ curves [see Figs. $3.7(\mathrm{~A})$ and (B)]. The resulting tunneling current at $0.3 \mathrm{~V}(-0.3 \mathrm{~V})$ varies from $25 \mathrm{pA}(50 \mathrm{pA})$ in the troughs to $1.9 \mathrm{nA}(2.3 \mathrm{nA})$ on the wires, 


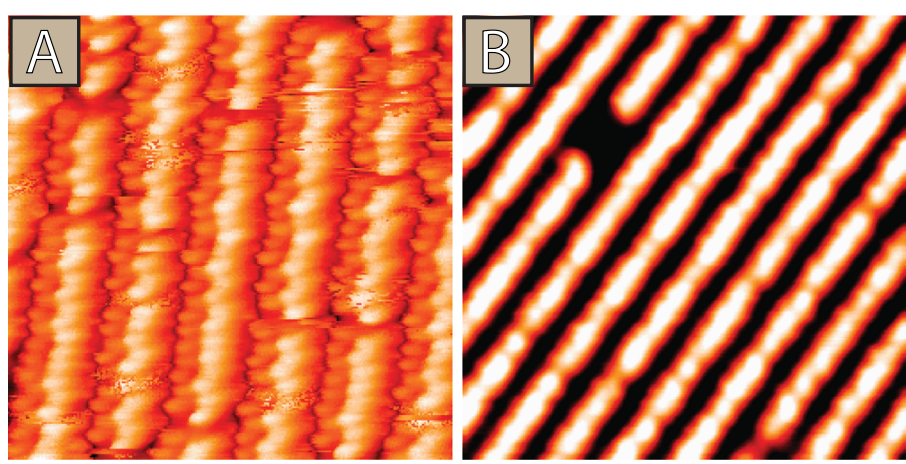

Figure 3.6: STM images of Au-induced nanowires prepared by Au deposition at $775 \mathrm{~K}$. The image in (A) resembles Fig 2(A) of Ref. [21]. Image size is 10 $\mathrm{nm}$ by $10 \mathrm{~nm}$, sample bias $-0.9 \mathrm{~V}$, tunneling current $3.0 \mathrm{nA}$. The image in (B) resembles Fig. 1(B) of Ref. [23]. Image size is 15 by $15 \mathrm{~nm}$, sample bias $0.7 \mathrm{~V}$, tunneling current $0.4 \mathrm{nA}$.
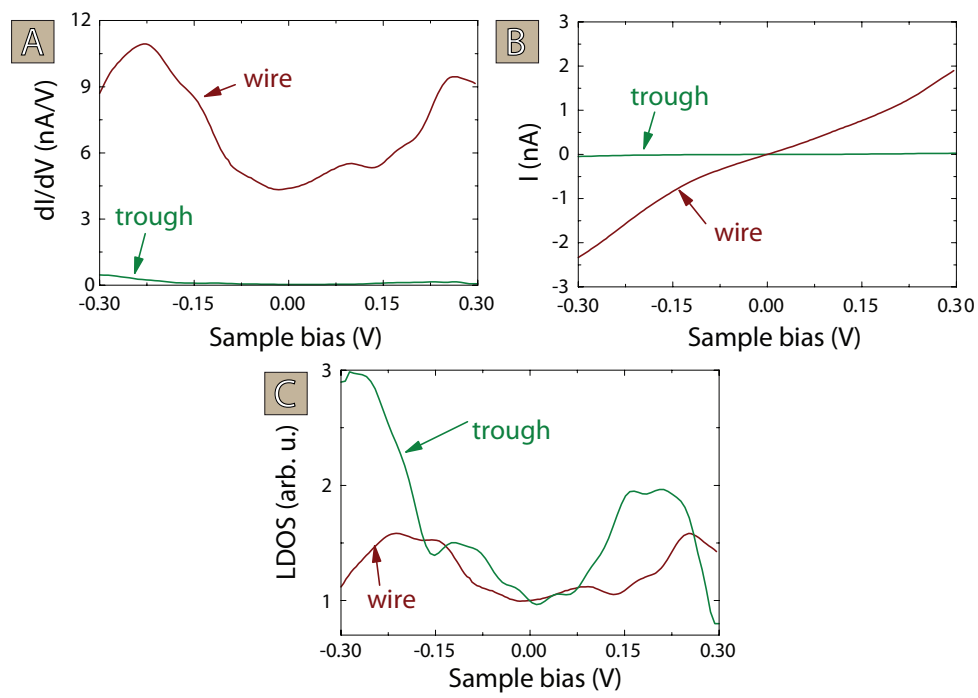

Figure 3.7: (A) dI/dV curves reproduced from Fig. 4(A) of Ref. [23]. (B) $\mathrm{I}(\mathrm{V})$ curves obtained by integrating the $\mathrm{dI} / \mathrm{dV}$ curves in (A). (C) LDOS curves extracted from the $\mathrm{dI} / \mathrm{dV}$ and $\mathrm{I}(\mathrm{V})$ data of Ref. [23]. 
suggesting that the authors have used different setpoints in the troughs and on the wires. Hence the $\mathrm{dI} / \mathrm{dV}$ curves cannot be compared directly. In order to compare the electronic properties of the troughs and the wires, we have normalized their $\mathrm{dI} / \mathrm{dV}$ curves by dividing them by I/V. Although the normalized quantity $(\mathrm{dI} / \mathrm{dV}) /(\mathrm{I} / \mathrm{V})$ does not reflect the exact local density of states (LDOS), it is the best one can do to compare local electronic structure information. In Fig. $3.7(\mathrm{C})$, the LDOS recorded on the wires and in the troughs, extracted from the $\mathrm{dI} / \mathrm{dV}$ curves of Schäfer et al. [23], is shown. In order to verify Schäfer et al.'s data [23], Au-induced nanowires have been prepared by accurately following the procedure used by Schäfer et al. [23], i.e. deposition of 0.5 monolayers of $\mathrm{Au}$ onto a $\mathrm{Ge}(001)$ sample kept at $775 \mathrm{~K}$. In Figs. 3.8(A) to $(\mathrm{C})$, the $\mathrm{I}(\mathrm{V}), \mathrm{dI} / \mathrm{dV}$, and LDOS curves recorded on the wires and in the troughs are shown. We have used the same setpoint values $(\mathrm{I}=3.0 \mathrm{nA}$ and $\mathrm{V}=-0.9 \mathrm{~V})$ for all $\mathrm{I}(\mathrm{V})$ curves. Most noticeable is the difference in the $\mathrm{I}(\mathrm{V})$ and $\mathrm{dI} / \mathrm{dV}$ of Schäfer et al. and our data. However, the LDOS curves are comparable. Nakatsuji et al. have investigated the electronic properties of the $\mathrm{Au} / \mathrm{Ge}(001)$ system angle-resolved photoelectron spectroscopy [30]. The experimental findings in this paper regarding the structural and electronic properties of the $\mathrm{Au} / \mathrm{Ge}(001)$ system are in good agreement with our observations. 

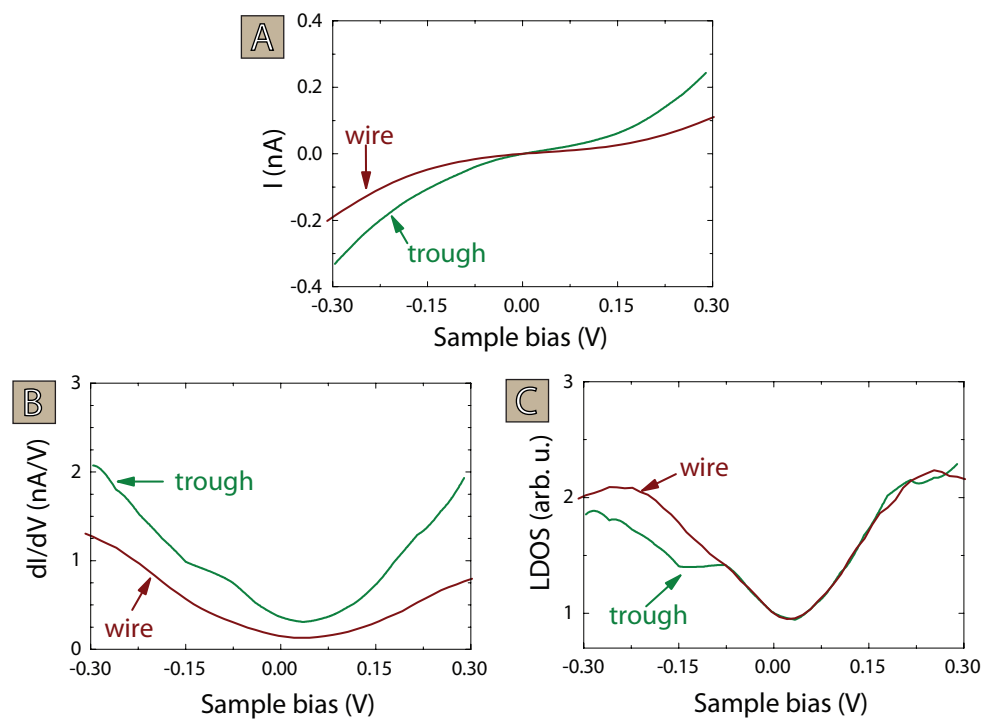

Figure 3.8: (A) - (C) I(V), dI/dV, and LDOS curves recorded on top and in between the nanowires. Setpoint current and bias are $3.0 \mathrm{nA}$ and $-0.9 \mathrm{~V}$, respectively.

\subsection{Conclusions}

In conclusion, using STM and STS we have studied the structural and electronic properties of $\mathrm{Au}$-induced nanowires on $\mathrm{Ge}(001)$ prepared by two different methods. In both cases the Au-induced nanowires are comprised of Ge dimers that have their bond aligned in a direction perpendicular to the nanowire direction and have a height of at least four atomic layers. The buckling of the Ge dimers leads to a $2 \times$ periodicity along the nanowires direction. At antiphase boundaries in this buckling registry Ge dimers are found which flip back and forth between their two buckled configurations. In contrast to previous research, in our measurements the differential conductivities of the nanowires and the regions in between the nanowires have very comparable values and are only marginally metallic. 


\section{Dynamics of Au-induced nanowires and molecular bridges}

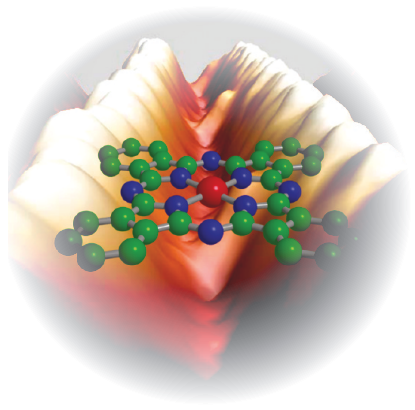

The ridges of Au-induced nanowires on a Ge(001) surface consist of buckled dimers that have their dimer bond aligned in a direction perpendicular to the nanowire direction. Neighbouring dimers have a strong preference to buckle in an opposite direction, leading to rows with a zigzag appearance. Dimers located at anti-phase boundaries continuously flip back and forth between their two buckled configurations. In the second part of the chapter we study the adsorption of $\mathrm{Cu}$-phthalocyanine $(\mathrm{CuPc})$ molecules on a Au-modified $\mathrm{Ge}(001)$ surface. We have found six different adsorption configurations. Four of these configurations are 'molecular bridge' configurations, where the molecule bridges two adjacent nanowires. For sufficiently high sample biases $(>1 \mathrm{~V})$, rotation and diffusion events of the $\mathrm{CuPc}$ molecules are observed. In this chapter we find that the time resolution of the STM (with the feedback loop switched off) allows us to measure the fast dynamics of both the flipflopping dimer and the rotating and diffusing $\mathrm{CuPc}$ molecule. 


\subsection{Introduction}

\subsubsection{Further examination of Au-induced nanowires}

The ability of the semiconductor industry to scale down the size of electronic components and putting evermore transistors on a silicon chip is saturating, because the lithographic top-down approach is reaching its technological and economic limits. An alternative, a bottom-up approach, is based on the assembly of well-defined nanoscale building blocks and provides a way of approaching the true atomic or molecular limit.

The research activity in this field was boosted by the advent of Scanning Tunneling Microscopy (STM) in the early 1980s which allows a detailed view on how atoms or molecules organize themselves in ordered patterns. Since then, many self-organized nanostructures have been reported. One important class of these nanostructures is formed by nanowires. During the last decade, several types of self-organized nanowires have been reported, such as $\mathrm{Au}$ on stepped $\mathrm{Si}(111)$, Pt on Ge (001) and $\mathrm{Au}$ on $\mathrm{Ge}(001)$ [13,20,21,23, 24,30-35]. However, before such nanowires can be applied in nanodevices, it is of the utmost importance to have a detailed understanding of their structural and electronic properties.

In this chapter we will focus our attention on metal-induced nanowires on semiconductor surfaces. These systems are very appealing because they combine the bests of two worlds: the atoms are firmly locked to the surface (and are thus less susceptible to a Peierls transition), while the electrons near the Fermi level are in principle decoupled from the semiconductor, since there are no bulk states in the band gap to hybridize with.

The deposition of $\mathrm{Au}$ and $\mathrm{Pt}$ on $\mathrm{Ge}(001)$ substrates leads, after proper treatment, to incredibly well-ordered arrays of nanowires that are perfectly straight and have lengths of up to micrometers [13, 20,21, 23, 24, 30,33-37]. Despite the fact that $\mathrm{Pt}$ and $\mathrm{Au}$ are adjacent in the periodic table, the $\mathrm{Pt} / \mathrm{Ge}(001)$ and $\mathrm{Au} / \mathrm{Ge}(001)$ systems differ significantly. The Pt chains have a height and width of only one atom, whereas the Au-induced chains are several atomic layers in height $[24,30,36,37]$ and the top ridges have a width of two atoms $[21,24]$. Despite these structural dissimilarities, there is another interesting difference: the $\mathrm{Pt}$ nanowires are static at room temperature, whereas the $\mathrm{Au}$-induced nanowires are, at least partly, dynamic.

It is the aim of this chapter to describe this dynamic behaviour. At room temperature we observed the flip-flopping of dimers that are located at the 
anti-phase boundaries in the nanowires. The flip-flopping process is thermally induced and its rate of occurrence is thus independent of the actual values of the tunnel current and sample bias.

\subsubsection{Au-induced nanowires as a template for molecules}

The adsorption configuration of a molecule adsorbed on a surface is dictated by the subtle interplay between the molecule-substrate interaction, the molecule-molecule interaction, and the geometrical structure of both the molecule and substrate. Understanding this complex interplay and being able to control the adsorption configuration is of great importance for molecular electronics, since the electronic properties of the adsorbed molecule are heavily affected by the substrate. In this chapter, we report on the adsorption of copper-phthalocyanine $(\mathrm{CuPc})$ molecules, see Fig. 4.1 on Au-modified $\mathrm{Ge}(001)$ substrates. Metal-phthalocyanines are of great technological relevance, since these molecules are used in organic solar cells, [38] organic field effect transistors, [39] and organic light emitting diodes [40]. The $\mathrm{CuPc}$ molecule consists of a four-lobed phthalocyanine ring with a $\mathrm{Cu}$ atom in the center of the molecule. The $\mathrm{Cu}$, with oxidation state $2+$, is bound to the phthalocyanine ring with two covalent and two co-ordinated covalent bonds. The $\mathrm{Cu}$ ion is small enough to fit in the cavity of the Pc macrocycle, making $\mathrm{CuPc}$ a planar molecule. The $\mathrm{CuPc}$ molecule has dimensions of $1.4 \mathrm{~nm}$ by 1.4 nm. Metal-phthalocyanine molecules can grow in a highly ordered fashion in both mono- and multilayers on surfaces, making them attractive candidates for technological applications [41]. The Au-modified Ge(001) substrates we have used in this study are comprised of well-ordered arrays of Au-induced nanowires $[20,21,23,24,30,33,34,36]$. The ridges of the nanowires consist of dimers that have their dimer bonds aligned perpendicular to the nanowire direction. The spacing between adjacent nanowires is $1.6 \mathrm{~nm}$, and the depth of the trenches between the wires is at least $0.6 \mathrm{~nm}$ [24].

Here, we show that the $\mathrm{CuPc}$ molecules adsorb in several bridge-like configurations on the Au-modified $\mathrm{Ge}(001)$ surface. A majority of $52 \%$ of the $\mathrm{CuPc}$ molecules adsorb in an 'ideal' bridge configuration, where all four lobes of the phthalocyanine ring bind with the nanowires. Of the remaining $\mathrm{CuPc}$ molecules, $27 \%$ adsorb in configurations where only two of the four lobes of the molecule bind with the nanowires. In the bridge configurations, the core of the $\mathrm{CuPc}$, i.e., the $\mathrm{Cu}$ atom, is fully decoupled from the underlying substrate. For sufficiently high sample biases, we are able to switch the $\mathrm{CuPc}$ 


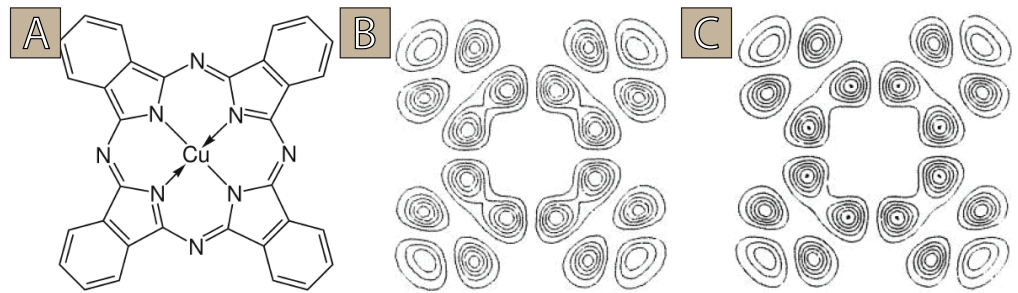

Figure 4.1: Molecular structure of $\mathrm{CuPc}$ (a) and contour plots of the charge densities of the HOMO (b) and LUMO (c). [42]

molecule between its different bridge configurations.

\subsection{Experimental methods}

Experiments were performed at room temperature using the Omicron STM1 operating in UHV at a base pressure of $5 \cdot 10^{11}$ mbar. For the $\mathrm{CuPc}$ experiments an Omicron LT-STM was used. Au nanowires were obtained as explained in detail in Chapter 2. The $\mathrm{CuPc}$ was deposited using a Knudsen cell equipped with a quartz crucible. The used $\mathrm{CuPc}$ was $>99 \%$ pure. The sample was directly facing the Knudsen cell's outlet at a distance of about 2 $\mathrm{cm}$. During the deposition, the temperature of the Knudsen cell was kept at $573 \pm 5 \mathrm{~K}$ and the sample was at room temperature. The deposited amount of $\mathrm{CuPc}$ varied from less than $1 \%$ to about $10 \%$ of a monolayer. After deposition, the sample was annealed at a temperature of $600 \pm 25 \mathrm{~K}$ for 2 mins. Subsequently, the sample was transferred to the STM chamber and cooled down to $77 \mathrm{~K}$.

\subsection{Dynamics of Au-induced nanowires on $\mathrm{Ge}(001)$}

As mentioned in the previous chapter, the $\mathrm{Au} / \mathrm{Ge}(001)$ system has been studied by several research groups. The first paper on $\mathrm{Au} / \mathrm{Ge}(001)$ was published by Wang and Altman [21]. In their paper, Wang and Altman showed that the deposition of $\mathrm{Au}$ on $\mathrm{Ge}(001)$ leads to well-ordered arrays of $\mathrm{Au}$ induced nanowires. A few years later, Schäfer et al. [23] reported a combined STM, Scanning Tunneling Spectroscopy (STS) and Angle-Resolved PhotoEmission Spectroscopy study (ARPES) of Au on Ge (001). At about the same time, van Houselt et al. [24] proposed a structural model of the Au-induced 


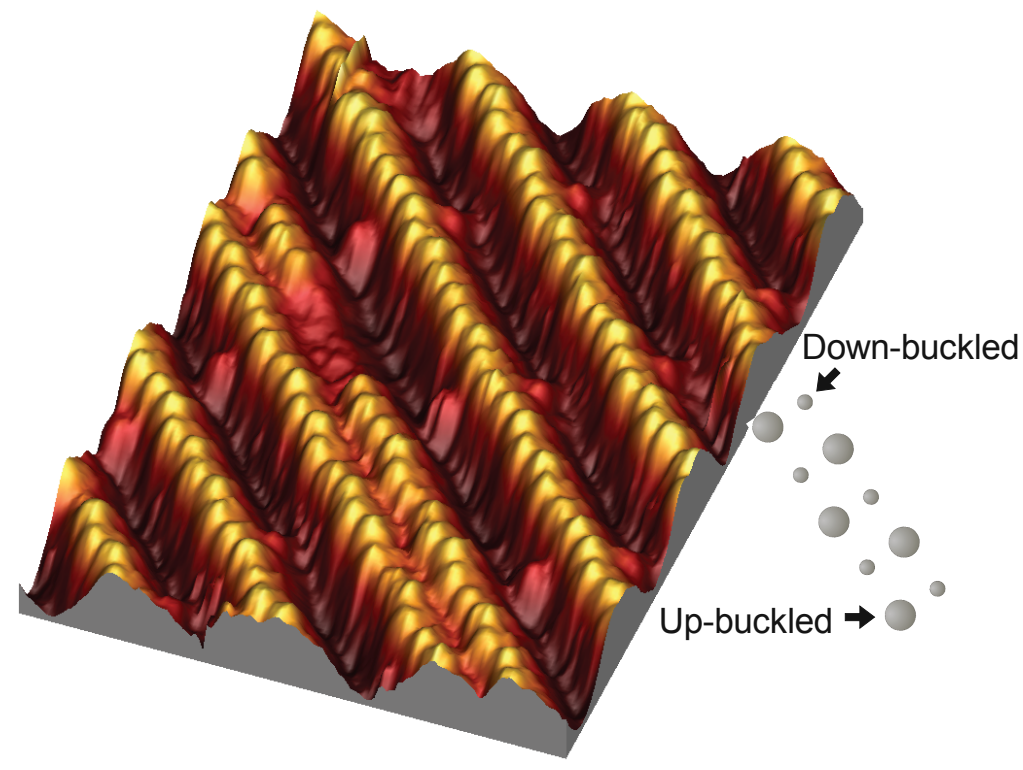

Figure 4.2: 3D STM image of Au-induced nanowires showing the protrusions in the trenches and the zigzag appearance of the ridges. The large (small) gray circles are the upward (downward) buckled atoms of the Ge dimers. The image is recorded with a sample bias of $-1.5 \mathrm{~V}$ and a tunnel current of $0.2 \mathrm{nA}$

nanowires based on a combined STM and STS study. Finally, the Komori group published a paper that included STM and ARPES data [30]. Despite several experimental $[21,23,24,30,36,37]$ and theoretical $[26,43]$ studies, there are still many unresolved questions regarding this particular system. What is most important is the exact structural model, since none of the proposed models seem to agree perfectly with the existing theoretical and experimental data [26,43], although the model proposed by Van Houselt et al. [24], and also discussed in Chapter 3, is very promising and is probably very close to reality.

Fig. 4.2 shows a 3D STM image of a Ge(001) surface after the deposition of 0.5 monolayer of $\mathrm{Au}$ at room temperature and subsequent annealing at $650 \mathrm{~K}$. The image shows a regular array of nanowires which are separated by $1.6 \mathrm{~nm}[21,23,24,30,33,34,36]$. It should be pointed out that the spacing between the third and fourth nanowire is only $0.8 \mathrm{~nm}$. This phenomenon (double wires) has also been reported by Wang et al. [21] and Schäfer et al. [23] The nanowires run along the [110] directions of the Ge(001) crystal. 
Their height is at least $6.0 \AA$; i.e., these structures are far too high (at least four times higher than a single atomic step on $\mathrm{Ge}(001)$ ), to be explained by atomic chains on a substrate as in the case of $\mathrm{Pt}$ on $\mathrm{Ge}(001)[13,20]$. The ridges of the nanowires have a width of two atoms $[24,36]$. The ridges have a zigzag appearance, just like the dimer rows in $\mathrm{c}(4 \times 2)$ patches on clean $\mathrm{Ge}(001)$, and therefore we suggest that buckled dimers reside on top of the ridges (see Fig. 4.2). The exact chemical nature of these ridge dimers remains, however, unknown.

In Fig. 4.3(A) a dimer that appears to be noisy is highlighted with an ellipse. These noisy dimers are exclusively found at anti-phase boundaries within the buckling registry. However, such noisy dimers were never observed on double wires. Since the time resolution of our STM in its standard imaging mode is insufficient to resolve the details of these noisy dimers, we have locked the tip of the STM on top of one of the atoms of the noisy dimer, opened the feedback loop and recorded the tunnel current as a function of time [44]. Current-time traces recorded on top of these noisy dimers reveal that they continuously flip back and forth between their two buckled configurations. Interestingly, the position of the anti-phase boundary jumps back and forth between two adjacent lattice positions and thus it is always the same dimer that exhibits flip-flop behaviour. This is in marked contrast to the clean Ge(001) surface where the anti-phase boundaries perform a one-dimensional random walk along the dimer rows $[28,45]$. There is also a substantial difference in the flip-flop frequency of the dimers: about $25 \mathrm{~Hz}$ for the noisy dimers of the Au-induced nanowires and several $\mathrm{kHz}$ from the Ge dimers of the clean $\mathrm{Ge}(001)$ surface [28].

A ball-and-stick model of the ridge of the nanowire is shown in Fig. 4.3(B). The fact that the anti-phase boundary only jumps back and forth between adjacent lattice positions is most probably caused by the structural details of the facetted sides of the 'nanowires'. Based on images recorded by an asymmetric STM tip, van Houselt et al. suggested that these facets are $\mathrm{Au}$ decorated $\mathrm{Ge}(111)$ regions $[24,30]$. At $77 \mathrm{~K}$, we did not observe any noisy dimers, suggesting that the flip-flop motion is thermally induced. In addition, open feedback loop current-time traces recorded on the noisy dimers at different set point voltages and tunnel currents support this conclusion, since the average flip-flop frequency is independent of the actual values of these set points. In Fig. 4.4 a typical plot of the tunneling current versus time is depicted. Fig. 4.5 shows a semi-log plot of the distribution of the 


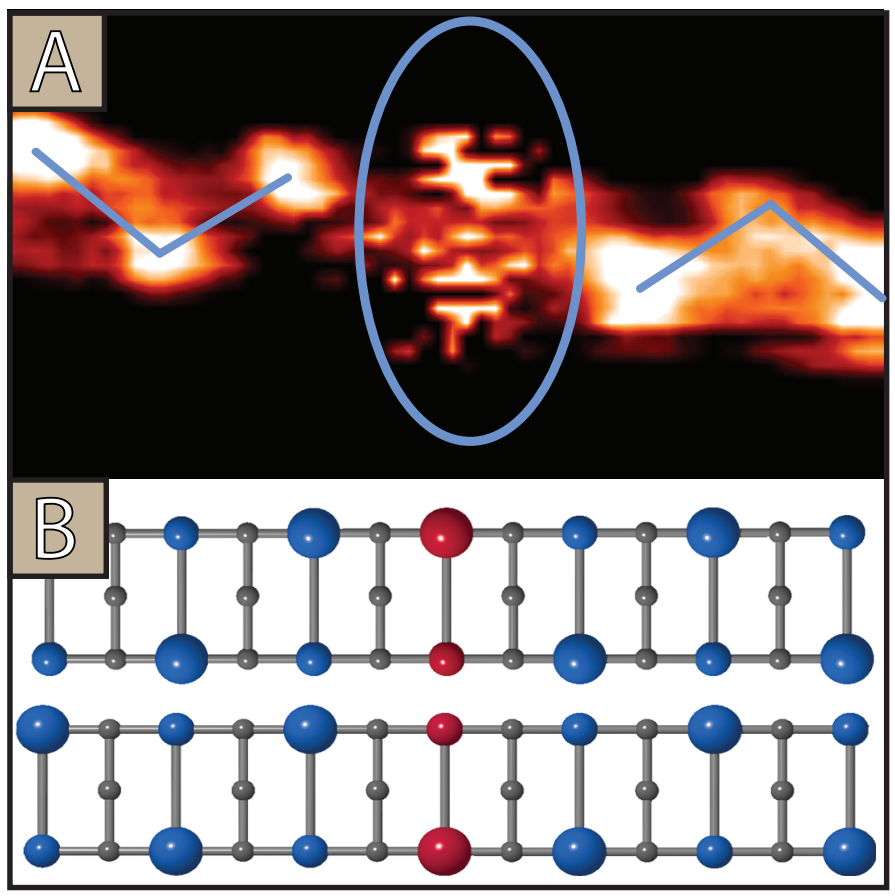

Figure 4.3: (A) a single Au-induced wire is shown. The zigzag appearance of the top Ge dimers is highlighted as well as a single dynamic dimer (ellipse). Sample bias is $-1.3 \mathrm{~V}$, and the tunnel current is $0.5 \mathrm{nA}$. (B) Shows a ball-andstick model of (A). Only the top three layers are depicted. The larger spheres are the upward buckled atoms of the dimer, while the smaller spheres are the downward buckled atoms of the dimers. The red dimer is the dimer that continuously flip-flops back and forth between its two buckled configurations. The anti-phase boundary jumps back and forth around the dynamic dimer.

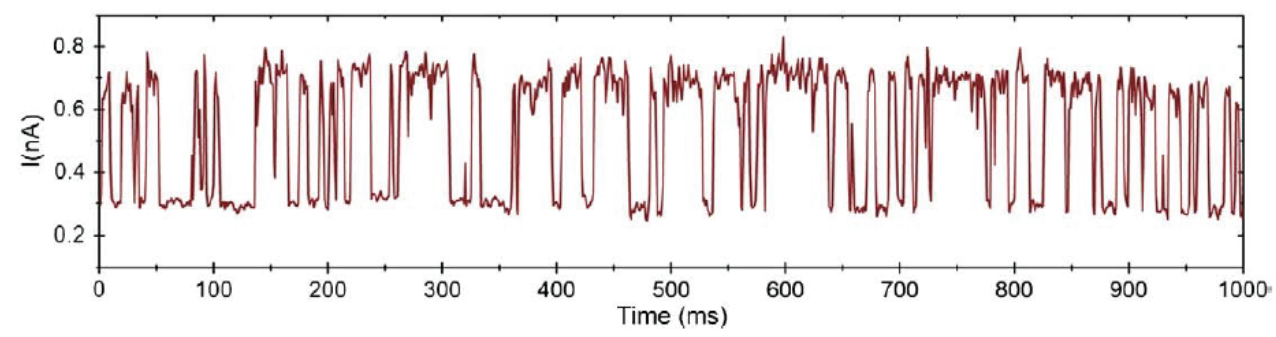

Figure 4.4: Tunneling current versus time measured on top of the atoms of a noisy dimer. Sample bias is $-1.0 \mathrm{~V}$. 


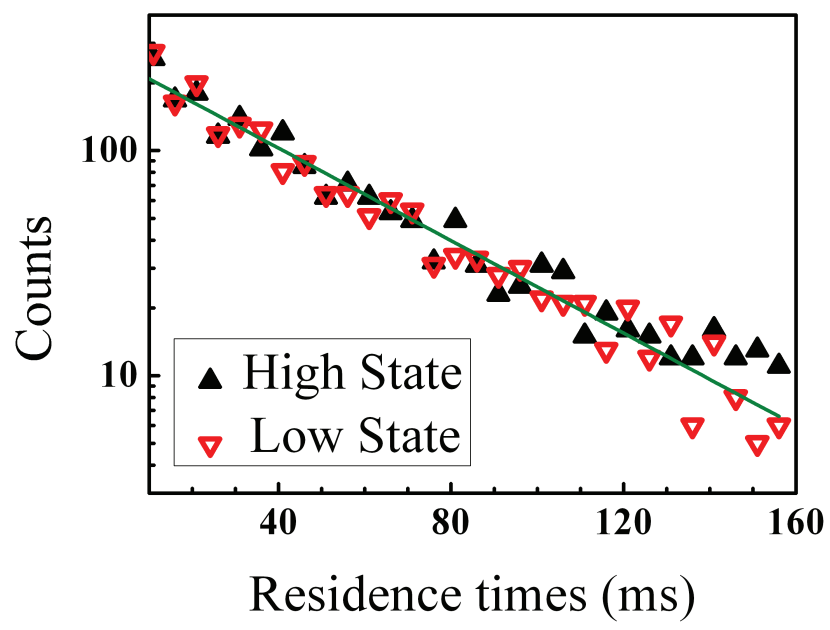

Figure 4.5: Histogram of residence times for the two buckled configurations of the flip-flop dimers. The straight line describes a fully stochastic process that runs at an average frequency of $25 \mathrm{~Hz}$. The average residence times in the low and high state are very comparable, indicating that the energy difference between both states is negligible.

residence times. The filled triangles refer to the high state, in which the dimer is buckled towards the tip, whereas the open triangles refer to the low state, where the dimer is buckled away from the tip. The straight line in this plot refers to a Poissonian distribution of residence times, i.e. a perfect stochastic distribution. The flip-flop frequency varies a little from noisy dimer to noisy dimer, but is typically $25 \mathrm{~Hz}$. If we assume an attempt frequency of $10^{13} \mathrm{~Hz}$ we find an activation barrier of about $0.68 \mathrm{eV}$, which is about $0.1 \mathrm{eV}$ higher than the activation barrier for flip-flop motion of Ge dimers of the clean $\mathrm{Ge}(001)$ surface [46]. For virtually all noisy dimers, the average residence times in both the high and low states are similar, implying that both states are energetically equivalent.

During STM measurements, another kind of dynamics on the nanowires sometimes occurs, which is illustrated in Fig. 4.6. For a correct interpretation, it should be noted that this STM image was built up line by line, from bottom to top. Consecutive lines in the scan show discontinuities in the dimer rows. This is highlighted by boxes 1 and 2. These discontinuities occur around dimer defects in the nanowires and are attributed to a diffusing dimer. These dimers are also occasionally seen diffusing further along the nanowires 


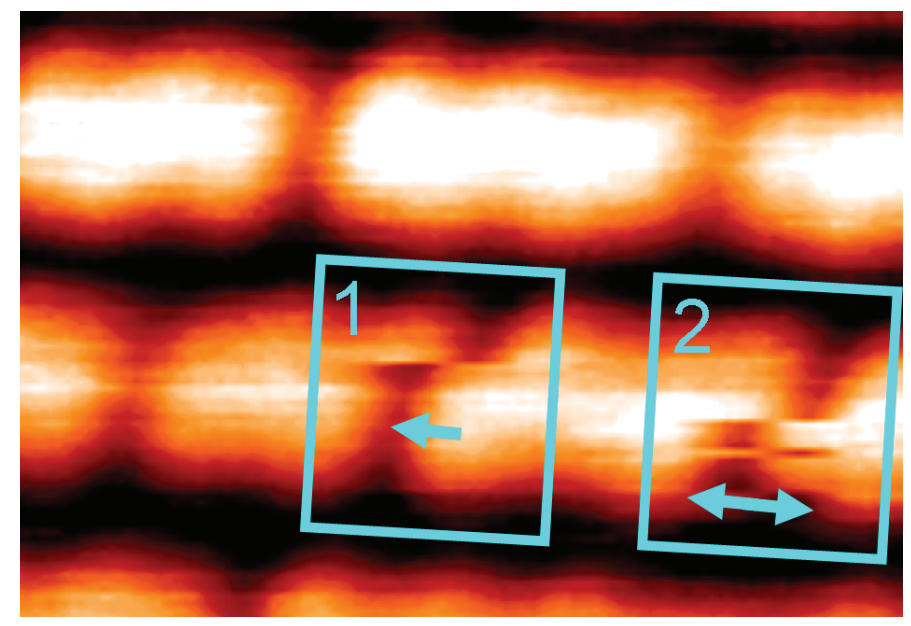

Figure 4.6: Moving dimers are highlighted by box 1 and 2 .

and double wires can also contain diffusing dimers. An interaction between the missing dimer defects has not been observed, while single missing dimer defects as well as clusters of missing dimers have been measured.

\subsection{Molecular bridges}

Fig. 4.7 shows an STM image after the deposition of a few percent of a monolayer of $\mathrm{CuPc}$ on a $\mathrm{Au}$-modified $\mathrm{Ge}(001)$ substrate. The $\mathrm{CuPc}$ molecules have a clover-like appearance and are found to adsorb in six different configurations. The different adsorption configurations are labeled A-F, and are shown in Fig. 4.8. In the middle column, the background corrected images of all the configurations are shown. The background correction is achieved with a 'flatten' filter. This filter is a combination of two Gaussian filters: a high pass filter, to remove long range topographic effects like bow, and a low pass filter, to suppress local noise [47]. This way, a function is generated and subtracted from each scan line. Schematic diagrams of these adsorption configurations are depicted in the right column. A majority of $52 \%$ of the molecules are adsorbed in bridge-like configurations where all four lobes of the $\mathrm{CuPc}$ bind to the Au-induced nanowires. Two lobes of the $\mathrm{CuPc}$ molecule bind to the dangling bonds of the Ge dimers on one nanowire, whereas the other two lobes bind to the dangling bonds of a neighboring nanowire. The latter results in 


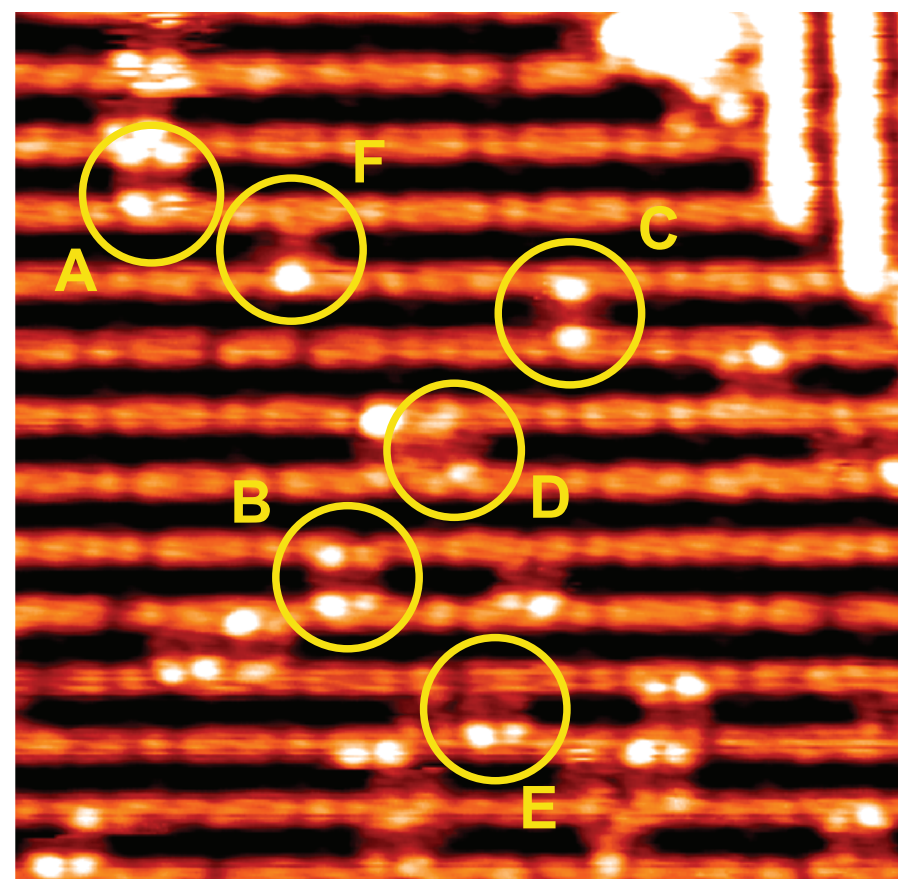

Figure 4.7: STM image of Au-induced nanowires with a few percent of a monolayer $\mathrm{CuPc}$ coverage showing six different $\mathrm{CuPc}$ adsorption configurations, labeled A-F (outlined by circles). The image is recorded at a sample bias of $+1.5 \mathrm{~V}$ and a tunnel current of $0.2 \mathrm{nA}$. The image size is $20 \times 20 \mathrm{~nm}^{2}$. 
$\mathrm{CuPc}$ molecules that form a 'bridge' between two adjacent nanowires. There are two types of these bridge configurations which are depicted in Fig. 4.8(A) and (B), respectively. The bridge configuration shown in Fig. 4.8(A) is exactly perpendicular to the nanowire direction, where the bridge configuration in Fig. 4.8(B) is slightly rotated with respect to the former configuration.

The four lobes of the configuration depicted in Fig. 4.8(A) and (B) show up as bright dots, although they are not always equally bright. The core of the $\mathrm{CuPc}$ molecule, i.e., the $\mathrm{Cu}$ atom, however, always appears dark. Theoretical calculations of Lippel et al. [42] have revealed that contour plots of the charge densities of the highest occupied molecular orbital (HOMO) and lowest unoccupied molecular orbital (LUMO) of $\mathrm{CuPc}$ adsorbed on a $\mathrm{Cu}$ surface are very similar in appearance. In general, our results comply with that result. For both molecular orbitals, each molecule shows up as four bright spots in an almost square configuration, whereas the core is always dim. Scanning tunneling microscopy images recorded at a variety of voltages revealed that the four aromatic rings of the molecule are visible at voltages above $+0.8 \mathrm{~V}$ and below $-0.8 \mathrm{~V}$. The core of the $\mathrm{CuPc}$ molecule always appears dark in the voltage range from -2.5 to $+2.5 \mathrm{~V}$.

Fig. $4.8(\mathrm{C})$ and a rotated version $(\mathrm{D})$ show a $\mathrm{CuPc}$ molecule adsorbed in another bridge-like configuration, where the bonding between the nanowires and $\mathrm{CuPc}$ only involves two lobes. The other two lobes are hanging freely in the $0.6 \mathrm{~nm}$ deep trough between the nanowires. In both cases, the $\mathrm{CuPc}$ molecule has a clover-like appearance. These configurations make up $27 \%$ of the positions taken by the molecules. Finally, Fig. 4.8(E) and (F) show two configurations where no bridge is formed between adjacent nanowires. In Fig. 4.8(E), two lobes bind to a nanowire and the other two lobes lie in the trench between the nanowires. The molecule shown in Fig. 4.8(F) binds with just one lobe to a nanowire, and the other lobes lie in the trench between the nanowires. In these two configurations, the molecule adsorbs a little closer to one of the nanowires, where one or two lobes make a bond, whereas the remaining lobes are lying in the trench between the two nanowires. The lobes always seem to bind with the downward buckled Ge dimer. Therefore, if the buckling of the dimers at two neighboring Au-induced nanowires is out of phase, it is harder for the $\mathrm{CuPc}$ molecule to adsorb in a bridge-like configuration.

Fig. 4.9 depicts two STM images of the same area. Fig. 4.9(A), taken at $-1.5 \mathrm{~V}$, shows the adsorbed $\mathrm{CuPc}$ molecules, while part (B), taken at a 


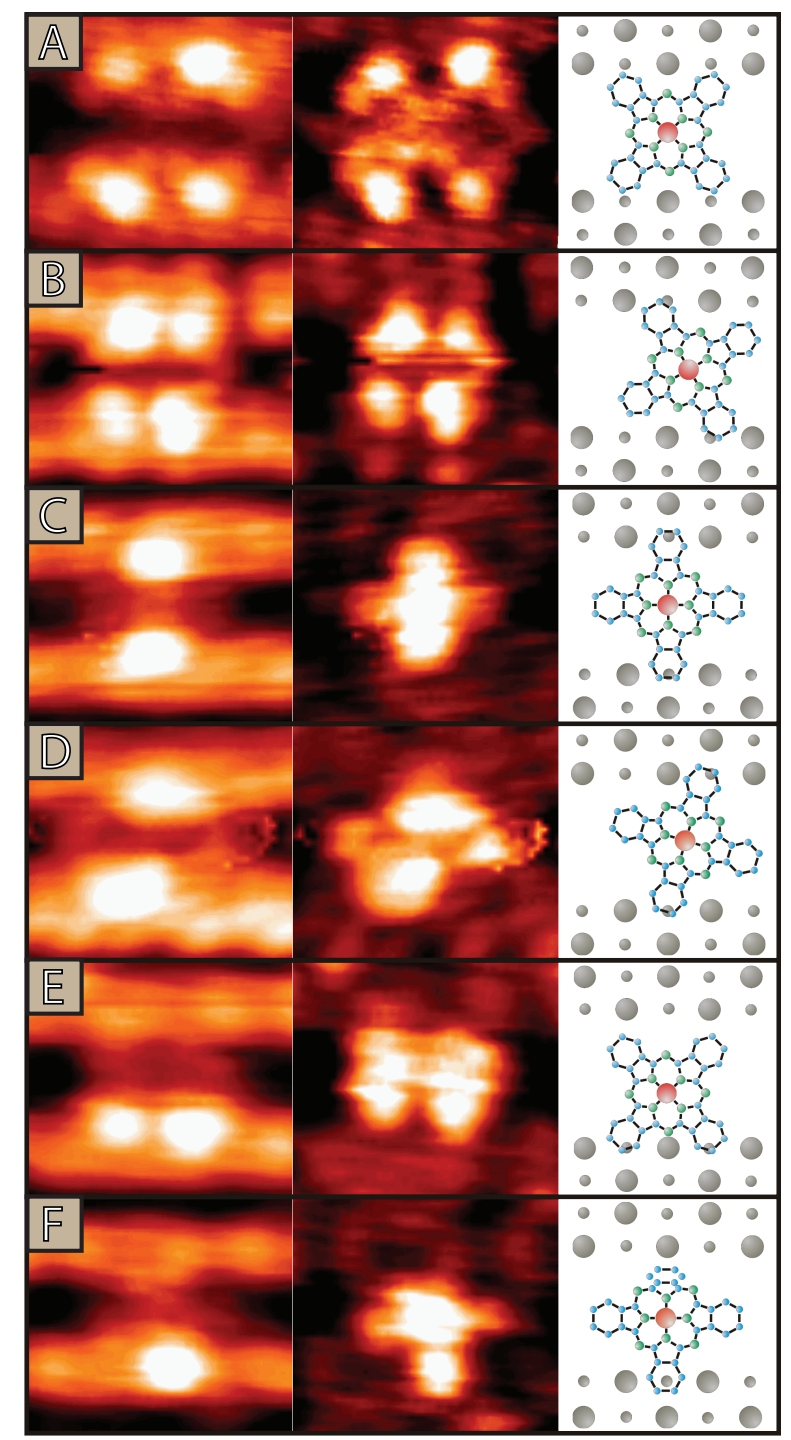

Figure 4.8: (A)-(F) In the first column of STM images, six different adsorption geometries of $\mathrm{CuPc}$ molecules on $\mathrm{Au}$-induced nanowires are shown. The second column displays the background corrected images of the first column, revealing more detail of the molecule. The third column shows a schematic representation of the different adsorption geometries on top of the buckled Ge dimers. The large and small gray dots refer to the up- and downward buckled atoms of the Ge dimers, respectively. The STM images are recorded at a sample bias of $+1.5 \mathrm{~V}$ and a tunnel current of $0.2 \mathrm{nA}$. The image size is $2.8 \times 2.5 \mathrm{~nm}^{2}$. 


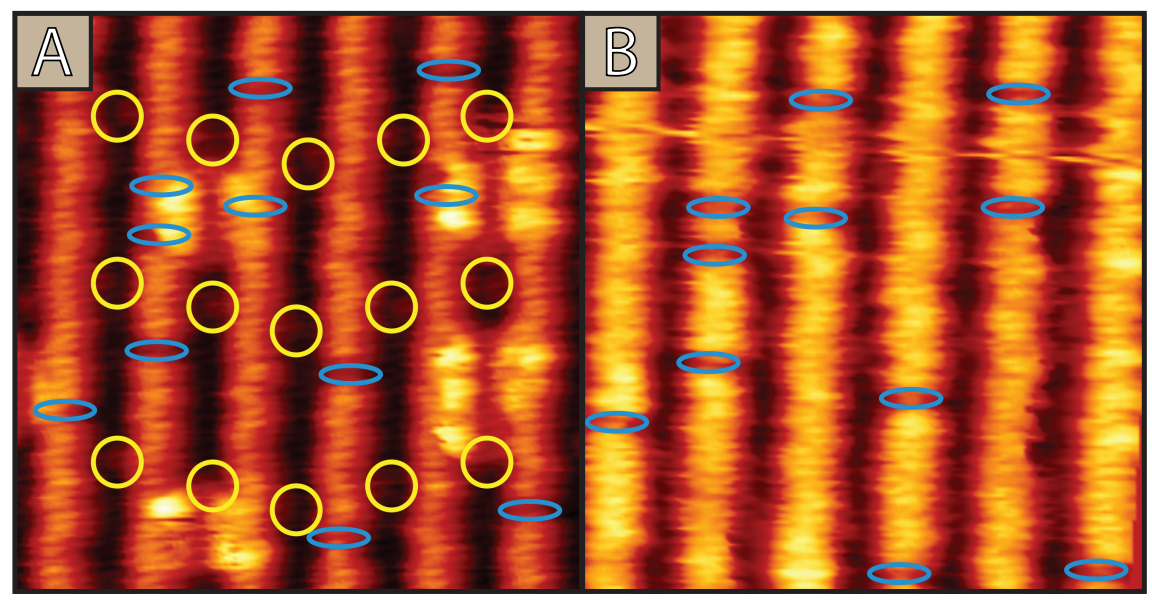

Figure 4.9: (A and B) STM images of the same area taken at -1.5 and -0.6 $\mathrm{V}$, respectively. The tunnel current is $0.2 \mathrm{nA}$. (A) $\mathrm{CuPc}$ molecules adsorbed on the Au-induced nanowires. The missing dimer defects are outlined by ellipses, and the protrusions in the trenches are outlined by circles. (B) CuPc molecules are not visible at this sample bias. Image size: $9.5 \times 9.5 \mathrm{~nm}^{2}$.

different bias of $-0.6 \mathrm{~V}$, only shows the Au-induced nanowires. This makes it possible to image the areas of the nanowire where the $\mathrm{CuPc}$ molecules have actually adsorbed. The missing dimer defects in the nanowires are outlined by ellipses, and the protrusions in the trenches are outlined by circles. Careful inspection of the images reveals that (1) the adsorption of the $\mathrm{CuPc}$ is not affected by the missing dimer defects in the nanowires and (2) $\mathrm{CuPc}$ molecules do not adsorb on the protrusions in the trenches.

Fig. 4.9(A) shows two molecules between the two rightmost nanowires where both molecules appear to have five lobes. The image is again made by scanning the tip over the surface from bottom to top and from left to right. The molecule jumps to a neighboring adsorption site when the tip scans across a certain lobe, and subsequently, the molecule jumps back to its initial site after the STM tip has passed. This is very different from what has been observed for the adsorption of $\mathrm{CuPc}$ molecules on Pt-induced nanowires, where the $\mathrm{CuPc}$ molecules can easily be moved along the nanowire by the tip [48]. The movement of the CuPc molecule on Au-induced nanowires is hindered by the protrusions in the trenches of the nanowires. These protrusions are spaced regularly by $3.2 \mathrm{~nm}$, and no molecules are found to adsorb 
on or to pass these protrusions.

In Fig. 4.10, a rotation from configuration D to configuration $\mathrm{A}$ and back to configuration $\mathrm{D}$ is shown. The image is scanned in the same way as Fig. 4.9. After scanning about one-third of the image, the $\mathrm{CuPc}$ switches from configuration $\mathrm{D}$ to $\mathrm{A}$, and roughly in the middle of the image, the $\mathrm{CuPc}$ switches back to its original orientation. The rotation and translation processes only occur at sample biases larger than about $1 \mathrm{~V}$, suggesting that these processes are induced by electrons that tunnel inelastically $[49,50]$. Current-time traces on the $\mathrm{CuPc}$ molecules with the feedback loop switched off, recorded at bias voltages larger than $1 \mathrm{~V}$, frequently revealed a telegraphlike signal where the current switches back and forth between two current levels, indicative of a conformational change of the $\mathrm{CuPc}$ molecule.

In Fig. 4.11, an open feedback loop $\mathrm{I}(\mathrm{V})$ trace recorded on top of one of the lobes of the $\mathrm{CuPc}$ molecule is shown. Above a threshold value of about $-1.1 \mathrm{~V}$, the current suddenly jumps to almost zero. In the voltage range from -1.1 to $-1.45 \mathrm{~V}$, the current is almost zero. At $-1.45 \mathrm{~V}$, the current suddenly jumps back to a high value again. This indicates that the $\mathrm{CuPc}$ molecule moved away from the tip at the moment the bias was around -1.1 V. After a small amount of time, the molecule relaxed and jumped back to its former position, resulting in a jump in the current at $-1.45 \mathrm{~V}$. It means that the dynamics in the molecules have a threshold bias of approximately $1.1 \mathrm{~V}$.

An artist impression of the $\mathrm{CuPc}$ molecule bridging two nanowires is shown in Fig. 4.12. The Au-induced nanowire ridges are very high in comparison to the size of the molecule and the gap. This implies that the molecule is in fact suspended above the trench, and thus the $\mathrm{Cu}$ atom is completely decoupled from the underlying substrate.

\subsection{Conclusions}

We have studied the dynamics of Au-induced nanowires on Ge (001). At room temperature, dimers located at anti-phase boundaries jump back and forth between their two degenerate buckled configurations. Furthermore, the anti-phase boundary is restricted to two adjacent sites, thus pinning the flipflop dimers. The flip-flop motion is fully thermally activated and does not depend on the actual values of the tunneling current and voltage.

The adsorption of $\mathrm{CuPc}$ molecules on Au-induced nanowires on $\mathrm{Ge}(001)$ is studied with scanning tunneling microscopy at $77 \mathrm{~K}$. Six different adsorption 

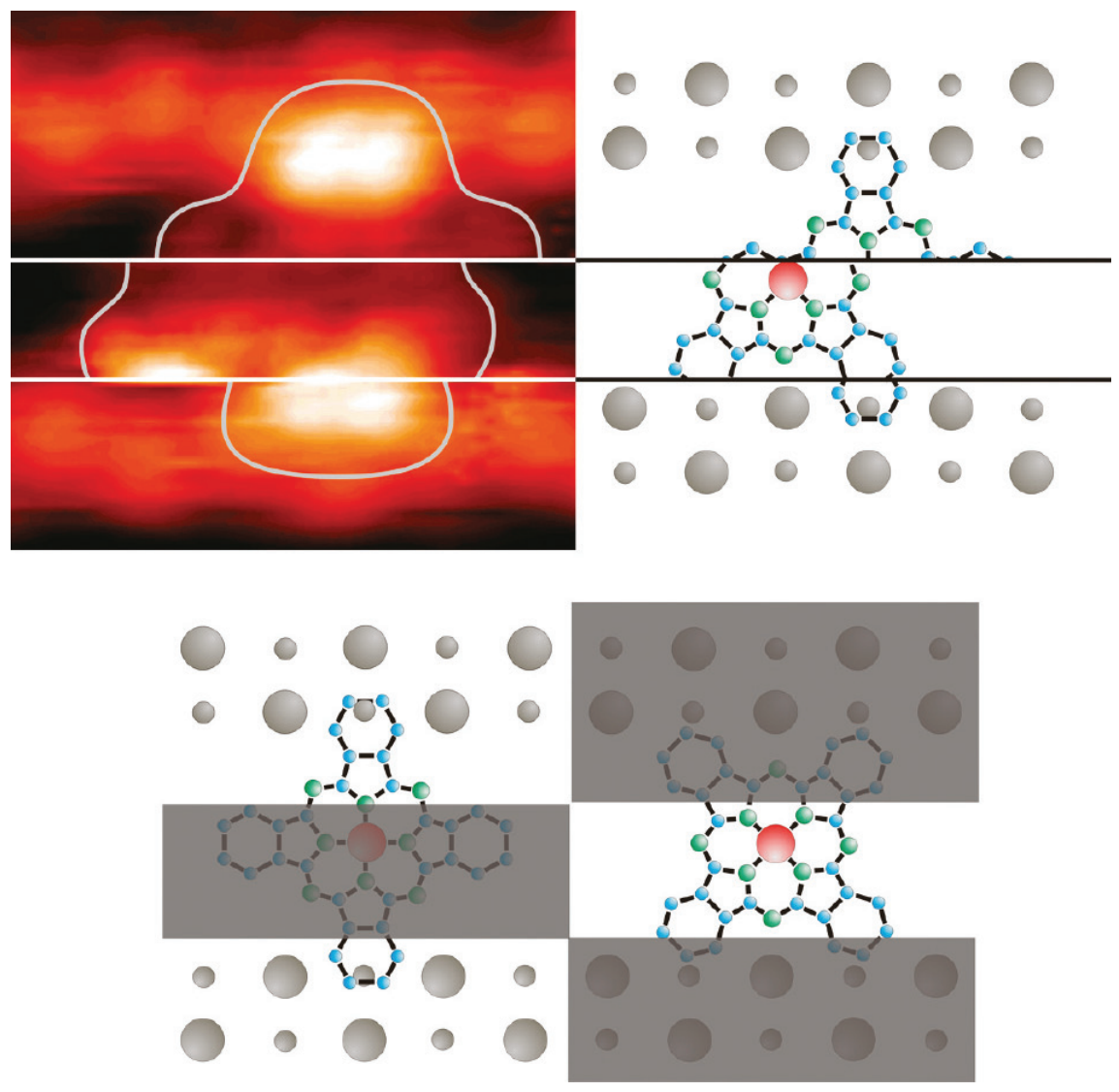

Figure 4.10: Top: STM image of a $\mathrm{CuPc}$ molecule, elucidated with contour lines, switching between two adsorption configurations (A and D), together with a schematic representation of the switching molecule. The STM image is recorded at $77 \mathrm{~K}$ with a sample bias of $-1.5 \mathrm{~V}$ and a tunnel current of $0.2 \mathrm{nA}$. Image size: $2.8 \times 2.8 \mathrm{~nm}^{2}$. Bottom: schematic representations of configurations A and D. The three white areas correspond to the upper, middle, and lower parts of the STM image shown above. The gray areas are added to complete the schematic diagrams of the $\mathrm{CuPc}$ molecule. 


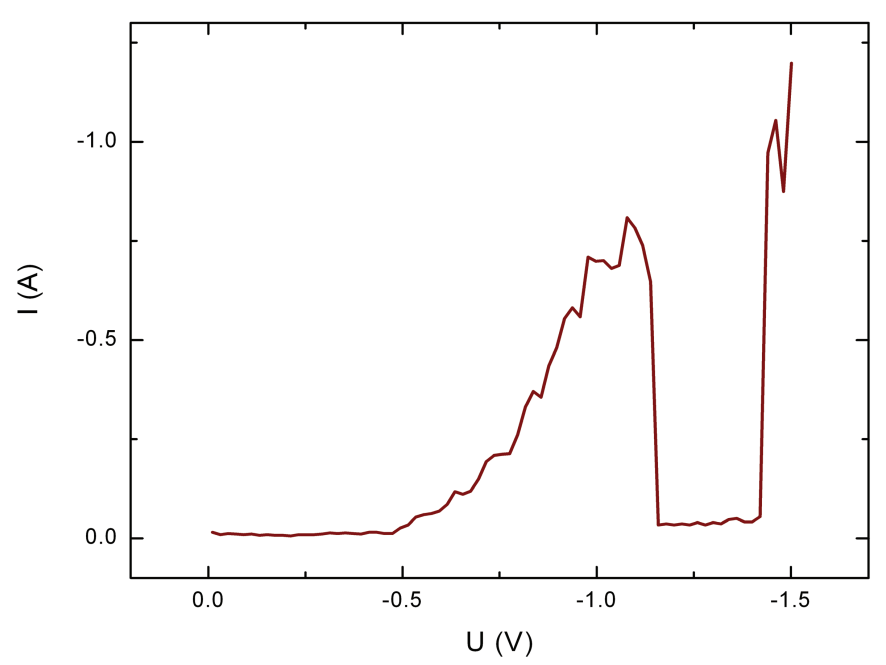

Figure 4.11: $\mathrm{I}(\mathrm{V})$ trace recorded on one of the lobes of a $\mathrm{CuPc}$ molecule, showing that the molecule diffuses away from the tip at about $-1.1 \mathrm{~V}$. At $-1.45 \mathrm{~V}$, the molecule jumps back to its original position. The set points were $-0.6 \mathrm{~V}$ and $0.2 \mathrm{nA}$.

configurations have been identified, where four adsorption configurations are forming 'molecular bridges' between two adjacent nanowires. In these molecular bridge geometries, the core of the $\mathrm{CuPc}$ molecule, i.e., the $\mathrm{Cu}$ atom, is fully decoupled from the underlying substrate. The adsorption of the $\mathrm{CuPc}$ molecules is not affected by the missing dimer defects in the nanowires; however, the $\mathrm{CuPc}$ molecules do not adsorb at the protrusions in the trenches. Tip induced diffusion and rotation processes are observed at sample biases larger than $\pm 1 \mathrm{~V}$. 


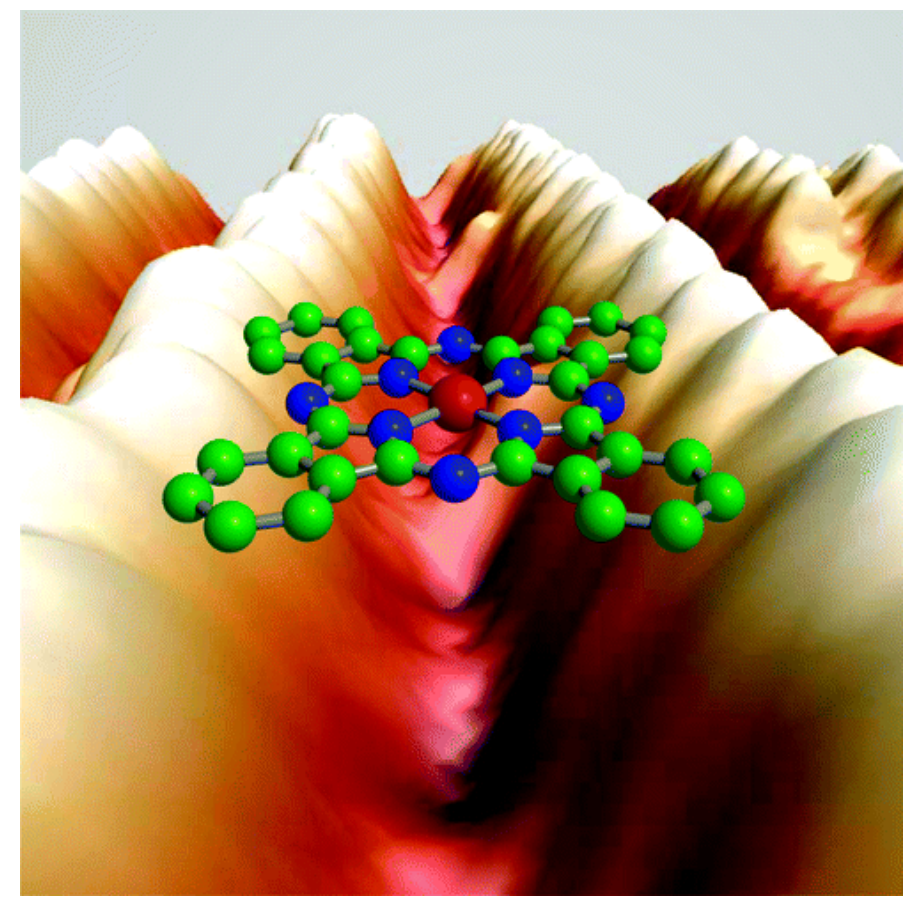

Figure 4.12: Artist impression of a CuPc molecule bridging two Au-induced nanowires with the $\mathrm{Cu}$ atom fully decoupled from the surface. 



\section{Co containing nano-islands on $\mathrm{Ge}(111)-\mathrm{c}(2 \times 8)$}

In this chapter we deposit cobalt on a Ge(111) substrate. On this surface Ge adatoms reconstruct into a $\mathrm{Ge}(111)-\mathrm{c}(2 \times 8)$ configuration. When a submonolayer amount of Co is deposited on this surface we observe that two types of nano islands are formed upon annealing: $(\sqrt{13} \times \sqrt{13}) \mathrm{R} 13.9^{\circ}$ and $(2 \times 2)$ islands. If subsequently several additional monolayers of $\mathrm{Co}$ are deposited on the $\mathrm{Ge}(111)$ substrate only very large threefold symmetric $(2 \times 2)$ islands are observed. These large $(2 \times 2)$ patches show several types of domain boundaries and a novel $(6 \times 2)$ reconstruction. In this chapter we discuss the morphology, the chemical composition and the growth process of both types of islands. 


\subsection{Introduction}

The growth of thin metal layers on semiconductor surfaces has attracted considerable attention during the last few decades. The interest in these systems is mainly due to their relevance for a number of technological applications, such as contacts in electronic devices and non-volatile memories [51]. The adsorption of the $3 d$ transition metals (such as $\mathrm{Co}, \mathrm{Ni}, \mathrm{Mn}$ and $\mathrm{Ti}$.) on $\mathrm{Ge}$ and Si (001) surfaces has been studied extensively due to their importance in dilute magnetic semiconductors [52-61]. Several $3 d$ transition metals, including Co, prefer a subsurface position and thereby generate defects in the top layer of the semiconductor group IV substrates [62-66]. In order to avoid intermixing Tsay et al. [67] deposited a Ag layer prior to the deposition of Co. The Ag layer forms a $(\sqrt{3} \times \sqrt{3}) \mathrm{R} 30^{\circ}$ reconstruction and prohibits the formation of non-ferromagnetic Co compounds. Tsay et al. demonstrated that $\mathrm{Co}$ grown on a $\mathrm{Ge}(111) / \mathrm{Ag}-(\sqrt{3} \times \sqrt{3}) \mathrm{R} 30^{\circ}$ substrate does not intermix with Ge and preserves its magnetic properties. This work was followed by a series of articles that addressed the various aspects of this appealing system [68-74].

Here we study the growth of Co on bare Ge(111)-c $(2 \times 8)$ surfaces. The phase diagrams of $\mathrm{Co} / \mathrm{Ge}$ and $\mathrm{Co} / \mathrm{Si}$ exhibit a rich variety of different phases. In the case of $\mathrm{Co} / \mathrm{Ge}$ orthorhombic $\mathrm{CoGe}_{2}$ and tetragonal $\mathrm{Co}_{5} \mathrm{Ge}_{7}$ are the most common phases. Despite the fact that we did not deposit a $\mathrm{Ag}$ buffer layer, our results are very similar to the system $\mathrm{Co}$ on $\mathrm{Ag} / \mathrm{Ge}(111)-(\sqrt{3} \times$ $\sqrt{3}) \mathrm{R} 30^{\circ}$. We also observe $(\sqrt{13} \times \sqrt{13}) \mathrm{R} 13.9^{\circ}$ reconstructed embedded islands at low annealing temperatures and $(2 \times 2)$ reconstructed ad-islands at higher annealing temperatures. Scanning tunneling spectroscopy experiments suggest that both types of islands contain Co atoms. In addition, we found a $(6 \times 2)$ superstructure for the $(2 \times 2)$ crystallites that is aligned along the high symmetry directions of the underlying $\mathrm{Ge}(111)$.

\subsection{Experimental aspects}

Experiments were performed using an Omicron ultra-high vacuum STM operating at a base pressure of $5 \cdot 10^{-11}$ mbar. Ge substrates were cut from nominally flat 3 in. single-side-polished and intrinsic wafers. The samples were mounted on Mo holders and contact with any metal has been avoided during the preparation. An atomically clean Ge(111) substrate was obtained 
by prolonged $800 \mathrm{eV} \mathrm{Ar}^{+}$ion sputtering followed by annealing the sample through resistive heating at $1100( \pm 25) \mathrm{K}[75,76]$. Large $\mathrm{c}(2 \times 8)$ reconstructed patches were obtained by gradually cooling the sample to room temperature. Sub-monolayer to several monolayer amounts of Co were evaporated by resistively heating a W wire wrapped with a pure Co $(99,995 \%)$ wire. During evaporation the sample was kept at room temperature. After evaporation the sample was annealed at $500( \pm 25) \mathrm{K}$ for five minutes and subsequently at $750( \pm 25) \mathrm{K}$ for two minutes. Before placing it into the STM the sample was cooled down to room temperature. All STM measurements were performed at room temperature.

\subsection{Results and discussion}

\subsubsection{Co on $\mathrm{Ge}(111)$ - Low coverage}

In Fig. 5.1 an empty state STM image of a $\mathrm{Ge}(111)-\mathrm{c}(2 \times 8)$ surface recorded at room temperature is shown. The surface exhibits large terraces separated by bilayer steps. The inset of Fig. 5.1 shows a high resolution image of the $\mathrm{Ge}(111)-\mathrm{c}(2 \times 8)$ surface. The structure of the $\mathrm{Ge}(111)-\mathrm{c}(2 \times 8)$ is well established. It consists of an arrangement of adatoms and rest atoms. A $\mathrm{c}(2 \times 8)$ unit cell comprises a $\mathrm{p}(2 \times 2)$ and $\mathrm{c}(4 \times 2)$ unit cell [77]. The bright dots visible in the inset of Fig. 5.1 are adatoms.

After depositing less than 0.1 ML of Co on the Ge(111) surface and a subsequent anneal to $500 \mathrm{~K}$ for five minutes, the surface is partly covered with $(\sqrt{13} \times \sqrt{13})$ R13.9 $9^{\circ}$ islands as shown in Fig. 5.2(A). Small scale empty and filled state STM images of the same $6 \mathrm{~nm}$ by $6 \mathrm{~nm}$ area are shown in Fig. $5.2(\mathrm{~B})$ and $5.2(\mathrm{C})$, respectively. The $(\sqrt{13} \times \sqrt{13}) \mathrm{R} 13.9^{\circ}$ unit cell is outlined by a diamond. It is pointed out that $\mathrm{Fu}$ et al. [68] and Tsay et al. [69] observed similar Co containing islands on the $\mathrm{Ag} / \mathrm{Ge}(111)-(\sqrt{3} \times \sqrt{3}) \mathrm{R} 30^{\circ}$ system. In Fig. 5.2(D) a line profile taken across a $(\sqrt{13} \times \sqrt{13}) \mathrm{R} 13.9^{\circ}$ island is depicted. The island is only $0.05 \mathrm{~nm}$ higher than the surrounding $\mathrm{Ge}(111)$ $\mathrm{c}(2 \times 8)$ surface and at the rim of the island a narrow $0.1 \mathrm{~nm}$ deep trough is observed.

When the sample is subsequently annealed to $750 \mathrm{~K}$ for two minutes a new type of island emerges as shown in Fig. 5.3(A). The number density of islands decreases, but at the same time their averaged height increases to at least three layers. These observations are consistent with those reported 


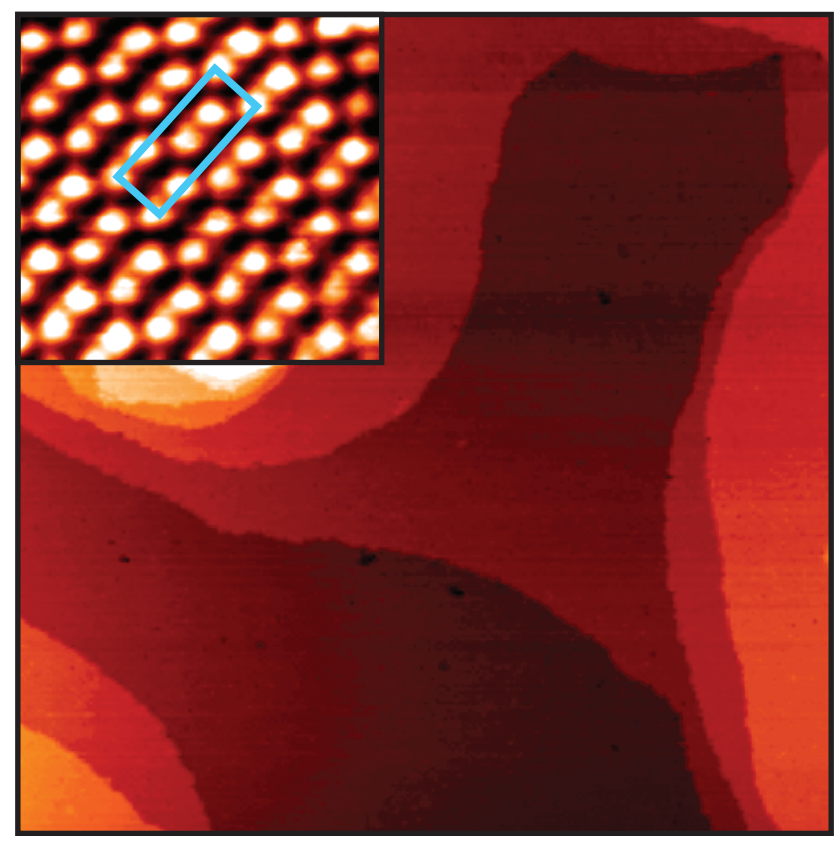

Figure 5.1: Scanning tunneling microscope image of a clean Ge(111)-c $(2 \times 8)$ surface showing large terraces and single bilayer steps. Setpoint is $1.1 \mathrm{~V}$ and $0.3 \mathrm{nA}$. Image size is $370 \times 370 \mathrm{~nm}^{2}$. The inset shows the $\mathrm{c}(2 \times 8)$ reconstructed $\mathrm{Ge}(111)$ surface. The rectangle represents a unit cell of the $\mathrm{c}(2 \times 8)$ reconstruction. Image size inset is $6 \times 6 \mathrm{~nm}^{2}$. 


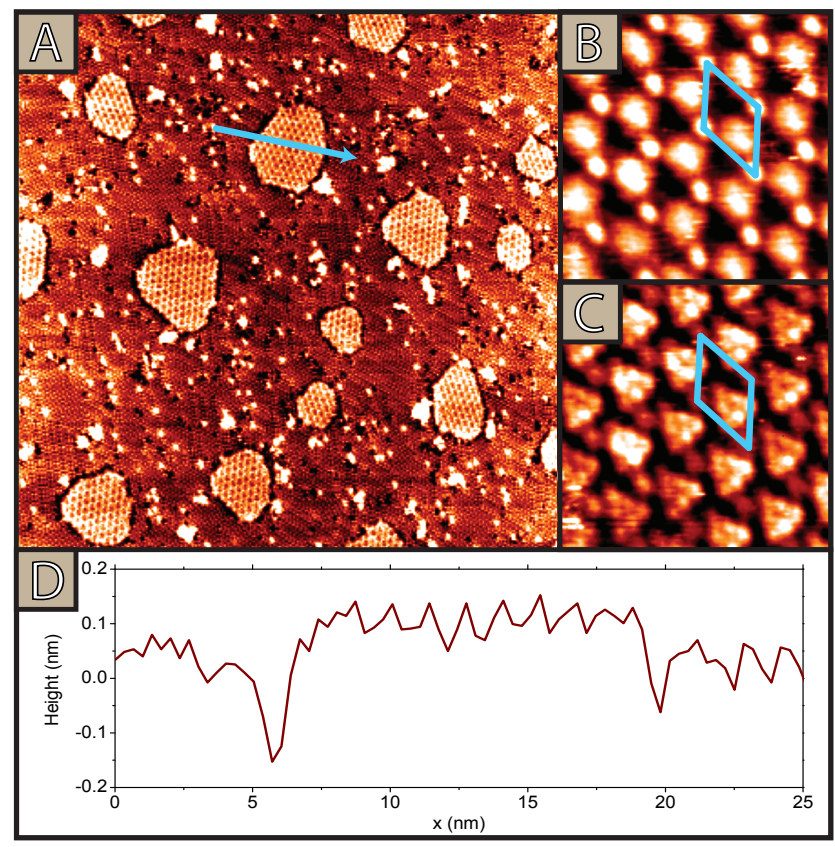

Figure 5.2: (A) A scanning tunneling microscope image showing the $(\sqrt{13} \times$ $\sqrt{13}) \mathrm{R} 13.9^{\circ}$ islands randomly distributed on $\mathrm{Ge}(111)$. In $(\mathrm{B})$ and $(\mathrm{C})$ a zoomed image of the $(\sqrt{13} \times \sqrt{13}) \mathrm{R} 13.9^{\circ}$ reconstruction is depicted at positive and negative sample bias, respectively. (D) Shows a profile scan taken along the arrow in (A). A $0.1 \mathrm{~nm}$ deep trough separates the islands from the surrounding $\mathrm{Ge}(111)$ terrace. The $(\sqrt{13} \times \sqrt{13}) \mathrm{R} 13.9^{\circ}$ islands are only 0.05 $\mathrm{nm}$ higher than the surrounding $\mathrm{Ge}(111)$ terraces. Setpoint and image sizes are: $(\mathrm{A})+1.1 \mathrm{~V}, 0.3 \mathrm{nA}$ and $70 \times 50 \mathrm{~nm}^{2},(\mathrm{~B})+1.5 \mathrm{~V}, 0.3 \mathrm{nA}$ and $6 \times 6$ $\mathrm{nm}^{2}$ and $(\mathrm{C})-1.5 \mathrm{~V}, 0.3 \mathrm{nA}$ and $6 \times 6 \mathrm{~nm}^{2}$. 


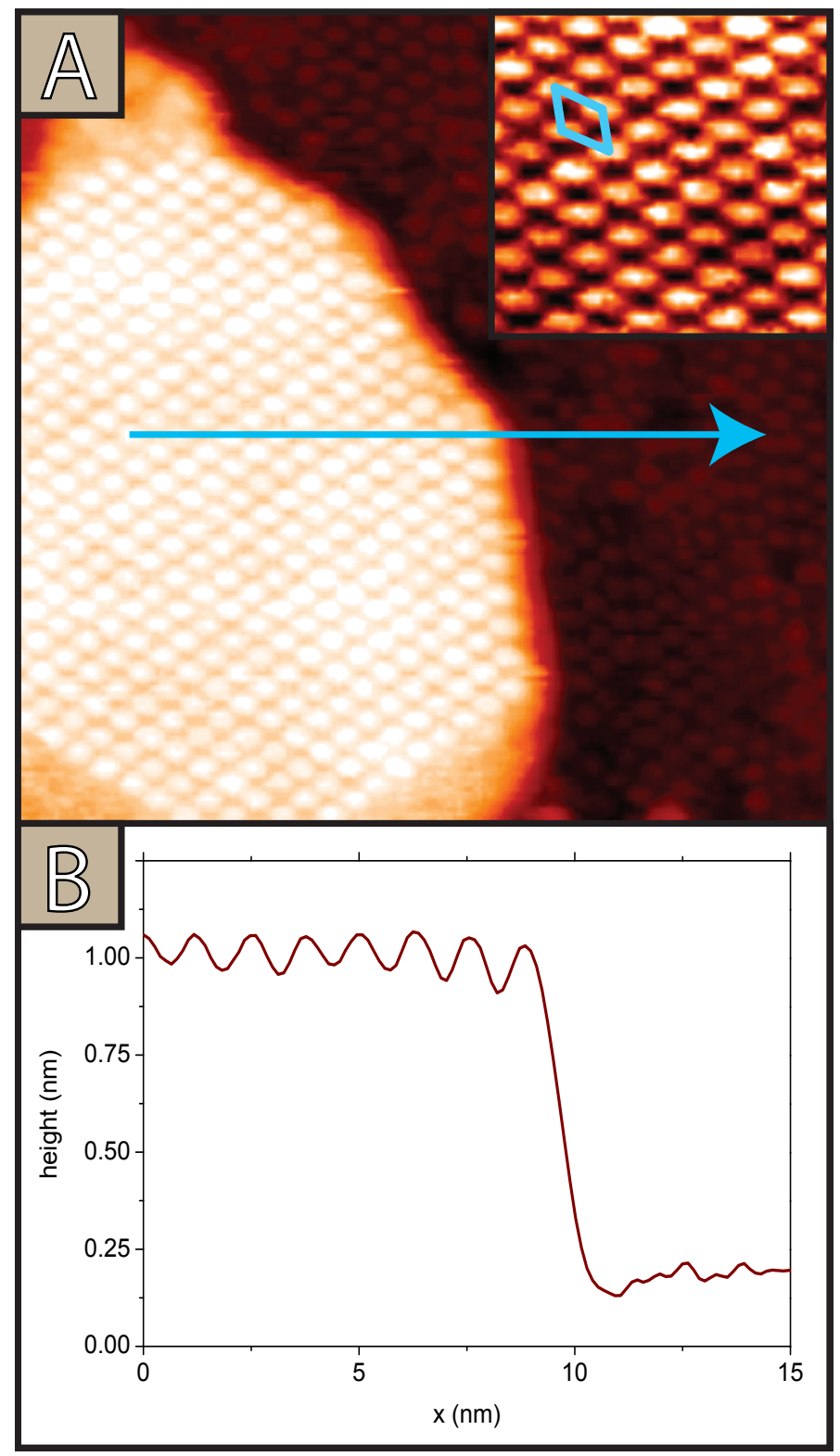

Figure 5.3: (A) Scanning tunneling microscope image of a $(2 \times 2)$ island after annealing at $750 \mathrm{~K}$. In the inset in (A) a close-up STM image of the $(2 \times 2)$ reconstruction is depicted. A profile scan taken along the $[11 \overline{2}]$ direction (arrow) in (A) is shown in (B). Setpoint is $0.5 \mathrm{~V}$ and $0.3 \mathrm{nA}$ in (A). Image sizes are $21 \times 21 \mathrm{~nm}^{2}$ and $5 \times 5 \mathrm{~nm}^{2}$ for (A) and the inset respectively. 
by $\mathrm{Fu}$ et al. $[68,70]$. The inset in $(\mathrm{A})$ shows the $(2 \times 2)$ reconstructed top of the island. In Fig. 5.3(B) a profile taken across a $(2 \times 2)$ island (see the arrow in $(\mathrm{A}))$ is shown. From this profile scan it is clear that this island is several atomic layers high. In addition, it is also clear from Fig. 5.3(A) that the $(2 \times 2)$ reconstruction is perfectly aligned with the $\mathrm{c}(2 \times 8)$ reconstruction of the surrounding Ge(111) surface. On the basis of our scanning tunneling microscopy measurements, we have to conclude that the $(2 \times 2)$ unit cell of the islands is comprised of well-ordered $\mathrm{CoGe}_{2}$ and a model for the $(2 \times 2)$ and $(\sqrt{13} \times \sqrt{13}) \mathrm{R} 13.9^{\circ}$ reconstructions is presented below.

In 2006 Chaput et al. suggested a model for the $(\sqrt{13} \times \sqrt{13}) \mathrm{R} 13.9^{\circ}$ reconstruction of $\mathrm{Co}$ on $\mathrm{Si}(111)$ and supported it with DFT calculations [78]. In close analogy to this model we suggest the schematic model of the $(\sqrt{13} \times \sqrt{13}) \mathrm{R} 13.9^{\circ}$ reconstruction of $\mathrm{Co}$ on $\mathrm{Ge}(111)$ shown in Fig. 5.4(A). The model in Fig 5.4(A) is basically the same as presented by Chaput et al. for Co on $\mathrm{Si}(111)$, only a small change is proposed. In the empty state image of Fig. 5.2(B) four small protrusions located at the corners of the unit cell and a large, more blurry, protrusion in the lower half of the unit cell are visible. The filled state image in Fig. 5.2(C) allows a clearer view. We propose that the small protrusions are single dangling bonds that lose some charge to nearby Ge atoms within the bilayer, indicated by the gray circles surrounded by a larger black circle in the top view image in 5.4. These empty states induce the strong protrusions in 5.2(B). In the filled-state image in Fig. $5.2(\mathrm{C})$ also a larger triangle, consisting of six smaller dots, is visible in the lower half of the $(\sqrt{13} \times \sqrt{13}) \mathrm{R} 13.9^{\circ}$ unit cell. Following Chaput et al. we assume that below this triangle three Ge atoms in the upper sublayer of the outermost Ge-bilayer are replaced by Co atoms as depicted by black filled circles in Fig. 5.4(A). These three Co atoms bind to six Ge adatoms which constitute the large triangle shown in gray in Fig. 5.4(A). Apparently, the six Ge adatoms in the direct vicinity of these Co atoms in the lower half of the $(\sqrt{13} \times \sqrt{13})$ R13.9 $9^{\circ}$ unit cell (dark-gray circles in Fig. 5.4 (A)) are responsible for the characteristic filled state feature of Fig. 5.2(A). A side view is shown in Fig. 5.4(B) where the adatom layer and the first two bilayers are depicted. Another attractive feature of this structure is the saturation of all dangling bonds in the lower part of the outermost bilayer. Strong support for this model comes from the observation that the long axis of the $(\sqrt{13} \times \sqrt{13}) \mathrm{R} 13.9^{\circ}$ unit cell makes a small angle of about $13.9^{\circ}$ with the alignment of the triangles (see lines A and B in Fig. 5.3). 


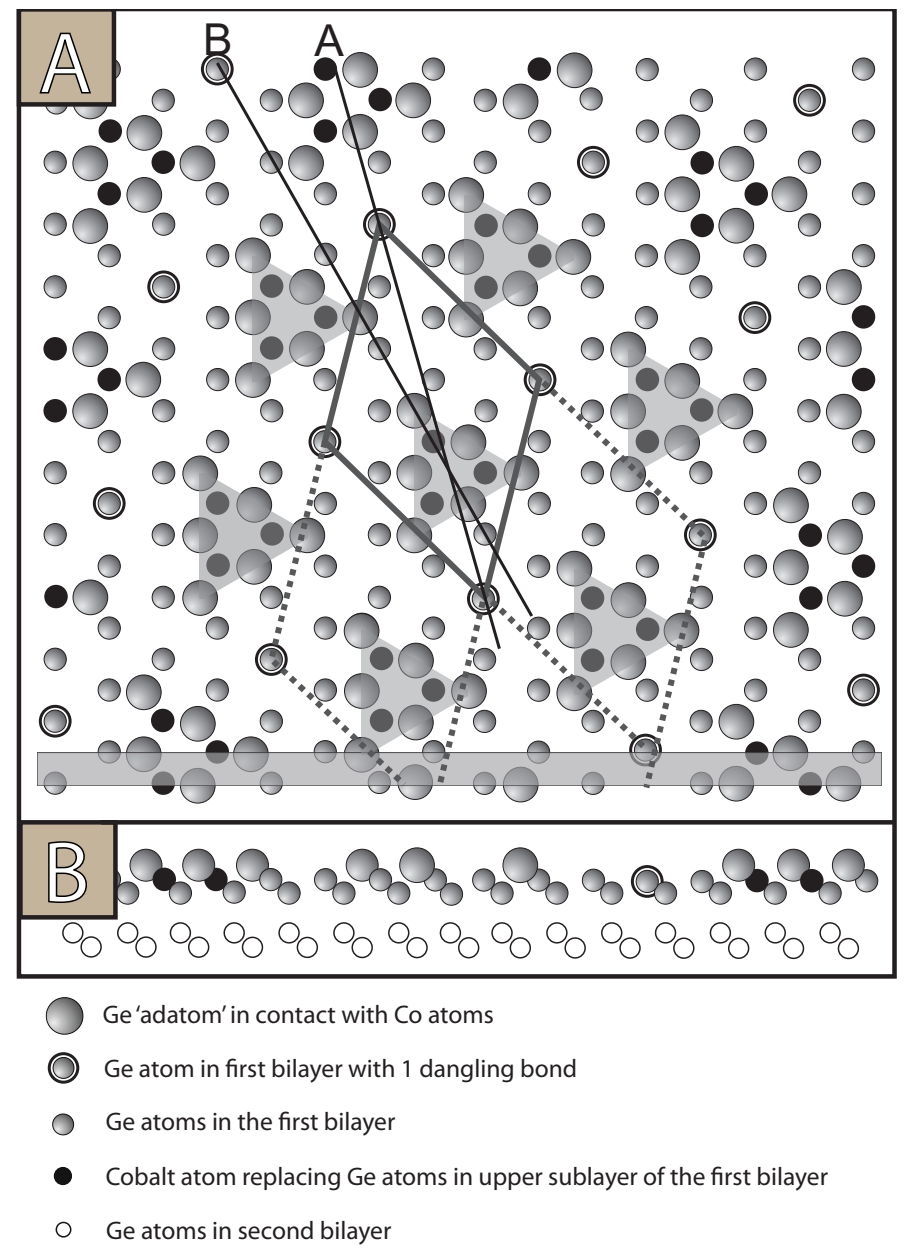

Figure 5.4: (A) Top view of the proposed model for the $(\sqrt{13} \times \sqrt{13}) \mathrm{R} 13.9^{\circ}$ unit cell (solid lines). Dotted lines: neighboring $(\sqrt{13} \times \sqrt{13}) \mathrm{R} 13.9^{\circ}$ unit cells. Gray triangles: 6 atom units that show up in the lower half of the $(\sqrt{13} \times \sqrt{13})$ R13.9 $9^{\circ}$ unit cell. We only show the top sublayer of the outermost bilayer. Line A: long axis of the $(\sqrt{13} \times \sqrt{13})$ R $13.9^{\circ}$ unit cell. Line B: direction of the small triangles. Lines A and B make an angle of $13.9^{\circ}$. (B) Side view of the $(\sqrt{13} \times \sqrt{13}) \mathrm{R} 13.9^{\circ}$ model taken at the gray rectangle shown in $(\mathrm{A})$. 


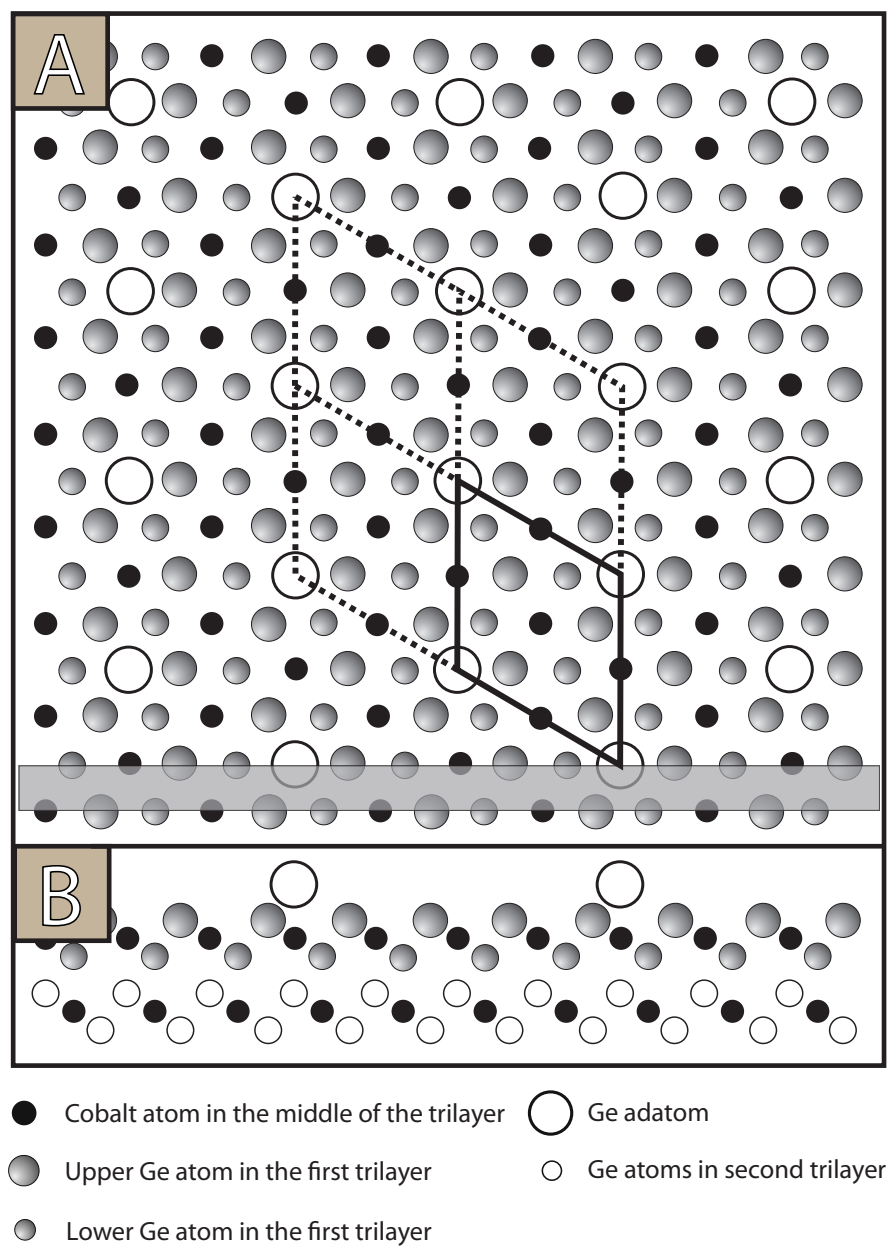

Figure 5.5: (A) Top view of the proposed $(2 \times 2)$ unit cell (solid lines). Dotted lines: neighboring $(2 \times 2)$ unit cells. (B) Side view of the $(2 \times 2)$ model taken at the grey rectangle shown in $(\mathrm{A})$. 
In Fig. 5.5(A) a schematic model is given for the $(2 \times 2)$ reconstruction which is in complete analogy with the model suggested by Zilani et al. for $(2 \times 2)$ islands of $\mathrm{Co}$ on $\mathrm{Si}(111)$ [79]. They suggest that their islands consist of crystalline $\mathrm{CoSi}_{2}$ with a fluorite structure. In the case of Co on Ge the $(2 \times 2)$ islands consist out of $\mathrm{CoGe}_{2}$. Because of their fluorite structure the $(2 \times 2)$ reconstructed $\mathrm{CoGe}_{2}$ islands are comprised of trilayers (see Fig. 5.5(B)), instead of the bilayers which are characteristic for the Ge(111) crystal. The in-plane lattice parameters can now be checked and they nicely correspond to our $\mathrm{CoGe}_{2}$ assignment.

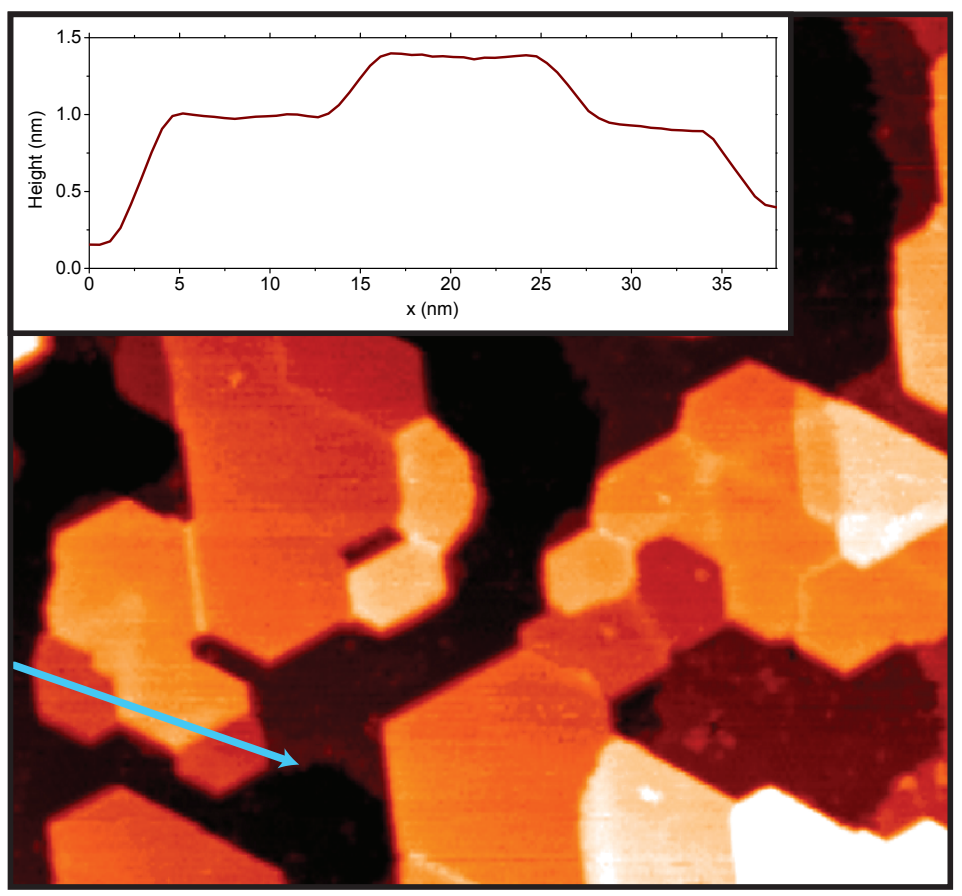

Figure 5.6: At higher Co coverage the Ge(111) surface is covered with hexagonal shaped threefold symmetric islands exhibiting a $(2 \times 2)$ reconstruction. An overview is shown and a profile scan is taken along the arrow. This profile is depicted in the inset. The smallest step height that is observed 0.35 $( \pm 0.05) \mathrm{nm}$, which corresponds to the height of a trilayer. Setpoint is +1.5 $\mathrm{V}$ and $0.3 \mathrm{nA}$. Scan size is $128 \times 128 \mathrm{~nm}^{2}$. 


\subsubsection{Co on $\mathrm{Ge}(111)$ - High coverage}

To further corroborate this assignment we checked the interlayer distance. We therefore increased the Co coverage to four monolayers. In Fig. 5.6 larger hexagonal, threefold symmetric, $(2 \times 2)$ islands are visible on which the height of a single trilayer can be measured. We find a trilayer height of $0.35( \pm 0.05) \mathrm{nm}$, which corresponds well to the theoretical value of 3.27 $\AA$, derived from the $\mathrm{CoGe}_{2}$ crystal structure. This result firmly confirms the assignment, because we could not find another CoGe alloy or a specific termination of pure $\mathrm{Co}$, which satisfies these numbers.

This implies that the crystallite depicted in Fig. 5.3 consists of three trilayers. On top of these trilayers Ge adatoms form the $(2 \times 2)$ reconstruction, again in close agreement with Ref. [79]. It is important to note that the triangular islands in the $(\sqrt{13} \times \sqrt{13}) \mathrm{R} 13.9^{\circ}$ reconstructed islands already contain, at least locally, the basic features of a $\mathrm{CoGe}_{2}$ trilayer. The triangles depicted in Fig. 5.4(A) form the basic element of the trilayer. The central three Co atoms, surrounded by three Ge atoms below and three more above, form a complete building block, while the surrounding additional three Ge corner atoms illustrate the strong tendency of surrounding Co by Ge atoms. The latter is further corroborated by the termination of the $(2 \times 2)$ structure by Ge adatoms. We stress that the models given in Figs. 5.4 and 5.5 are obviously basic geometrical models.

The increased temperature apparently enables the further spreading of the $\mathrm{CoGe}_{2}$ phase (see Fig. 5.6). By starting from the shaded triangular $\mathrm{CoGe}_{2}$ patches within the $(\sqrt{13} \times \sqrt{13})$ R $13.9^{\circ}$ domains (cf. Fig. 5.4) as nuclei, the $\mathrm{CoGe}_{2}$ phase is grown upon increasing the temperature and the first trilayer of a $(2 \times 2)$ island is created. We note that the $(2 \times 2)$ islands first have a minimum height of three trilayers (cf. Fig. 5.3) and laterally expand during their growth. At later stages also single trilayer height differences are observed (Fig. 5.6). We observe a novel $(6 \times 2)$ reconstruction as is illustrated in Fig. 5.7. Fig. 5.7(A) shows an STM image recorded at a voltage of only $-0.035 \mathrm{~V}$ of another $(2 \times 2)$ reconstructed island. Every third adatom row appears brighter (as has been highlighted in Fig. 5.7(B)). We slightly favor a growth scenario in which the islands initially grow as 3 trilayers high entities, possibly set by surface stress due to slight mismatches between Ge $\{111\}$ and epitaxial $\mathrm{CoGe}_{2}$, and eventually form (111) oriented facets. In the lateral sense the slight mismatch could be compensated by a periodic, different Co- (or Ge-) coordination at the interface, leading to the $(6 \times 2)$ reconstruc- 
tion. The $\{11 \overline{1}\}$ fluorite crystallites may subsequently expand layer wise, which would naturally explain the unilateral nature of the reconstruction. This scenario requires sufficient mobility (or sufficiently high temperature) to enable both Ge and Co to move laterally across the surface to form the thermodynamically favorable $\mathrm{CoGe}_{2}$ crystallites.

In Fig. 5.8(A) the surface is shown after annealing to $750 \mathrm{~K}$ for ten minutes. Several domain boundaries between the $(2 \times 2)$ reconstructed domains are visible. We have labeled these domain boundaries type 1, 2 and 3 respectively. All domain boundaries are characterized by a phase shift between the adjacent $(2 \times 2)$ domains. Types (1) and (2) both are dynamic, while type (3), which is highlighted by an ellipse, is perfectly stable. The observed dynamics of the type (1) boundaries can be caused by vacancies, clustering on the surface, subsurface defects, or different surface stresses experienced by the islands at the boundary. The wormlike shapes observed at the domain boundary have been observed before by Saedi et al. [80] Type (2) is basically a type (3) boundary decorated with some adatoms. These adatoms can diffuse along the domain boundary resulting in the observed fuzzy appearance of the domain boundary. A current-time trace with the feedback loop disabled is recorded on top of a type (2) domain boundary (see Fig. 5.8(B)). Three current levels are observed in Fig. 5.8(B) indicating that the adatom underneath the STM tip is able to move along the domain boundary, and that at least three different configurations can be discerned. We suggest that the adatom hops back and forth between these three positions.

Finally, scanning tunneling spectroscopy measurements have been performed and are shown in Fig. 5.9. Figure 5.9(A) shows differential conductivities of a clean $\operatorname{Ge}(111)-\mathrm{c}(2 \times 8)$ surface and a $(\sqrt{13} \times \sqrt{13}) \mathrm{R} 13.9^{\circ}$ reconstructed island. The clean $\mathrm{Ge}(111)-\mathrm{c}(2 \times 8)$ surface exhibits a characteristic Ge adatom peak at $0.5 \mathrm{eV}$. Furthermore, a band gap is observed with a width of 0.6-0.7 eV. Fig. 5.9(B) shows the differential conductivity of $(2 \times 2)$ reconstructed islands. Both Co containing reconstructions have no apparent band gap and the Ge adatom peak is suppressed in both cases. Moreover, both reconstructed islands have a non-zero differential conductivity at the Fermi level, supporting the fact that Co atoms are present. 


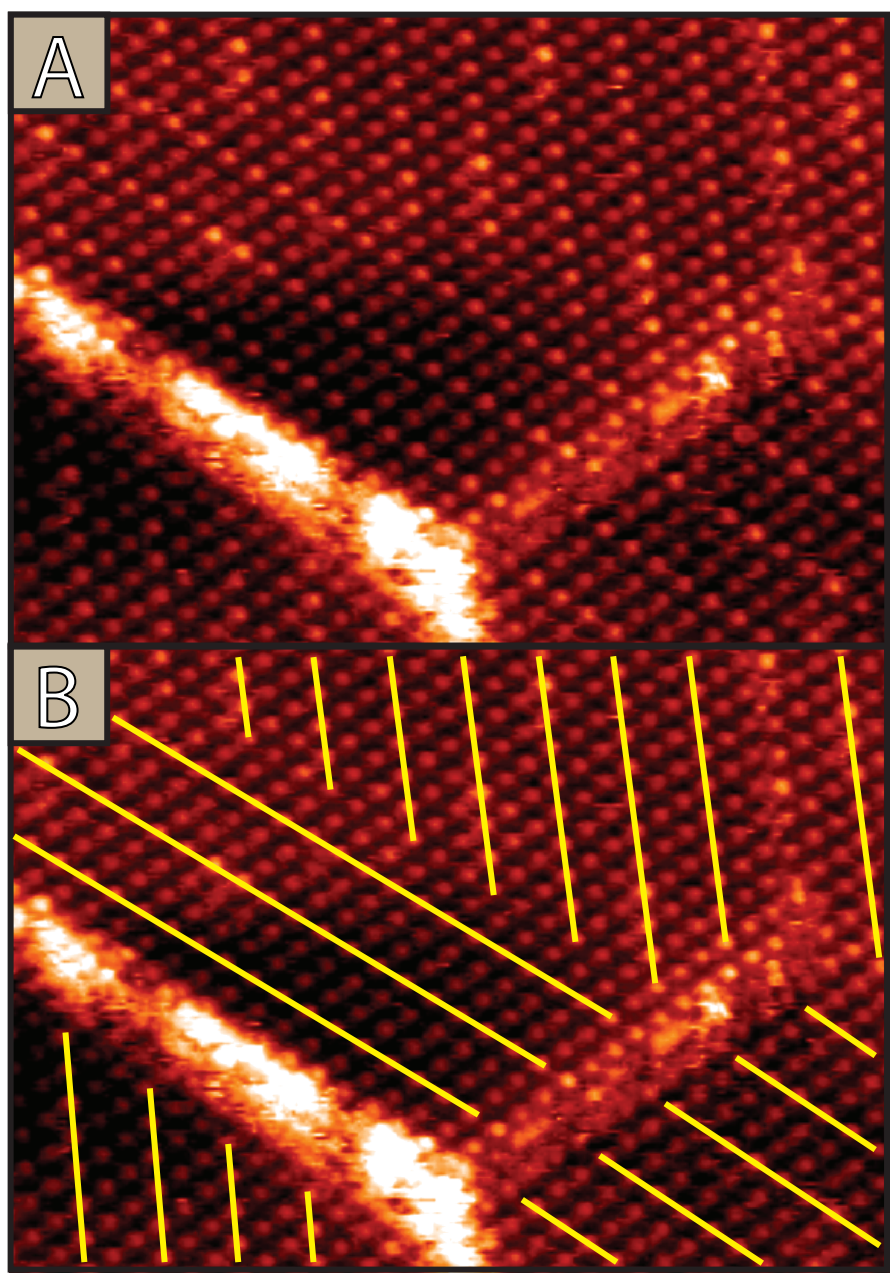

Figure 5.7: (A) An image of a $(2 \times 2)$ reconstructed island. The $(6 \times 2)$ superstructure is outlined by lines in (B). Setpoint is $-0.035 \mathrm{~V}$ and $0.3 \mathrm{nA}$. Image size is $23 \times 16 \mathrm{~nm}^{2}$. 


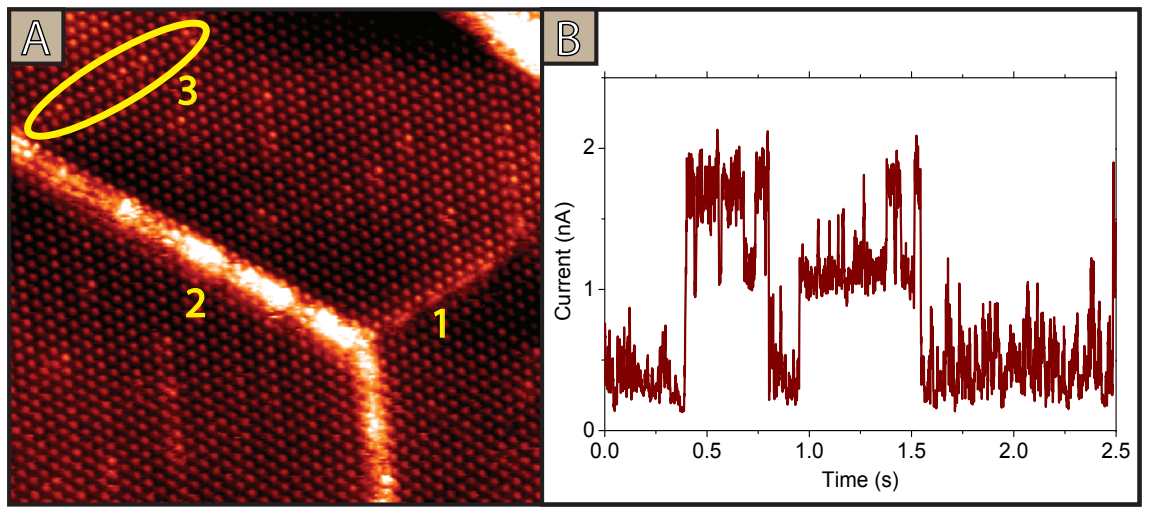

Figure 5.8: A detailed scanning tunneling microscope image of a $(2 \times 2)$ island (A). Three types of domain boundaries are observed on the $(2 \times 2)$ reconstructed surface. Types (1) and (2) are dynamic, whereas type (3) is static. Type (1) domain boundaries contain some vacancies and atoms jump back and forth along the boundaries giving rise to a wormlike appearance. Type (2) domain boundaries are decorated type (3) domain boundaries. Most adatoms are mobile resulting in a fuzzy appearance of the domain boundary. (B) A current time trace with the feedback loop disabled of a type (2) domain boundary. The setpoint in $(\mathrm{A})$ is $-0.25 \mathrm{~V}$ and $0.3 \mathrm{nA}$. Image size is $35 \times 35$ $\mathrm{nm}^{2}$. Setpoint for the current time trace in $(B)$ is $-0.25 \mathrm{~V}$ and $0.4 \mathrm{nA}$. 


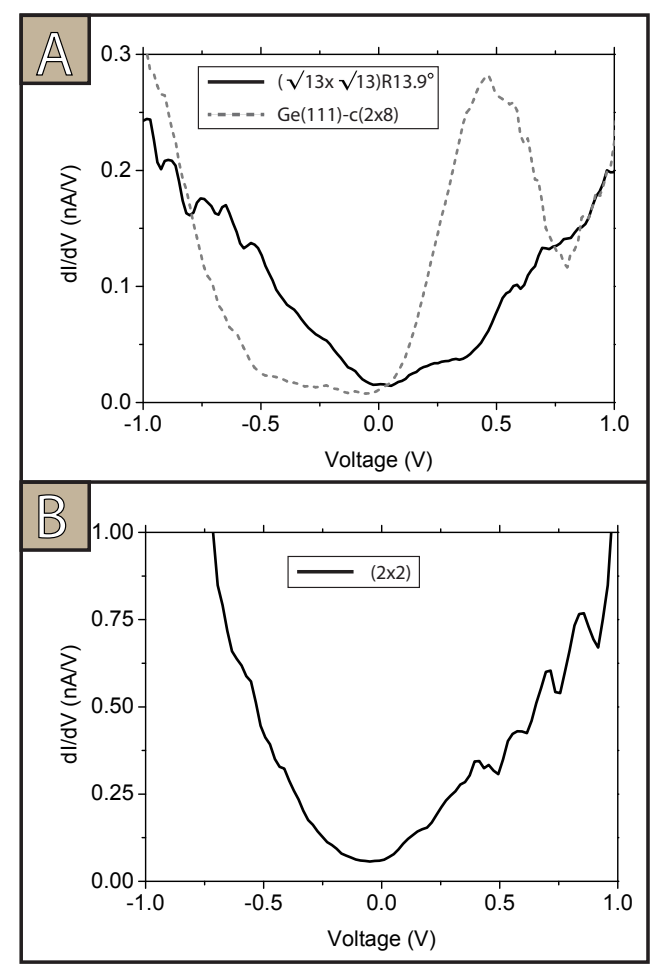

Figure 5.9: (A) Differential conductivities of the $\mathrm{Ge}(111)-\mathrm{c}(2 \times 8)$ reconstructed surface and a $(\sqrt{13} \times \sqrt{13})$ R $13.9^{\circ}$ island. (B) Differential conductivity of a $(2 \times 2)$ island. Only the $\mathrm{Ge}(111)-\mathrm{c}(2 \times 8)$ surface shows a band gap. Setpoints are $+1.5 \mathrm{~V}, 0.5 \mathrm{nA}$ and $-0.5 \mathrm{~V}, 0.3 \mathrm{nA}$ for $(\mathrm{A})$ and $(\mathrm{B})$ respectively. 


\subsection{Conclusions}

The growth of Co on $\mathrm{Ge}(111)-\mathrm{c}(2 \times 8)$ has been studied with scanning tunneling microscopy and spectroscopy. At low annealing temperatures $(500 \mathrm{~K})$ embedded $(\sqrt{13} \times \sqrt{13}) \mathrm{R} 13.9^{\circ}$ reconstructed islands are formed, whereas annealing at higher temperatures $(750 \mathrm{~K})$ results into the formation of $(2 \times 2)$ ad-islands. The structure and composition of the islands are straightforward when accepting guidance from literature for $\mathrm{Co} / \mathrm{Si}(111)$. The $(2 \times 2)$ islands consist of $(111)$ oriented $\mathrm{CoGe}_{2}$ with a fluorite structure. The $(2 \times 2)$ reconstruction results from the termination of one out of four outermost Co atoms by Ge adatoms. The $(2 \times 2)$ ad-islands exhibit different types of antiphase domain boundaries as well as a $(6 \times 2)$ superstructure at higher coverages. Some of these domain boundaries are dynamic at room temperature, whereas others are completely static. The low temperature $(\sqrt{13} \times \sqrt{13}) \mathrm{R} 13.9^{\circ}$ phase contains elements from the interface of the $\mathrm{CoGe}_{2}$ phase. Within the unit cell 3 out 13 atoms in the upper sub-layer of the outermost Ge bilayer are replaced by Co atoms. This triangular configuration is terminated by six $\mathrm{Ge}$ adatoms. On the corners of the $(\sqrt{13} \times \sqrt{13}) \mathrm{R} 13.9^{\circ}$ unit cell we find a single dangling bond that has transferred charge to nearby Ge atoms in the bilayer. Scanning tunneling spectroscopy measurements indicate the presence of Co atoms in the $(2 \times 2)$ and $(\sqrt{13} \times \sqrt{13}) \mathrm{R} 13.9^{\circ}$ reconstructed islands. 


\section{Co-induced nanocrystals on $\mathrm{Ge}(001)$ and $\mathrm{Ge}(111)$ surfaces}

Cobalt has different properties than e.g. gold and platinum when it is deposited on the Ge(001) surface. Previous work has revealed that the Co is located as embedded islands within the Ge(001) surface at low coverages [58]. When the coverage is increased to several monolayers strain starts to affect the surface morphology. In this chapter we investigate the structural and electronic properties of Co nanocrystals on $\mathrm{Ge}(001)$ and $\mathrm{Ge}(111)$ substrates. The properties are to some extent similar to the Co on $\mathrm{Si}(001)$ system, however, there are also a number of distinct differences. For the system $\mathrm{Co} / \mathrm{Ge}(001)$ we found two types of nanocrystals that are either flat-topped or peaked. 


\subsection{Introduction}

The creation of low-dimensional and nanometer sized artificial structures on surfaces has been an important research topic for many decades. The interest in these nanostructures is huge because they exhibit attractive, and evenmore important, tunable electronic properties which pave the way to technologically relevant applications. The most straightforward way to tune the electronic properties of these nanostructures is by tailoring their size, shape and dimension. A way to accomplish control over these key parameters is to use the lattice misfit between substrate and nanostructure. Recent studies have revealed that the deposition of metals such as $\mathrm{Pt}[20], \mathrm{Au}[21$, $23,30]$, and Co on semiconductor group IV (001) surfaces [58,81-89] leads to a plethora of novel nanostructures.

Several groups have studied the growth of Co on Si surfaces [55, 89-94], while the growth of Co on Ge surfaces attracted much less attention. The growth of thicker Co layers on $\mathrm{Ge}(001)$ has, however, been addressed in quite some detail by Choi et al. [95] and De Keyser et al. [96] In these studies several cobalt germanides, namely $\mathrm{CoGe}, \mathrm{CoGe}_{2}$ and $\mathrm{Co}_{5} \mathrm{Ge}_{7}$, were found. Ge and Si both have a diamond lattice with lattice constants of $0.566 \mathrm{~nm}$ and $0.543 \mathrm{~nm}$, respectively. It is noteworthy to point out that the (001) projected lattice constant of $\mathrm{Ge}(0.40 \mathrm{~nm})$ is very comparable to the c-lattice constant $(0.407 \mathrm{~nm})$ of the hcp Co lattice.

The lattice misfit in heteroepitaxial systems often leads to the formation of strain stabilized nanoclusters. In the early nineties of the twentieth century Tersoff and Tromp [97] put forward a generic model to explain the shape evolution of nanoclusters. They showed that strained islands are compact at small sizes, but become elongated beyond a certain critical size. An experimental study of the $\mathrm{Co} / \mathrm{Si}(001)$ system by Brongersma et al. [94] revealed that this system almost perfectly obeys the generic Tersoff and Trompmodel. The question that immediately pops up is whether the $\mathrm{Co} / \mathrm{Ge}(001)$ system behaves in a similar fashion. This is a very relevant question, because both systems, i.e. $\mathrm{Co} / \mathrm{Si}(001)$ and $\mathrm{Co} / \mathrm{Ge}(001)$, behave differently at sub-monolayer Co coverages [55, 58, 90-94].

In this chapter we will focus on the growth behavior of Co-induced nanocrystals on the $\mathrm{Ge}(001)$ and (111) surfaces. We have found a coexistence of peaked nanocrystals (PNCs) and flat-topped nanocrystals (FNCs). Scanning tunneling spectroscopy and helium ion microscopy measurements reveal that the 
chemical composition and structure of the PNCs and FNCs are significantly different from the underlying Ge substrate. Interestingly, only the PNCs exhibit a compact to elongated shape transition. On top of the FNCs onedimensional structures are observed which show dynamic behavior at room temperature.

\subsection{Experimental aspects}

Experiments were performed with an Omicron ultra-high vacuum STM. The base pressure was $5 \cdot 10^{-11}$ mbar. Ge substrates were cut from nominally flat 3 in. single-side-polished and lightly $\mathrm{Sb}$ doped n-type wafers with a resistivity of less than $0.01 \Omega \cdot \mathrm{cm}$. The samples were mounted on Mo holders and contact with any metal was avoided during the preparation. Atomically clean $\mathrm{Ge}(001)$ and $\mathrm{Ge}(111)$ substrates were obtained by prolonged $800 \mathrm{eV}$ Ar ion sputtering followed by annealing the sample through resistive heating at 1100 $( \pm 25) \mathrm{K}[25,76]$. Several monolayers (3-5 monolayers) of Co were evaporated by resistively heating a W wire wrapped with a pure Co (99.995\%) wire. The amount of deposited Co was kept constant throughout all our experiments. During evaporation the sample was kept at room temperature. After evaporation the $\mathrm{Ge}(001)$ sample was annealed at $600( \pm 25) \mathrm{K}$ for 8 minutes and for a shorter period of 4 minutes at $700( \pm 25) \mathrm{K}$. The Ge(111) sample was annealed at $500( \pm 25) \mathrm{K}$, at $750( \pm 25) \mathrm{K}$ (see Chapter 5$)$, then 5 minutes at $800( \pm 25) \mathrm{K}$ and finally 5 minutes at $900( \pm 25) \mathrm{K}$. Before placing it into the STM the sample was cooled down to room temperature. All STM measurements were performed at room temperature. Helium Ion Microscopy (HIM) [98] has been performed ex-situ after the STM investigations were completed. HIM images were recorded using both the Everhart-Thornley (ET) detector and the Micro Channel Plate (MCP) detector. While the first one allows the surface sensitive high resolution imaging of the sample morphology utilizing secondary electrons, the latter counts the number of back scattered He atoms, thus allowing elemental and structural characterization of the specimen. Sample transfer from the UHV STM to the UHV HIM has been performed as quickly as possible. However, oxidation of both the Ge substrate and the Co nanocrystals during sample transfer cannot be excluded. The unique UHV-HIM [99] with a base pressure of $5 \cdot 10^{-9} \mathrm{mbar}$ allows the prolonged exposure of the sensitive nanostructures to the He beam. The primary energy of the He beam has been varied from $10 \mathrm{kV}$ to $35 \mathrm{kV}$. 


\subsection{Results and discussion}

\subsubsection{Bistability of Co-induced nanocrystals on $\mathrm{Ge}(001)$}

In Fig. 6.1(A) a room temperature STM image of a Co/Ge(001) substrate is shown after the deposition of about 3 monolayers of Co and subsequent annealing at $600 \mathrm{~K}$ for 8 minutes and at $700 \mathrm{~K}$ for 4 minutes. The observed 3D clusters can be divided into two different classes: (1) FNCs (Fig. 6.1(B)) and (2) PNCs (Fig. 6.1(C)). The PNCs can be divided into compact and elongated crystals. The PNCs have widths of about 10-35 $\mathrm{nm}$ and lengths of $10-60 \mathrm{~nm}$. The FNCs have sizes ranging from about $20 \times 20 \mathrm{~nm}^{2}$ to $50 \times 50$ $\mathrm{nm}^{2}$. The height of the nanocrystals varies between $4 \mathrm{~nm}$ and $7 \mathrm{~nm}$. There is no firm relation between the surface projected size and the height of the PNCs and FNCs. The PNCs and the FNCs are always aligned along the high symmetry directions, i.e. the dimer row directions, of the (001) surface. The top of the FNCs is reconstructed. On top of these nanocrystals well-aligned 1D structures are observed. The spacing between adjacent lines is often 2.8 $( \pm 0.2) \mathrm{nm}$, but occasionally larger spacings of $3.2( \pm 0.2 \mathrm{~nm})$ and $3.6( \pm 0.2)$ $\mathrm{nm}$ are found as well. The $1 \mathrm{D}$ structures or lines are composed of regularly spaced entities.

STS measurements are performed on the flat terraces as well as on the two types of nanocrystals. The differential conductivity, which is roughly proportional to the density of states, of the three different structures is shown in Fig. 6.2. The flat terraces display a rather large band gap which is comparable with the band gap of Ge. The differential conductivities of the two types of nanocrystals are distinctly different, but both exhibit a clear metallic character. Since the density of states of the nanocrystals is so different from that of Ge we have to conclude that both types of nanocrystals contain Co. The crystal structure and exact chemical composition of both types of nanocrystals are probably different as well. Possible candidates for the nanocrystals are $\mathrm{CoGe}_{2}, \mathrm{Co}_{5} \mathrm{Ge}_{5}$ or $\mathrm{CoGe}[94,95]$. The distinct peak in the density of states observed for FNCs at $-0.5 \mathrm{~V}$ bias voltage is a typical fingerprint of Co $[100,101]$. This indicates that the flat top facet of the FNCs consists of Co atoms. HIM has been used to check the homogeneity of the

sample surface. In the $1 \mu \mathrm{m}^{2}$ large ET HIM image presented in Fig. 6.3(A) a total of roughly 250 nanocrystals can be seen. The average aspect ratio $(\mathrm{AR})$ is 1.54. However, the presence of the elongated nanocrystals leads to a second maximum in the distribution at an AR of 1.70 and a maximum AR of 


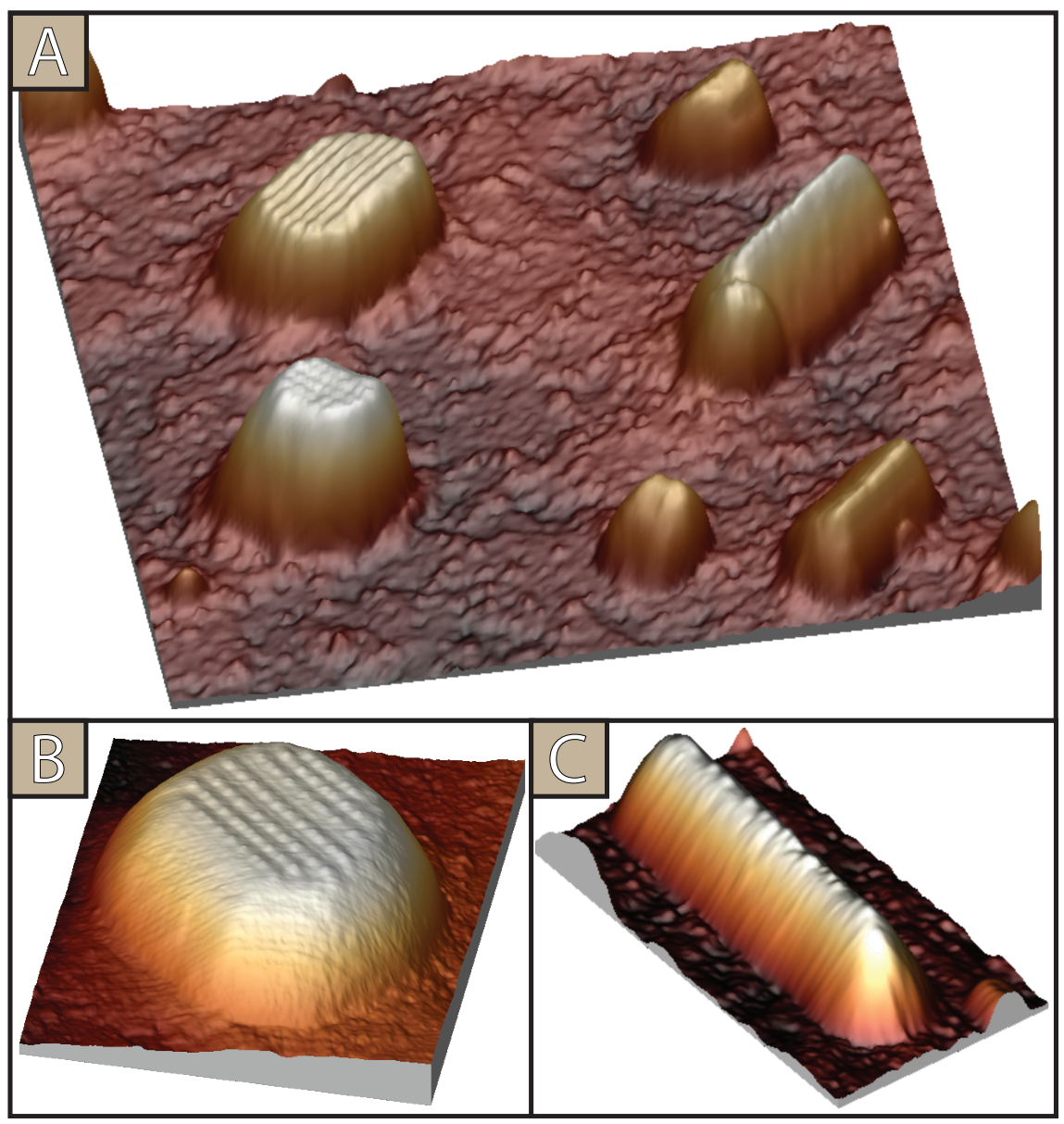

Figure 6.1: Scanning tunneling microscopy images of Co-induced nanocrystals on a $\mathrm{Ge}(001)$ substrate. (A) An overview on the Co-induced nanocrystals on the Ge(001) surface. The image size is $140 \times 140 \mathrm{~nm}^{2}$. The height of the highest nanocrystal is $7 \mathrm{~nm}$. Two different types of crystals are observed: (B) flat-topped nanocrystals (FNCs) and (C) peaked nanocrystals (PNCs). Images (B) and (C) have sizes of $50 \times 50 \mathrm{~nm}^{2}$ and $30 \times 55 \mathrm{~nm}^{2}$, respectively. Sample bias is $-1.5 \mathrm{~V}$ and tunneling current is $0.5 \mathrm{nA}$. The heights of the nanocrystals in (B) and (C) are $6 \mathrm{~nm}$ and $5 \mathrm{~nm}$, respectively. 


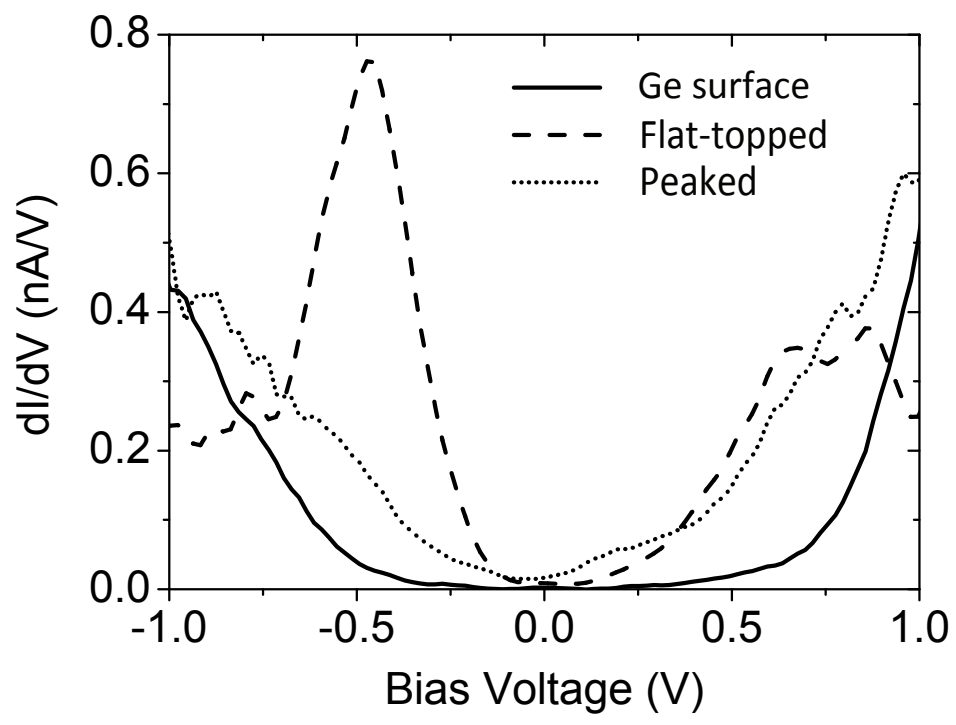

Figure 6.2: Differential conductivity (dI/dV) recorded on bare Ge(001) terraces (solid line), flat-topped nanocrystals (large dash) and peaked nanocrystals (small dash). The results are averaged over more than 100 traces per curve, with setpoints $\mathrm{I}_{t}=0.45 \mathrm{nA}$ and $\mathrm{V}_{g}=-1.5 \mathrm{~V}$. 
3.13. The comparable low energy of the secondary electrons - created by the energy loss of the He due to electronic stopping in the material - and their origin from a surface near region make the method very sensitive to changes of the work function. The contrast between the nanocrystals and the Ge substrate is based on this effect. The back scattered He image presented in Fig. 6.3(B) has been obtained using the MCP detector. The nanocrystals are clearly visible and also their different shapes can be identified. Here contrast is based on the backscatter probability of He. However, for this particular sample the contrast stems not from the different backscatter probabilities of Co and Ge. Depending on the thickness of the lighter Co top-layer either no contrast (thin Co film) or a reverse contrast (thick Co layer) would be expected. The increased backscatter probability is a result of the different crystal structures of the nanocrystals. The incommensurate nanocrystals block the open channels in the underlying $\mathrm{Ge}(001)$ substrate, thus locally increasing the backscatter yield. This is confirmed by Fig. 6.3(C), which has been recorded under identical conditions but with a $10^{\circ}$ sample tilt. The (001) channels are not parallel to the He ion beam anymore and backscattering has increased on the whole sample surface rendering the nanocrystals invisible.

The width and length ( $w$ and $l$, respectively) of the PNCs and FNCs are plotted against the square root of the island size in Fig. 6.4. Beyond a critical island size of about $400 \mathrm{~nm}^{2}$ a shape transition from compact PNC to elongated PNC is observed. Brongersma et al. [94] have found a similar shape transition of $\mathrm{CoSi}_{2}$ clusters on $\mathrm{Si}(001)$. However, in the $\mathrm{Co} / \mathrm{Si}(001)$ case the shape transition occurred at a much larger cluster size [94]. The FNCs, which turn out to be always larger than $400 \mathrm{~nm}^{2}$, remain compact up to at least $2000 \mathrm{~nm}^{2}$. A possible explanation for the latter is that the critical crystal size is simply larger than $2000 \mathrm{~nm}^{2}$, but it might also be that these FNCs do not exhibit this shape transition at all i.e. the FNCs could already be relaxed by misfit dislocations. This way they do not require sharp apexes and shape transitions to relax the strain $[88,89]$. Interestingly, we did not observe even a single FNC that has a size smaller than the critical PNC size, suggesting that PNCs with the critical size can evolve in either elongated PNCs or compact FNCs.

The shape of nanostructures on surfaces is in general governed by two energetic terms, the boundary energy and strain relaxation energy. The boundary energy term favors compact nanostructure shapes, whereas the 


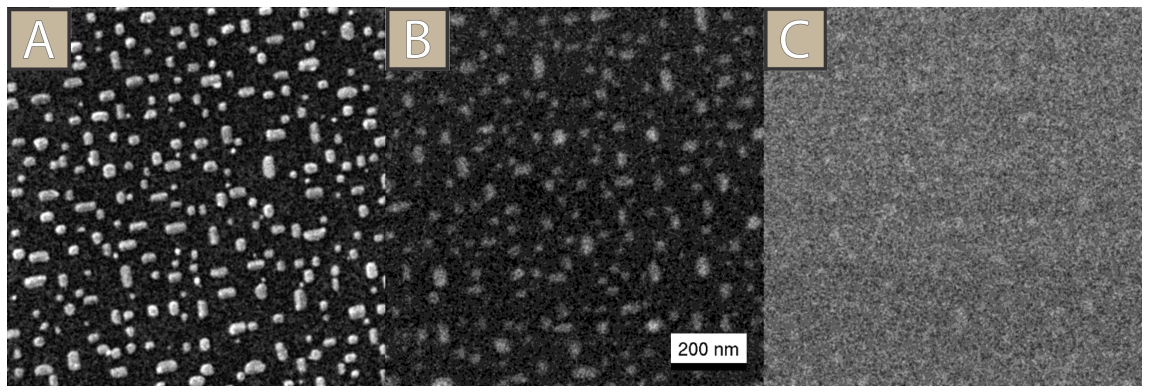

Figure 6.3: (A) Everhart-Thornley He ion microscope image (FOV: $1 \mu \mathrm{m}^{2}$ ) obtained at $35 \mathrm{kV}$ with a beam current of $0.2 \mathrm{pA}$ and a dwell time of 80 $\mu \mathrm{s}$. About 250 PNCs and FNCs are visible. (B) Back scattered He image $\left.\left(1 \mu \mathrm{m}^{2}\right)\right)$ of the same sample recorded with $10 \mathrm{kV}$, a beam current of 0.1 pA and a dwell time of $160 \mu \mathrm{s}$. PNCs and FNCs are visible as they locally increase backscatter probability by lifting the channeling condition for the underlying $\mathrm{Ge}(001)$ crystal. (C) Back scattered He image recorded under identical conditions as (B) but with a sample tilt of $10^{\circ}$. Under this non channeling condition for the $\mathrm{Ge}(001)$ wafer the nanostructures cannot be seen.

strain relaxation term prefers to maximize the total boundary length. As pointed out by Tersoff and Tromp [97] a balance of these two terms reveals that nanostructures on surfaces, i.e. islands or nanoclusters, are compact for small sizes and elongated for large sizes. The latter is of course true for heteroepitaxial systems where a lattice misfit is virtually always present, however Li et al. [102] and Zandvliet et al. [103] have shown that it can also hold for homoepitaxial systems.

\subsubsection{D nanostructures on FNCs}

A topography image of the 1D structures on top of the FNCs is displayed in Fig. 6.5(A). In Fig. 6.5(A) several of these wires are shown and a profile scan has been made along the arrow. The profile scan is depicted in Fig. 6.5(B). The wires are positioned at least $2.8( \pm 0.2) \mathrm{nm}$ apart, but larger distances, i.e. $3.2( \pm 0.2) \mathrm{nm}$ and $3.6( \pm 0.2) \mathrm{nm}$ are sometimes observed as well. The wires are comprised of small square-shaped features that have a size of about $1 \mathrm{~nm}^{2}$. The height of these entities is $0.14( \pm 0.02) \mathrm{nm}$. Furthermore, the square-shaped entities have a preferred nearest neighbor intrarow spacing of $1.6( \pm 0.2) \mathrm{nm}$; however smaller and larger distances do occasionally occur. 


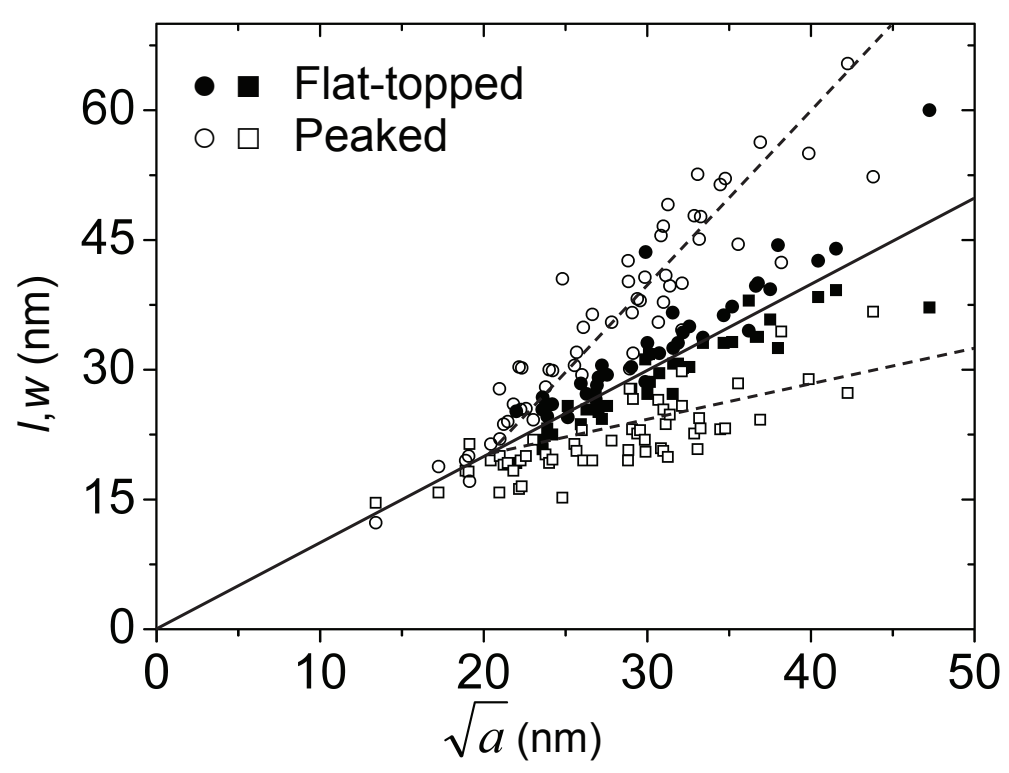

Figure 6.4: Length ' $l$ ' (circles) and width ' $w$ ' (squares) of the FNCs and PNCs as a function of the square root of the projected surface area of the PNCs or FNCs. PNCs with a projected surface area larger than about $400 \mathrm{~nm}^{2}$ have an elongated shape, whereas smaller PNCs are compact. FNCs are compact for sizes up to at least $2000 \mathrm{~nm}^{2}$. 
The ordering of the entities in neighboring rows is in virtually all cases out of phase. Some of the square-shaped entities have a frizzy appearance in the STM images. For instance, the entity in the middle of the topmost row jumps from left to right (the image is scanned from left to right and from bottom to top). It should be noted that this entity was not present in the first few scan lines of this row. The latter implies that the entity has diffused to this row during imaging.

These dynamic entities are observed quite frequently and a nice example is given in Fig. 6.6. The frizzy appearance of the entity indicates that it jumps back and forth between two positions. Current-time traces with the feedback loop disabled are taken on top of the entity shown in Fig. 6.6(B). An example of such a current-time trace is depicted in Fig. 6.6(A). Two current levels can be distinguished and within 10 seconds the entity jumps back and forth several times. The typical jump frequency of the square-shaped entity is about $1 \mathrm{~Hz}$. The averaged jump frequency is independent of the actual sample bias and tunneling current set points indicating that the observed motion is thermally induced. The majority of the jumps occur within the chain. Similar observations have been made for $\mathrm{Si}$ on $\mathrm{Si}(111)-(5 \times 2)-\mathrm{Au}$ [104]. Interestingly, there are a few more analogies between these two systems: (1) the well-defined spacing between adjacent chains, (2) the well-defined spacing between entities within the chain and (3) the out-of-phase registry of the entities within adjacent chains.

The size and height of the square shaped units suggest that they are comprised of two Ge dimers. In addition, imaging at $+1.5 \mathrm{~V}$ and $-1.5 \mathrm{~V}$ sample bias results in very similar appearing images, which is another hallmark of Ge dimers. However, our measurements are not conclusive regarding the exact structure and composition of these square shaped units. In particular, the STS data recorded on top of the FNCs reveal a clear signature of Co.

\subsubsection{Co-induced nanocrystals on $\mathrm{Ge}(111)$}

Similar Co-induced nanocrystals can be observed on a Ge(111) substrate when the sample shown in Fig. 5.6 is annealed for five minutes at a temperature of $800( \pm 25) \mathrm{K}$. An STM image is shown in Fig. 6.7(A). The projected surface area and the height of the $(2 \times 2)$ reconstructed $\mathrm{CoGe}_{2}$ islands decreases drastically, while many large and elongated Co nanocrystals aligned along the three high symmetry directions can be observed. The width $w$ of these nanocrystals never exceeds a value of $45 \mathrm{~nm}$, while the length $l$ 


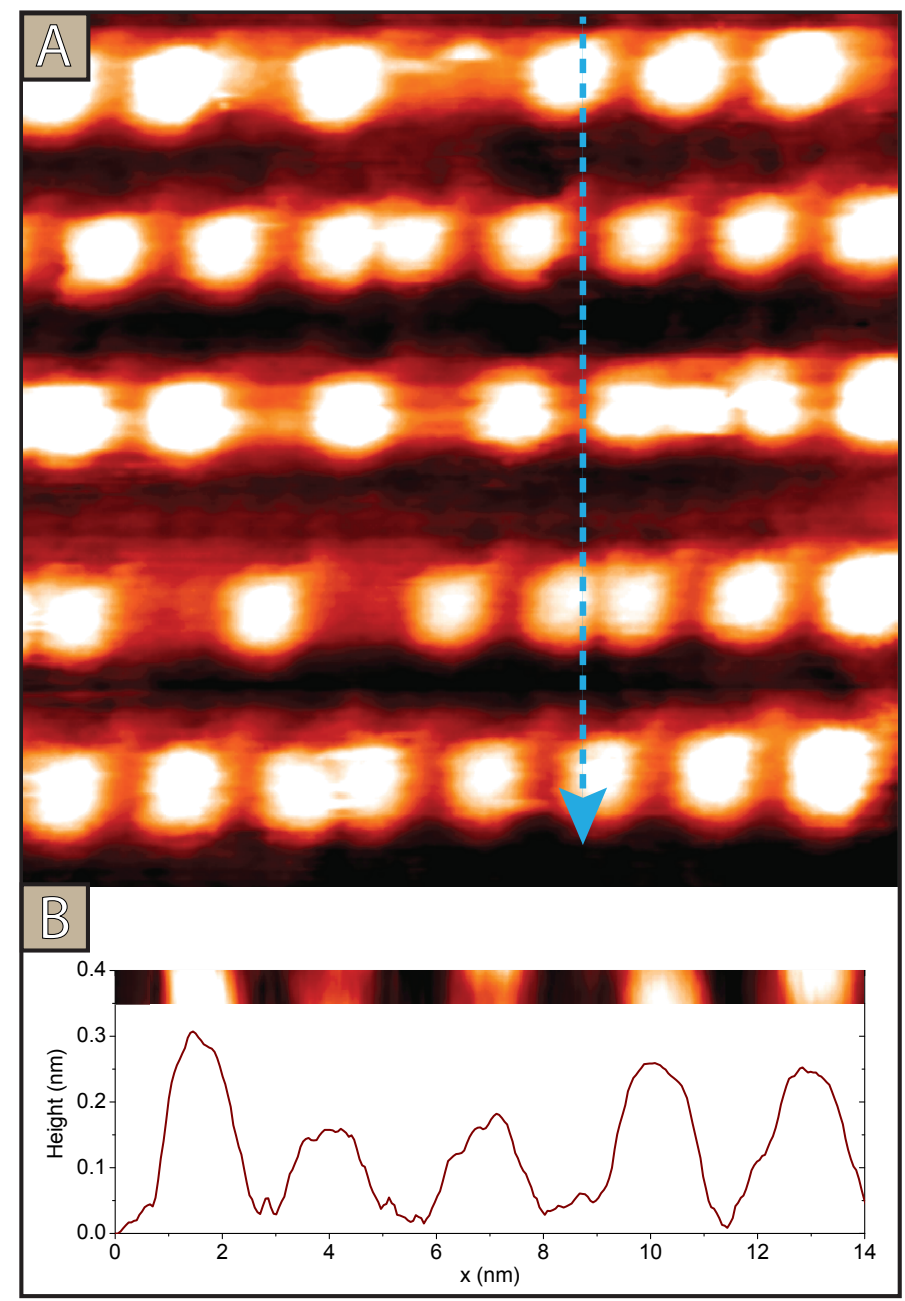

Figure 6.5: A close-up of the 1D structures observed on top of the FNCs. (B) A line scan taken along the arrow. Sample bias is $+1.5 \mathrm{~V}$ and tunneling current is $0.6 \mathrm{nA}$. 


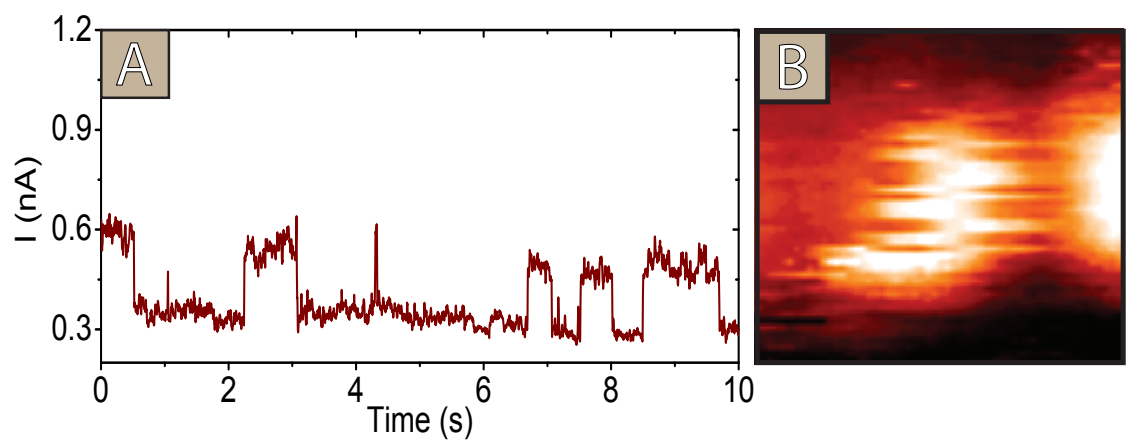

Figure 6.6: A current-time trace with the feedback loop disabled taken on one of the dynamic entities of the 1D structures which are observed on the FNCs. Two distinct levels are observed indicating that the entity hops back and forth between two positions. (B) STM image $\left(4 \mathrm{~nm}^{2}\right)$ of a dynamic entity that jumps back and forth between two positions (the image is scanned from left to right and from bottom to top). Sample bias is $+1.5 \mathrm{~V}$ and tunneling current is $0.6 \mathrm{nA}$.

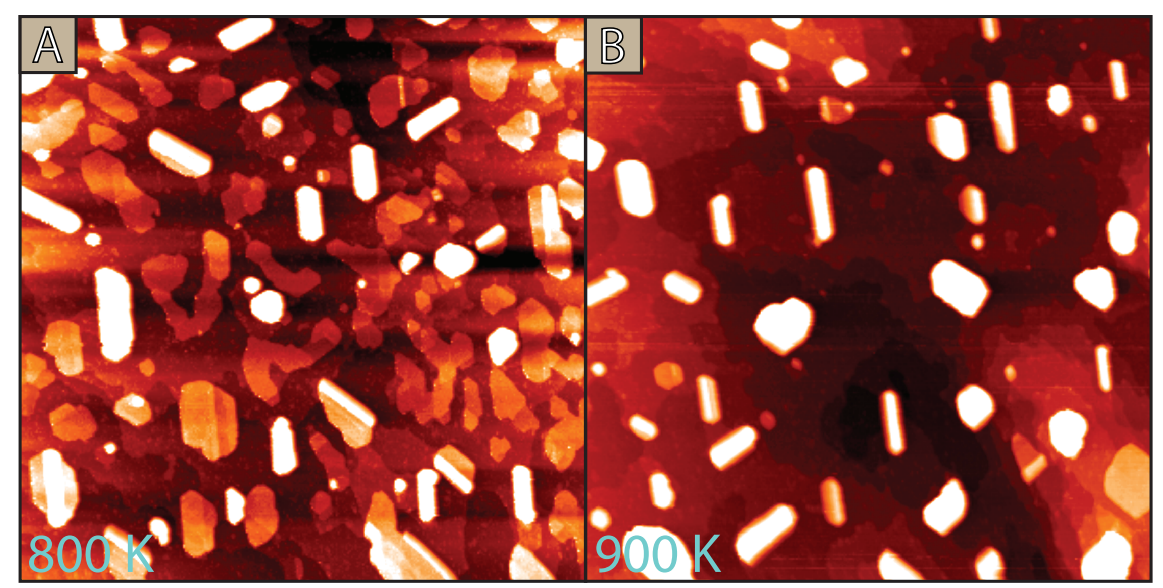

Figure 6.7: Overview of $\mathrm{Co} / \mathrm{Ge}(111)$ surface after annealing at (A) $800 \mathrm{~K}$ and (B) $900 \mathrm{~K}$. Scan size is $600 \times 600 \mathrm{~nm}^{2}$ and setpoints are $-1.5 \mathrm{~V}$ and $0.4 \mathrm{nA}$. 
ranges from 40 to $130 \mathrm{~nm}$. A clear relation between the surface projected size of the nanocrystal and its height cannot be found. Many of the elongated Co-induced nanocrystals in Fig. 6.7(A) are located on top of $(2 \times 2)$ reconstructed islands. Furthermore, there are large clusters that do not show any elongation. When the sample is subsequently annealed for five minutes at a higher temperature of $900( \pm 25) \mathrm{K}$ we obtain the surface shown in Fig. $6.7(\mathrm{~B})$. The $(2 \times 2)$ reconstructed islands have almost completely vanished, only the nanocrystals remain. We can again distinguish elongated and compact nanocrystals. The size of the elongated islands has not changed significantly, however, the compact clusters appear to be much larger. The absence of the $(2 \times 2)$ reconstruction is an indication that at higher annealing temperatures significant mass transport takes place.

When we look more closely to the surface shown in Fig. 6.7(A) we observe very narrow nanocrystals on top of the $(2 \times 2)$ islands. Fig $6.8(\mathrm{~A})$ is a zoom in on a similar $(2 \times 2)$ island (from a different area than shown in Fig. 6.7). Two step edges can clearly be discerned. A profile scan is taken along the arrow and shown in Fig. 6.8(B). From the profile scan it is clear that the step edges must be decorated with Ge or Co atoms. The steps act as nucleation sites.

The domain boundaries that were shown in Fig. 5.8(A) are another type of nucleation site. Two different domains can be observed in Fig. 6.9(A) (highlighted by yellow lines). A large elongated protrusion is located on the boundary between these domains. A profile scan taken along the arrow in Fig. 6.9(A) is given in Fig. 6.9(B). The height of the protrusion indicates that it consists out of at least 2 to 3 atomic layers. Just as step edges on the surface, these domain boundaries act as nucleation sites for the formation of large elongated nanoclusters. Here the shape of the nucleation site has a large effect on the crystal shape.

Scanning tunneling spectroscopy measurements have been performed on the surface shown in Fig. 6.7(B). dI/dV curves, which are closely related to the DOS, for the Ge surface in between the nanocrystals, and the elongated nanocrystals are shown in Fig. 6.10. The non-zero DOS value at the Fermi level of the nanocrystals suggests the presence of Co atoms. The absence of the $+0.5 \mathrm{~V}$ peak of the $\mathrm{Ge}(111)$ surface indicates the absence of Ge adatoms. 


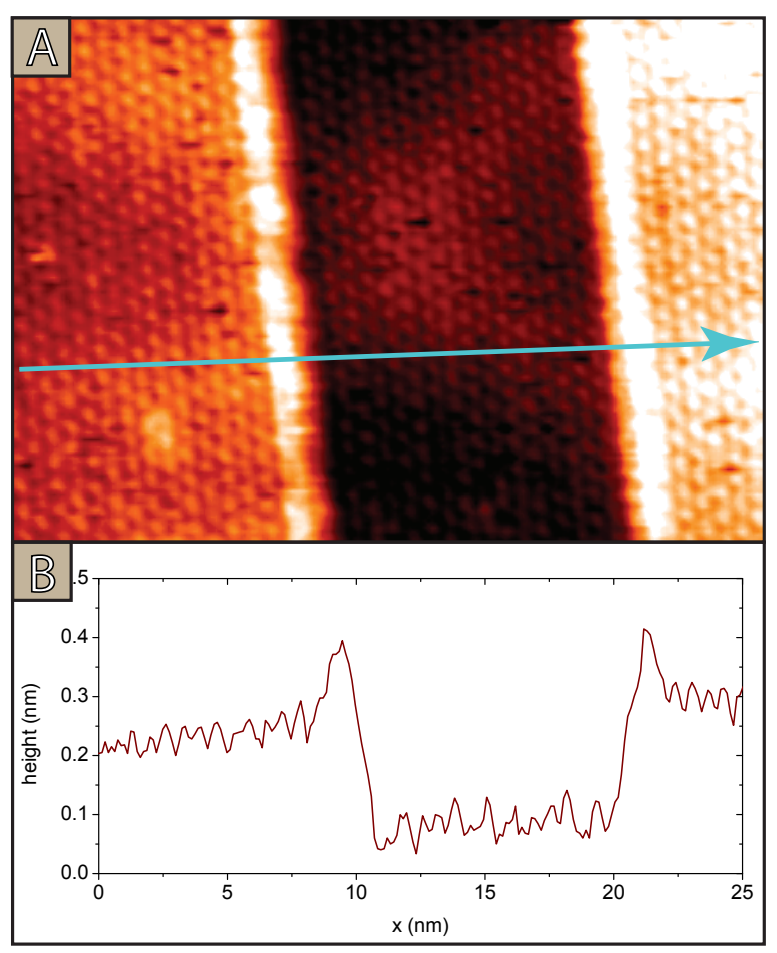

Figure 6.8: (A) STM image showing two decorated step edges. (B) A profile scan taken along the arrow in (A). Scan size of (A) is $25 \times 16 \mathrm{~nm}^{2}$ and setpoints are $-0.3 \mathrm{~V}$ and $0.4 \mathrm{nA}$. 


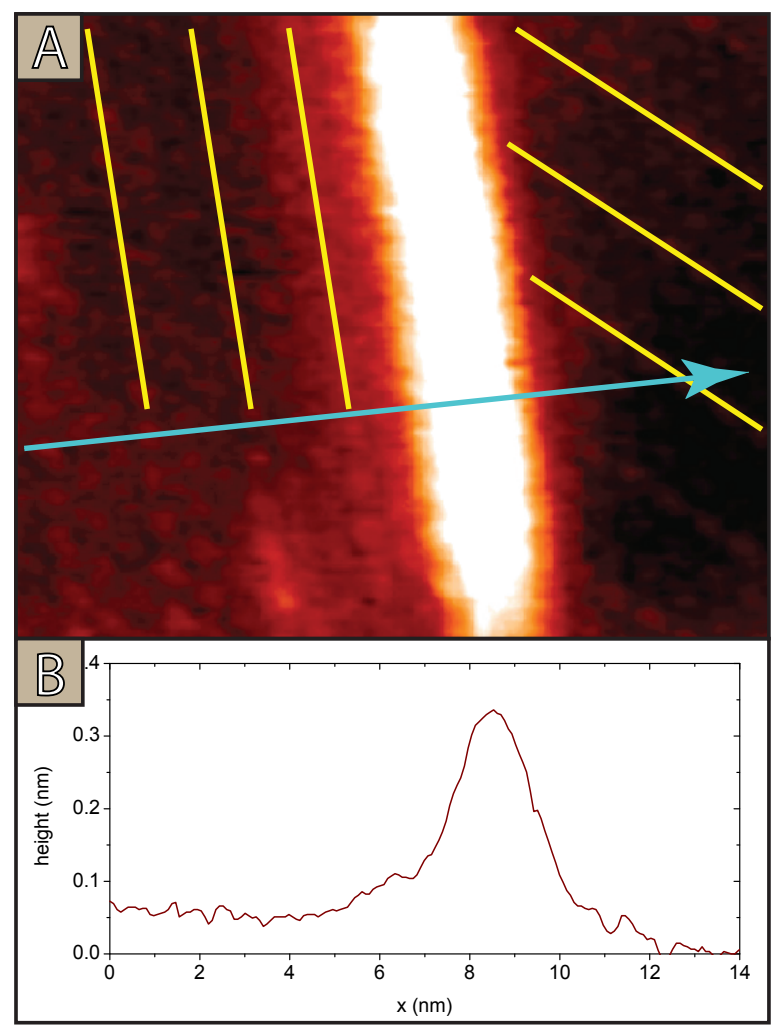

Figure 6.9: (A) STM image of a decorated domain boundary. The direction of the different domains is indicated with yellow lines. A profile scan (B) is taken along the arrow in (A). Scan size is $15 \times 12 \mathrm{~nm}^{2}$ and set points are $-0.062 \mathrm{~V}$ and $0.4 \mathrm{nA}$. 


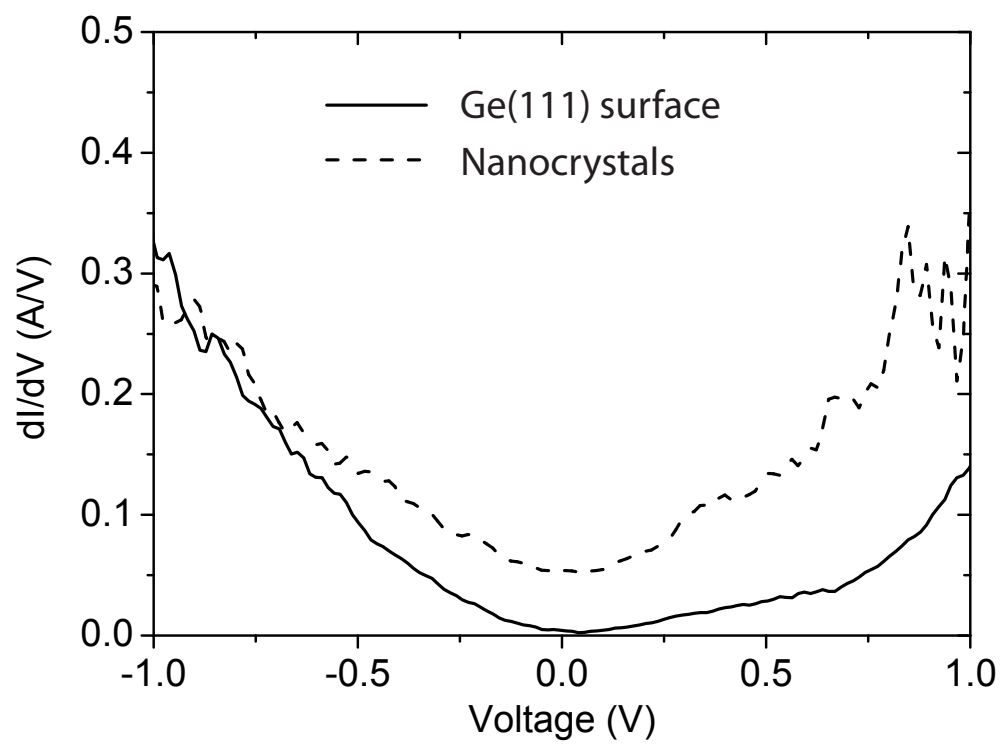

Figure 6.10: dI/dV curves of the Co-induced nanocrystals and the Ge(111) surface. Setpoints are $-1.5 \mathrm{~V}$ and $0.3 \mathrm{nA}$.

\subsection{Conclusions}

In summary, the deposition of Co on $\mathrm{Ge}(001)$ and subsequent annealing leads to the formation of two types of nanoclusters, namely PNCs and FNCs. STS and $\mathrm{He}$ ion microscopy measurements reveal that the nanocrystals contain cobalt. The PNCs are compact below a critical island size of about $400 \mathrm{~nm}^{2}$ and elongated beyond that size. The FNCs are, however, compact up to at least $2000 \mathrm{~nm}^{2}$. On the top facet of these FNCs 1D structures are found. These 1D structures are perfectly straight, have a height of two atomic layers and the top layer consists of square-shaped entities. Some of these entities exhibit dynamic motion during imaging. Furthermore, very similar elongated Co nanocrystals can be observed on the Ge(111) surface. They follow the three high symmetry directions. The shape of the nanocrystals is governed by the boundary and strain energies, and also by the shape of step edges and domain boundaries that act as nucleation sites. 


\section{VII \\ Electronic growth of Ir nanowires on $\mathrm{Ge}(001)$}

The notion that quantum size effects in the growth of thin metal films can lead to smooth growth and magic film layer thicknesses has already been recognized a few decades ago [105-108]. However, in thin film growth it is impossible to directly visualize these quantum size effects in real space. Here we have visualized the electron standing waves patterns in self-organized metallic Ir nanowires grown on Ge(001) surfaces using STM. The conduction electrons, i.e. the electrons near the Fermi level, are confined between both ends of the nanowire leading to the observed electron standing waves patterns and the quantization of nanowire lengths. These experiments provide direct insight in the intimate relation between growth and quantum size effects and show unambiguously that the growth of iridium nanowires is stabilized by an electronic effect. 


\subsection{Introduction}

One-dimensional (1D) electron systems have recently received much attention $[18,109-116]$. This interest is driven by the fact that these systems display a myriad of exciting physical phenomena, such as the quantization of conductance and spin and charge density waves [35,117-119]. Even more intriguing and exotic new physics emerges when electron-electron interactions are taken into account [112-119]. Unfortunately, true 1D electron systems are virtually impossible to realize. An elegant way to realize a quasi 1D electron system is by using a quantum mechanical break junction (QMBJ) set up $[3,4]$. Almost perfect linear chains of atoms have been created in these experiments, all showing evidence for quantum conductance. The most viable examples involve the $5 d$-transition metals $\mathrm{Au}, \mathrm{Pt}$ and Ir. However, a severe drawback of QMBJ chains is their length being limited to only a few atoms.

The aforementioned drawback can be overcome by growing self-organizing atom chains on semiconductor surfaces. These systems constitute the best candidates for model systems to study the exotic and intriguing phenomena of $1 \mathrm{D}$ electron systems. Fortunately, the heavy $5 d$-transition metals as $\mathrm{Pt}$ and $\mathrm{Au}$ have a strong tendency to self-organize into defect free, straight, long and narrow nanowires upon annealing, subsequent to deposition on semiconductor group IV (001) surfaces [13, 20,21, 23, 24,33,34,120]. The Pt and $\mathrm{Au}$-induced nanowires, although different in nature, i.e. in their structure $[20,24]$, share the property of being able to attain lengths of up to a few microns. Guided by the similarities in quantum transport between Ir on the one hand and $\mathrm{Au}$ and $\mathrm{Pt}$ on the other hand, we have investigated the self-organized growth of Ir/Ge(001) using STM and STS in an attempt to expand the playground for $1 \mathrm{D}$ physics.

\subsection{Experimental aspects}

Experiments were performed using an Omicron room temperature UHV STM operating at a base pressure of $5 \cdot 10^{-11}$ mbar. Ge(001) samples were cut from nominally flat 3 inch single-side-polished and nearly intrinsic n-type wafers. The samples were mounted on Mo holders and contact of the samples with any other metal has been carefully avoided during the preparation. An atomically clean $\mathrm{Ge}(001)$ substrate was obtained by several cycles of prolonged 800 $\mathrm{eV} \mathrm{Ar}^{+}$ion sputtering, followed by annealing the sample through resistive 
heating at $1100( \pm 25) \mathrm{K}[76]$. The clean samples exhibited a well-ordered $(2 \times 1) / c(4 \times 2)$ domain pattern (see Fig. $7.1(\mathrm{~A}))$. Subsequently, a fraction of a monolayer (0.01-0.3) of Ir was deposited on the surface by resistively heating a $99.9 \%$ pure Ir wire [13]. During evaporation the sample was kept at room temperature. After evaporation the sample was annealed at temperatures ranging from $450 \mathrm{~K}$ to $650 \mathrm{~K}$. Before placing it into the STM the sample was cooled down to room temperature. All STM and STS measurements were performed at room temperature.

\subsection{Results and discussion}

The Pt nanowires and the Au-induced nanowires on $\mathrm{Ge}(001)$ are prime examples of how self-organization can result in beautifully organized domains of regular and parallel $1 \mathrm{D}$ wires. The former are oriented parallel to the dimer row directions, i.e. along the $<110>$ directions of a pristine $\mathrm{Ge}(001)$ surface. These domains can extend up to a micrometer with low defect densities [20]. The separation of adjacent wires is well-defined and in both cases equal to 1.6 $\mathrm{nm}$. Also the surrounding parts of the surface, not covered with wires, are pretty regular except for the so-called $\alpha$-terraces, which exhibit a high degree of disorder [20]. Encouraged by this success we have tried to achieve a similar result for the intimately related $5 d$-transition metal Ir. All efforts ended in a disappointing result, even after lengthy exploration of the parameter space for annealing (temperature, anneal times, heating and cooling rates, etc.). Without exception a quite messy arrangement of short wires was obtained without a well-defined distance between the wires and quite disordered adjacent terraces, very much like the above mentioned $\alpha$-terraces. In Figs. 7.1(B) and 7.1(C) representative STM images are shown. We do observe Ir nanowires with a density that depends on the amount of pre-deposited Ir. These wires are oriented perpendicular to the substrate dimer row directions. Surprisingly, a zoom-in on the wire structure, as shown in inset of Fig. 7.1(B), reveals that the wire is composed of a well-ordered double chain running perpendicular to the direction corresponding to that of the dimer rows on the original, clean host terrace, which is still vaguely visible. The white protrusions are assigned as Ir atoms. The chains in the twin-structure are separated by $0.57 \mathrm{~nm}$ and the periodicity along the chains amounts to 0.8 $\mathrm{nm}$, i.e. exactly twice the in-plane Ge distance. Judging from many images like this, there is no apparent reason why these wires could not extend over 


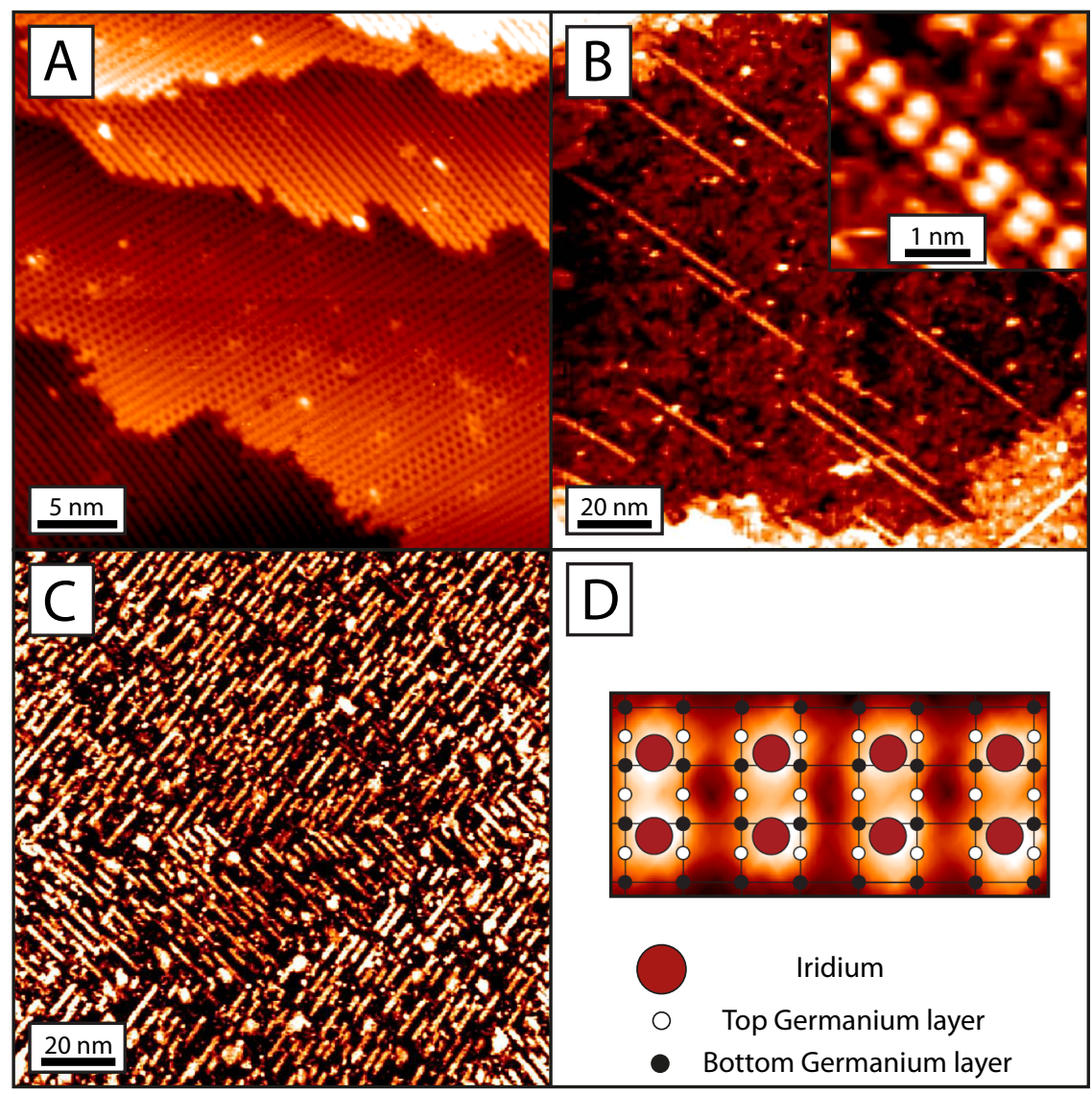

Figure 7.1: (A) Scanning tunneling microscopy image of Ge(001) prior to Ir deposition. (B) Scanning tunneling microscope image after the deposition of $0.01 \mathrm{ML}$ Ir and annealed at $450 \mathrm{~K}$. (C) Scanning tunneling microscope image after the deposition of $0.3 \mathrm{ML}$ of Ir and annealed at $450 \mathrm{~K}$. (D) Close up on an Ir nanowire. A simple ball and stick model for an Ir nanowire is superimposed on the STM image. Set points are in (A) -1.5 V, $0.5 \mathrm{nA},(\mathrm{B})$ $-0.55 \mathrm{~V}, 0.5 \mathrm{nA}$, inset: $-0.86 \mathrm{~V}, 0.2 \mathrm{nA}(\mathrm{C}) 0.50 \mathrm{~V}, 0.5 \mathrm{nA}$ and $(\mathrm{D})-0.86 \mathrm{~V}$, $0.2 \mathrm{nA}$. 


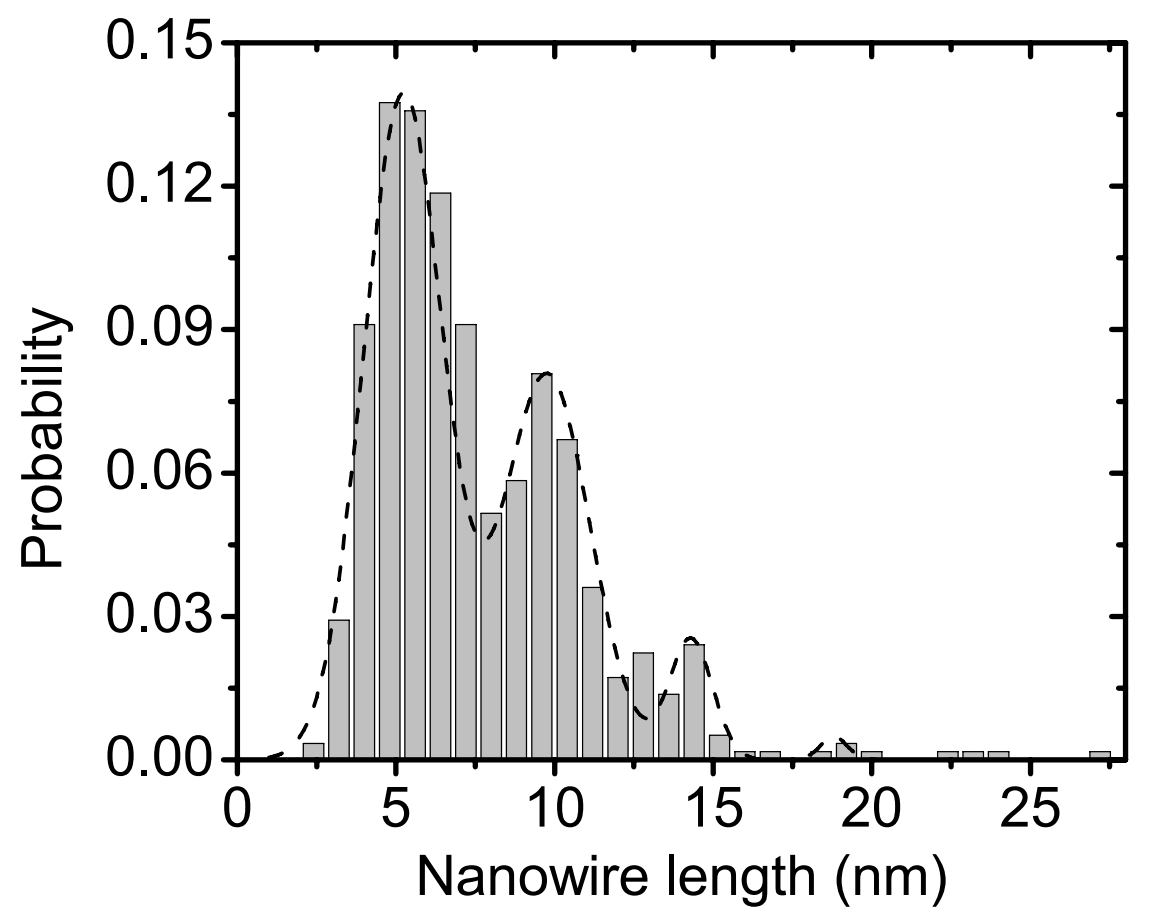

Figure 7.2: Histogram of the length distribution of $\mathrm{Ir}$ nanowires $(\mathrm{N}=582)$. The dashed line serves as a guide to the eye.

a very long distance.

In order to understand why the Ir wires do not grow to huge lengths and to shed light on the obvious differences between Ir and $\mathrm{Pt} / \mathrm{Au}$ we show in Fig. 7.2 a histogram of the length distribution, obtained from 582 individual Ir nanowires. The histogram shows unequivocally an intriguing oscillation of the length of the wire with a period of about $4.8 \mathrm{~nm}$. A strong preference for wires with a length of $4.8 \mathrm{~nm}, 9.6 \mathrm{~nm}$ and $14.4 \mathrm{~nm}$ is clearly established, while indications for preferred lengths of about $19 \mathrm{~nm}$ and $23 \mathrm{~nm}$ are visible. We consider this as strong evidence for an electronic stabilization of the length of the nanowires. In other words, we suggest that quantum size interferences are responsible for the preferred lengths of the wires. Before discussing this feature and its consequences in more detail below, we first briefly discuss the basic features of quantum stability in thin metal films. We do note in addition, that the periodicity of the length-oscillations in Fig. 7.2 is $4.8 \mathrm{~nm}$, 
i.e. 6 elementary units of the nanowire.

The notion that quantum-size effects (QSE) can affect the surface properties and stability of thin metal films on semiconductors or metals with a projected band gap dates back to 1976. The meeting of the condition for the presence of a standing wave pattern of the Fermi electrons between the interfaces, i.e. quantum confinement, was found energetically favorable. Schulte [105] reported self-consistent electronic structure calculations that revealed thickness dependent oscillations in the work function. Experimental evidence that QSE affect epitaxial thin film growth has indeed been found by Hinch et al. [107] for $\mathrm{Pb}$ on $\mathrm{Cu}(111)$ and by Smith et al. [121] for $\mathrm{Ag}$ on GaAs(110). A preferred film thickness is obtained if the following condition applies:

$$
\lambda_{F}=2 n_{d} \cdot \frac{d}{n} \quad \mathrm{n}=1,2,3, \ldots \ldots
$$

with $\lambda_{F}$ the Fermi wave length, $n_{d}$ the number of layers with interatomic spacing $d$. Another feature of electronic nature is the scattering of (Fermi) electrons by an isolated defect, a step edge or as in this case the end of a wire. This density modulation, which arises from an interference of incoming and reflected electron waves, has a periodicity of $\lambda_{F} / 2$. This electron density modulation is referred to as a Friedel oscillation and is given by $[122,123]$,

$$
\rho(r)=\rho(0)+A \frac{\sin \left(2 k_{F} r+\delta\right)}{r^{D}}
$$

where $k_{F}$ is the Fermi wave vector, $\rho_{0}$ the background electron density, $\delta$ a phase factor, $A$ the amplitude of the Friedel oscillation, $D$ the dimension of the electron system and $r$ the position with respect to the defect or impurity. The phase factor is closely related to charge spilling that occurs due to a non-perfect meeting of condition (1). Zhang et al. [108] pointed out that in principle three effects: quantum confinement size interference, charge spilling and substrate induced Friedel oscillations contribute to the eventual thermodynamic stability of a thin film. Jia et al. [124] strongly suggested that Friedel oscillations can contribute to the stability of, in particular, thin $\mathrm{Pb}$ films in an anomalous fashion. The main access road to these Friedel oscillations in a film is through calculations. Experimentally, direct access is impossible, but QSE in electron reflectivity for electrons above the vacuum level have been observed, both in integral measurements [125-127] and in position resolved experiments [128-131]. However, due to their unique geom- 


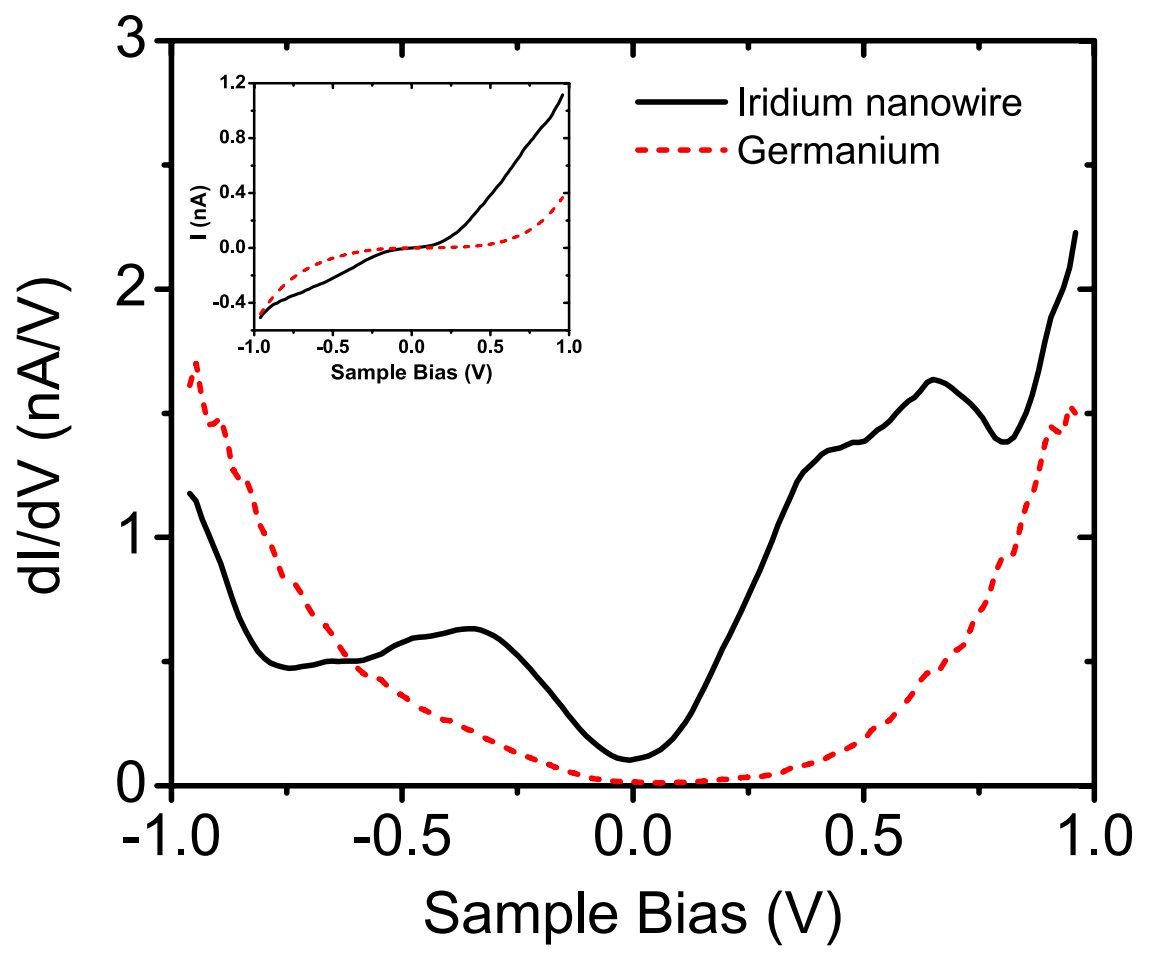

Figure 7.3: Differential conductivity (dI/dV) versus sample bias (V) for Ir nanowires (solid line) and Ge(001) (dashed line). Inset: corresponding $\mathrm{I}(\mathrm{V})$ curves. Set points are $-1 \mathrm{~V}$ and $0.5 \mathrm{nA}$.

etry, the Ir wires would offer a unique and viable opportunity to access the relationship between size selection and Friedel oscillations in a most direct fashion. This is further corroborated by the fact that Friedel oscillations decay very slowly in a $1 \mathrm{D}$ system. However, first we have to demonstrate that the Ir wires are metallic.

In Fig. 7.3 the differential conductivities of the Ir nanowires and the surrounding terraces are shown. In contrast to the surrounding terraces the Ir nanowires exhibit clearly a non-vanishing density of states at the Fermi level, indicating that they are metallic indeed. At $0.3-0.35 \mathrm{eV}$ below the Fermi level a pronounced electronic state is observed in the density of states of the nanowires. Despite the fact that this electronic state is located on the nanowires, thermal and instrumental broadening are too large to resolve the exact dimensionality from the energy dependence of the density of states [13]. 

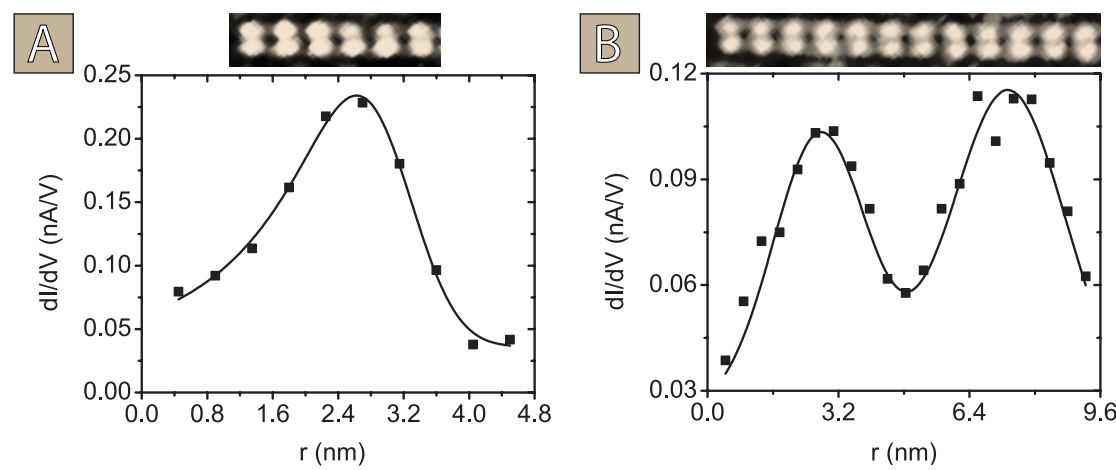

Figure 7.4: Spatial variation of the differential conductivity (dI/dV) at the Fermi edge for a Ir nanowire with a length of $4.8 \mathrm{~nm}(\mathrm{~A})$ and $9.6 \mathrm{~nm}(\mathrm{~B}) . \mathrm{r}=0$ refers to one of the ends of the nanowire. The solid lines serve as a guide to the eye. Scanning tunneling microscopy images of the Ir nanowires are shown at the top of both graphs.

After having fulfilled the two necessary requirements, i.e. systematic size preferences and a nonzero density of states at the Fermi level, the crucial experiment is to measure the real space density of states across the nanowires and to relate its anticipated oscillatory nature to the preferred length of the wires. In Figs. 7.4(A) and 7.4(B) the spatial variation of the density of states along the nanowires is shown. An Ir nanowire with a length of $\mathrm{L}=4.8 \mathrm{~nm}$ exhibits one well-defined local density of states maximum at $\mathrm{L} / 2$, whereas an Ir nanowire of length $\mathrm{L}=9.6 \mathrm{~nm}$ displays two maxima at $\mathrm{L} / 4$ and $3 \mathrm{~L} / 4$ and a node at $\mathrm{L} / 2$, respectively. These results show unambiguously that the observed size preference has its origin in an electronic effect. The period of the differential conductivity oscillations decreases with increasing energy. The density of states oscillations are most pronounced at negative sample biases and decay with increasing energy. This is consistent with the density of states for a $1 \mathrm{D}$ electronic state, which exhibits a maximum at the bottom of the band. Here we tentatively conclude that the electronic state with a band minimum at $\mathrm{E}_{0}=-0.3-0.35 \mathrm{eV}$ provides the Fermi electrons. First of all, we note that the density of states oscillates very strongly. This is attributed to the slow decay of Friedel oscillations in 1D systems resulting in pronounced standing wave patterns. The spill over at the ends appears to be quite low, although we cannot exclude some contributions. 
Most importantly, however, is the wave length of the oscillations of about $4.8-5 \mathrm{~nm}$, which corresponds exactly with the measured preferences for certain lengths in the histogram displayed in Fig. 7.2. From the observed direct match between the observed oscillations in the density of states and the preferred size of the wires we can only conclude that quantum size effects are responsible for the obtained size distribution of the Ir wires on $\mathrm{Ge}(001)$. We do note that for a 1D system the Fermi wavelength, $\lambda_{F}$, is directly coupled to the number density of free electrons, $n_{1}$, at the Fermi level, irrespective of the effective mass of the electrons: $\lambda_{F}=\frac{4}{n_{1}}$. With $\lambda_{F}=9.6 \mathrm{~nm}$ one arrives at $\mathrm{n}_{1}=0.42 \mathrm{~nm}^{-1}$, or the Ir atoms contribute roughly $\frac{1}{3}$ electrons per period to the DOS in the wires at the Fermi level.

Two last remarks have to be made about the histogram of the lengths of the Ir nanowires. These lengths are certainly subject to a length limitation imposed by the local width of the terraces. Therefore and unfortunately, the exact size of the histogram does not provide insight in the relative energies of the various sizes. However, it is noted that a preference for smaller lengths is inhibitive for the outgrowth to micrometer lengths. We believe that this is the reason for the lack of success of our attempts to grow welldefined, almost macroscopic domains of Ir wires in contrast to the Pt and the $\mathrm{Au}$-induced wires on $\mathrm{Ge}(001)$. Most important in the present context is, however, a preference for lengths with multiples of approximately $4.8 \mathrm{~nm}$, i.e. 6 periods of $0.8 \mathrm{~nm}$ within the nanowire. This would indicate that the $1 \mathrm{D}$ analogue of equation (1) is well-satisfied and one is dealing with a combined electronic effect: quantum size effects and constructive interference of the Friedel oscillations, which hardly decay along the wire.

\subsection{Conclusions}

In summary, the deposition and subsequent annealing of submonolayer amounts of Ir on $\mathrm{Ge}(001)$ results into the formation of Ir nanowires. The nanowires are defect free, have a constant width of $0.57 \mathrm{~nm}$ and can be as long as $100 \mathrm{~nm}$. Their periodicity along the wire corresponds to $0.8 \mathrm{~nm}$. The length histogram reveals strong preferences for lengths with multiples of about $4.8 \mathrm{~nm}$, i.e. 6 elementary units of the nanowire. These nanowires are metallic and the density of states shows well-defined oscillations along the wires with a period that corresponds to the size distribution. We ascribe these findings to quantum size stabilization of selected wire lengths, very 
similar to well-known thickness preference in thin films. Unlike the thin film case, we are able to directly probe the relevant spatial variation of the density of states, which allows us to pin down the electronic nature of the length preference. The nanowires have a preference for magic lengths that are integer multiples of half of the Fermi wave length. 


\section{Bibliography}

[1] Moore, G. E. Electronics 38, 114 (1965).

[2] Brunco, D. P., De Jaeger, B., Eneman, G., Mitard, J., Hellings, G., Satta, A., Terzieva, V., Souriau, L., Leys, F. E., Pourtois, G., Houssa, M., Winderickx, G., Vrancken, E., Sioncke, S., Opsomer, K., Nicholas, G., Caymax, M., Stesmans, A., Van Steenbergen, J., Mertens, P. W., Meuris, M., and Heyns, M. M. .

[3] Yanson, A., Bollinger, G., van den Brom, H., Agrait, N., and van Ruitenbeek, J. M. Nature 395, 783 (1998).

[4] Ohnishi, H., Kondo, Y., and Takayanagi, K. Nature 395, 780 (1998).

[5] Klitzing, K. V., Dorda, G., and Pepper, M. Phys. Rev. Lett. 45, 494 (1980).

[6] Tsui, D. C., Stormer, H. L., and Gossard, A. C. Phys. Rev. Lett. 48, 1559 (1982).

[7] Langlin, R. B. Phys. Rev. Lett. 50, 1395 (1983).

[8] Geim, A. K. and Novoselov, K. S. Nat. Mater. 6, 183 (2007).

[9] Novoselov, K. S., Geim, A. K., Morozov, S. V., Jiang, D., Katsnelson, M. I., Grigorieva, I. V., Dubonos, S. V., and Firsov, A. A. Nature 438, 197 (2005).

[10] Tomonaga, S. Prog. Theor. Phys. 5, 544 (1950).

[11] Luttinger, J. M. J. Math. Phys. 4, 1154 (1963).

[12] Yanson, A. I., Rubio Bollinger, G., Van Den Brom, H. E., Agraït, N., and Van Ruitenbeek, J. M. Nature 395, 783 (1998). 
[13] Oncel, N., Van Houselt, A., Huijben, J., Hallbäck, A.-S., Gurlu, O., Zandvliet, H. J. W., and Poelsema, B. Phys. Rev. Lett. 95, 1 (2005).

[14] Van Houselt, A., Oncel, N., Poelsema, B., and Zandvliet, H. J. W. Nanoletters 6, 1439 (2006).

[15] Gambardella, P., Dallmeyer, A., Maiti, K., Malagoli, M. C., Eberhardt, W., Kern, K., and Carbone, C. Nature 416, 301 (2002).

[16] Nilius, N., Wallis, T. H., and Ho, W. Science 297, 1853 (2002).

[17] Yeom, H. W., Takeda, S., Rotenberg, E., Matsuda, I., Horikoshi, K., Schaefer, J., Lee, C. M., Kevan, S. D., Ohta, T., Nagao, T., and Hasegawa, S. Phys. Rev. Lett. 82, 4898 (1999).

[18] Losio, R., Altmann, K. N., Kirakosian, A., Lin, J. ., Petrovykh, D. Y., and Himpsel, F. J. Phys. Rev. Lett. 86, 4632 (2001).

[19] Segovia, P., Purdle, D., Hengsberger, M., and Baer, Y. Nature 402, 504 (1999).

[20] Gurlu, O., Adam, O., Zandvliet, H., and Poelsema, B. Appl. Phys. Lett. 83, 4610 (2003).

[21] Wang, J., Li, M., and Altman, E. I. Phys. Rev. B 70, 1 (2004).

[22] Wang, J., Li, M., and Altman, E. I. Surf. Sci. 596, 126 (2005).

[23] Schäfer, J., Blumenstein, C., Meyer, S., Wisniewski, M., and Claessen, R. Phys. Rev. Lett. 101, 236802 (2008).

[24] van Houselt, A., Fischer, M., Poelsema, B., and Zandvliet, H. J. W. Phys. Rev. B 78, 233410 (2008).

[25] Zandvliet, H. J. W., Swartzentruber, B. S., Wulfhekel, W., Hattink, B. J., and Poelsema, B. Phys. Rev. B 57, R6803 (1998).

[26] Sauer, S., Fuchs, F., Bechstedt, F., Blumenstein, C., and Schäfer, J. Phys. Rev. B 81, 075412 (2010).

[27] Howes, P. B., Norris, C., Finney, M. S., Vlieg, E., and Van Silfhout, R. G. Phys. Rev. B 48, 1632 (1993). 
[28] Van Houselt, A., Van Gastel, R., Poelsema, B., and Zandvliet, H. J. W. Phys. Rev. Lett. 97 (2006).

[29] Fischer, M., Van Houselt, A., Kockmann, D., Poelsema, B., and Zandvliet, H. J. W. Phys. Rev. B 76, 245429 (2007).

[30] Nakatsuji, K., Niikura, R., Shibata, Y., Yamada, M., Iimori, T., and Komori, F. Phys. Rev. B 80, 081406 (2009).

[31] Erwin, S. C. and Weitering, H. H. Phys. Rev. Lett. 81, 2296 (1998).

[32] Snijders, P. C. and Weitering, H. H. Rev. Mod. Phys. 82, 309 (2010).

[33] van Houselt, A., Kockmann, D., Mocking, T. F., Poelsema, B., and Zandvliet, H. J. W. Phys. Rev. Lett. 103, 209701 (2009).

[34] Schäfer, J., Blumenstein, C., Meyer, S., Wisniewski, M., and Claessen, R. Phys. Rev. Lett. 103, 209702 (2009).

[35] van Houselt, A., Gnielka, T., M. Fischer, M., Aan de Brugh, J. M. J., Oncel, N., Kockmann, D., Heid, R., Bohnen, K. P., Poelsema, B., and Zandvliet, H. J. W. Surf. Sci. 602, 1731 (2008).

[36] Kockmann, D., Mocking, T. F., Houselt, A. v., Poelsema, B., and Zandvliet, H. J. W. J. Phys. Chem. C 113, 17156 (2009).

[37] Schäfer, J., Meyer, S., Blumenstein, C., Roensch, K., Claessen, R., Mietke, S., Klinke, M., Podlich, T., Matzdorf, R., Stekolnikov, A. A., Sauer, S., and Bechstedt, F. New J. Phys. 11, 49 (2009).

[38] Peumans, P., Yakimov, A., and Forrest, S. R. J. Appl. Phys. 93, 3693 (2003).

[39] Lunt, R. R., Benziger, J. B., and Forrest, S. R. Adv. Mater. 19, 4229 (2007).

[40] Blochwitz, J., Pfeiffer, M., Fritz, T., and Leo, K. Appl. Phys. Lett. 73, 729 (1998).

[41] Isvoranu, C., Åhlund, J., Wang, B., Ataman, E., Mrtensson, N., Puglia, C., Andersen, J. N., Bocquet, M. ., and Schnadt, J. J. Chem. Phys. 131 (2009). 
[42] Lippel, P. H., Wilson, R. J., Miller, M. D., Wöll, C., and Chiang, S. Phys. Rev. Lett. 62, 171 (1989).

[43] López-Moreno, S., Romero, A. H., Muñoz, A., and Schwingenschlögl, U. Phys. Rev. B $\mathbf{8 1}$ (2010).

[44] Van Houselt, A. and Zandvliet, H. J. W. Rev. Mod. Phys. 82, 1593 (2010).

[45] Sato, T., Iwatsuki, M., and Tochihara, H. J. Electron Microscopy 48, 1 (1999).

[46] Van Houselt, A., Van Gastel, R., Poelsema, B., and Zandvliet, H. J. W. Phys. Rev. Lett. 97, 266104 (2006).

[47] Horcas, I., Fernández, R., Gómez-Rodríguez, J. M., Colchero, J., Gómez-Herrero, J., and Baro, A. M. Rev. Sci. Instrum. 78 (2007).

[48] Saedi, A., Berkelaar, R. P., Kumar, A., Poelsema, B., and Zandvliet, H. J. W. Phys. Rev. B $\mathbf{8 2}$ (2010).

[49] Van Houselt, A. and Zandvliet, H. J. W. Rev. Mod. Phys. 82, 1593 (2010).

[50] Saedi, A., Van Houselt, A., Van Gastel, R., Poelsema, B., and Zandvliet, H. J. W. Nanoletters 9, 1733 (2009).

[51] McKee, R. A., Walker, F. J., Nardelli, M. B., Shelton, W. A., and Stocks, G. M. Science 300, 1726 (2003).

[52] Ishiyama, K., Taga, Y., and Ichimiya, A. Phys. Rev. B 51, 2380 (1995).

[53] Zandvliet, H. J. W., Louwsma, H. K., Hegeman, P. E., and Poelsema, B. Phys. Rev. Lett. 75, 3890 (1995).

[54] Ishiyama, K., Taga, Y., and Ichimiya, A. Surf. Sci. 349, 267 (1996).

[55] Scheuch, V., Voigtländer, B., and Bonzel, H. P. Surf. Sci. 372, 71 (1997).

[56] Bennett, P. A. and Von Känel, H. J. Phys. D 32, R71 (1999). 
[57] Tsui, F., He, L., Ma, L., Tkachuk, A., Chu, Y. S., Nakajima, K., and Chikyow, T. Phys. Rev. Lett. 91, 177203 (2003).

[58] Zandvliet, H. J. W., Van Houselt, A., and Hegeman, P. E. Surf. Sci. 605, 1129-1132 (2011).

[59] Zhu, W., Weitering, H. H., Wang, E. G., Kaxiras, E., and Zhang, Z. Phys. Rev. Lett. 93, 126102 (2004).

[60] Krause, M. R., Stollenwerk, A. J., Reed, J., LaBella, V. P., Hortamani, M., Kratzer, P., and Scheffler, M. Phys. Rev. B 75, 205326 (2007).

[61] Mocking, T. F., Hlawacek, G., and Zandvliet, H. J. W. Surf. Sci. 606, 924 (2012).

[62] Prabhakaran, K. and Ogino, T. Appl. Surf. Sci. 100, 518 (1996).

[63] Köhler, U., Jusko, O., Muller, B., Horn-von Hoegen, M., and Pook, M. Ultramicroscopy 42-44, 832 (1992).

[64] Niehus, H., Köhler, U., Copel, M., and Demuth, J. J. Microsc. 152, 735 (1988).

[65] Park, C., Bakhtizin, R., Hashizume, T., and Sakurai, T. J. Vac. Sci. Technol. B 12, 2049 (1994).

[66] Chang, C., Huang, Y., Chen, C., and Tsong, T. Surf. Sci. Lett. 267, 8 (1996).

[67] Tsay, J. S., Nieh, H. Y., Yang, C. S., Yao, Y. D., and Chin, T. S. J. Appl. Phys. 93, 8728 (2003).

[68] Fu, T.-Y., Lin, C.-L., and Tsay, S.-L. Surf. Sci. 600, 4058 (2006).

[69] Tsay, S.-L., Kuo, C.-Y., Lin, C.-L., Chen, W.-C., and Fu, T.-Y. Surf. Interface Anal. 40, 1641 (2008).

[70] Fu, T.-Y., Tsay, S.-L., and Lin, C.-L. J. Nanosci. Nanotechnol. 8, 608 (2008).

[71] Lin, C.-L., Tsay, S.-L., Chen, C.-R., Huang, X.-L., and Fu, T.-Y. J. Nanosci. Nanotechnol. 10, 4500 (2010). 
[72] Huang, X.-L., Chou, C.-H., Lin, C.-L., Tomaszewska, A., and Fu, T.-Y. Thin Solid Films 519, 8410 (2011).

[73] Huang, X.-L., Lin, C.-L., Tomaszewska, A., Chen, C.-R., and Fu, T.-Y. Nanoscale Res. Lett. 7, 189 (2012).

[74] Huang, X.-L., Tomaszewska, A., Lin, C.-L., Tsay, S.-L., Chou, C.-H., and Fu, T.-Y. Thin Solid Films 520, 5304 (2012).

[75] Zandvliet, H. J. W. and Van Silfhout, A. Surf. Sci. 195, 138 (1988).

[76] Zandvliet, H. J. W. Physics Reports 388, 1 (2003).

[77] Becker, R. S., Swartzentruber, B. S., Vickers, J. S., and Klitsner, T. Phys. Rev. B 39, 1633 (1989).

[78] Chaput, L., Dulot, F., Hanf, M., and Wetzel, P. Surf. Sci. 604, 513 (2010).

[79] Zilani, M. A. K., Liu, L., Xu, H., Feng, Y. P., Wang, X. ., and Wee, A. T. S. J. Phys.: Condens. Matter 18, 6987 (2006).

[80] Saedi, A., Poelsema, B., and Zandvliet, H. J. W. J. Phys.: Condens. Matter 22, 264007 (2010).

[81] Goldfarb, I. and Briggs, G. A. D. J. Mater. Res. 16, 744 (2001).

[82] Goldfarb, I. and Briggs, G. A. D. J. Vac. Sci. Technol. B 20, 1419 (2002).

[83] Sun, H. P., Chen, Y. B., Pan, X. Q., Chi, D. Z., Nath, R., and Foo, Y. L. Appl. Phys. Lett. 87, 211909 (2005).

[84] Sun, H. P., Chen, Y. B., Pan, X. Q., Chi, D. Z., Nath, R., and Foo, Y. L. Appl. Phys. Lett. 86, 071904 (2005).

[85] Tsuruta, A., Chu, W. G., Tamura, K., Ishii, H., Owari, M., and Nihei, Y. Surf. Interf. Anal. 37, 230 (2005).

[86] Gaudet, S., Detavernier, C., Kellock, A. J., Desjardins, P., and Lavoie, C. J. Vac. Sci. Technol. A 24, 474 (2006). 
[87] Myagkov, V. G., Mikhlin, Y. L., Bykova, L. E., Bondarenko, G. N., and Turpanov, I. A. Dokl. Phys. Chem. 431, 72 (2010).

[88] Goldfarb, I. Surf. Sci. 601, 2756 (2007).

[89] Goldfarb, I., Cohen-Taguri, G., Grossman, S., and Levinshtein, M. Phys. Rev. B 72, 075430 (2005).

[90] Goldfarb, I., Grossman, S., and Cohen-Taguri, G. Appl. Surf. Sci. 252, 5355 (2006).

[91] Goldfarb, I. and Briggs, G. A. D. Phys. Rev. B 60, 4800 (1999).

[92] Goldfarb, I., Banks-Sills, L., Eliasi, R., and Briggs, G. A. D. Interf. Sci. 10, 75 (2002).

[93] Brongersma, S. H., Castell, M. R., Perovic, D. D., and Zinke-Allmang, M. J. Vac. Sci. Technol. B 16, 2188 (1998).

[94] Brongersma, S. H., Castell, M. R., Perovic, D. D., and Zinke-Allmang, M. Phys. Rev. Lett. 80, 3795 (1998).

[95] Choi, J., Lim, D. K., Kim, Y., and Kim, S. J. Phys. Chem. C 114, 8992 (2010).

[96] De Keyser, K., Van Meirhaeghe, R. L., Detavernier, C., Jordan-Sweet, J., and Lavoie, C. J. Electrochem. Soc. 157, H395 (2010).

[97] Tersoff, J. and Tromp, R. M. Phys. Rev. Lett. 70, 2782 (1993).

[98] Hill, R. and Faridur Rahman, F. H. M. Nucl. Instrum. Methods A 645, 96 (2011).

[99] Van Gastel, R., Barriss, L., Stanford, C., Hlawacek, G., Scipioni, L., Merkle, A. P., Voci, D., Fenner, C., Zandvliet, H. J. W., and Poelsema, B. Microsc. Microanal. 17, 928 (2011).

[100] Eom, D., Prezzi, D., Rim, K. T., Zhou, H., Lefenfeld, M., Xiao, S., Nuckolls, C., Hybertsen, M. S., Heinz, T. F., and Flynn, G. W. Nanoletters $\mathbf{9}, 8$ (2009).

[101] Barral, M. A., Weissmann, M., and Llois, A. M. Phys. Rev. B 72, 125433 (2005). 
[102] Li, A., Liu, F., and Lagally, M. G. Phys. Rev. Lett. 85, 1922 (2000).

[103] Zandvliet, H. J. W. and Van Gastel, R. Phys. Rev. Lett. 99, 136103 (2007).

[104] Bussmann, E. Phys. Rev. Lett. 101, 266101 (2008).

[105] Schulte, F. K. Surf. Sci. 55, 427 (1976).

[106] Feibelman, P. J. Phys. Rev. B 27, 1991 (1983).

[107] Hinch, B. J., Koziol, C., Toennies, J. P., and Zhang, G. Europhys. Lett. 10, 341 (1989).

[108] Zhang, Z., Niu, Q., and Shih, C. . Phys. Rev. Lett. 80, 5381 (1998).

[109] Segovia, P., Purdie, D., Hengsberger, M., and Baer, Y. Nature 402, 504-507 (1999).

[110] Auslaender, O. M., Yacoby, A., De Picciotto, R., Baldwin, K. W., Pfeiffer, L. N., and West, K. W. Science 295, 825 (2002).

[111] Bockrath, M., Cobden, D. H., Lu, J., Rinzler, A. G., Smalley, R. E., Balents, L., and McEuen, P. L. Nature 397, 598 (1999).

[112] Lee, J., Eggert, S., Kim, H., Kahng, S. ., Shinohara, H., and Kuk, Y. Phys. Rev. Lett. 93, 166403 (2004).

[113] Blumenstein, C., Schäfer, J., Mietke, S., Meyer, S., Dollinger, A., Lochner, M., Cui, X. Y., Patthey, L., Matzdorf, R., and Claessen, R. Nature Physics 7, 776 (2011).

[114] Nakatsuji, K. and Komori, F. Nature Physics 8, 174 (2012).

[115] Blumenstein, C., Schäfer, J., Mietke, S., Meyer, S., Dollinger, A., Lochner, M., Cui, X. Y., Patthey, L., Matzdorf, R., and Claessen, R. Nature Physics 8, 174 (2012).

[116] Heimbuch, R., Kuzmin, M., and Zandvliet, H. J. W. Nature Physics 8, 697 (2012).

[117] Haldane, F. D. M. J. Phys. C 14, 2585 (1981). 
[118] Kane, C. L. and Fisher, M. P. A. Phys. Rev. Lett. 68, 1220 (1992).

[119] Giamarchi, T. Oxford University Press (2004).

[120] Oncel, N. and Nicholls, D. J. Cond. Mat. Phys. 25, 014010 (2013).

[121] Smith, A. R., Chao, K. ., Niu, Q., and Shih, C. . Science 273, 226 (1996).

[122] Friedel, J. Adv. Phys. 3, 446 (1954).

[123] Crommie, M. F., Lutz, C. P., and Eigler, D. M. Nature 363, 524 (1993).

[124] Jia, Y., Wu, B., Li, C., Einstein, T. L., Weitering, H. H., and Zhang, Z. Physical Review Letters 105, 066101 (2010).

[125] Jonker, B. T., Bartelt, N. C., and Park, R. L. Surf. Sci. 127, 183 (1983).

[126] Jonker, B. T. and Park, R. L. Surf. Sci. 146, 93 (1984).

[127] Jonker, B. T. and Park, R. L. Surf. Sci. 146, 511 (1984).

[128] Scheunemann, T., Feder, R., Henk, J., Bauer, E., Duden, T., Pinkvos, H., Poppa, H., and Wurm, K. Solid State Comm. 104, 787 (1997).

[129] Bollmann, T. R. J., Van Gastel, R., Zandvliet, H. J. W., and Poelsema, B. Phys. Rev. Lett. 107, 176102 (2011).

[130] Bollmann, T. R. J., Van Gastel, R., Zandvliet, H. J. W., and Poelsema, B. Phys. Rev. Lett. 107, 136103 (2011).

[131] Bollmann, T. R. J., Van Gastel, R., Zandvliet, H. J. W., and Poelsema, B. New J. of Phys. 13, 103025 (2011). 



\section{Summary}

This thesis deals with the deposition of three different metals, namely $\mathrm{Au}$, Co and Ir, on an atomically clean Ge substrate. It covers a single topic: one-dimensional structures. By depositing very small amounts (up to a few monolayers) of metal atoms on a Ge substrate and a consecutive annealing step, the physical and electronic properties of the resulting surface deviates from the clean substrate and the deposited metal in its pure form. When we deposit the $5 d$-transition metals, $\mathrm{Au}$ and $\mathrm{Ir}$, on the $\mathrm{Ge}(001)$ surface, the surface reconstructs into narrow nanowires, only two to several atoms wide. The deposition of Co on $\mathrm{Ge}(001)$ and $\mathrm{Ge}(111)$, however, results into nanoislands and nanocrystals.

The capability of a scanning tunneling microscope to image metal-induced nanostructures at an atomic resolution, makes it a perfect method for determining the surface morphology at the atomic scale. Furthermore, its spectroscopic capabilities are a powerful tool when it comes to locally extracting electronic and dynamic properties. The experimental setup and the sample preparation procedure are dealt with in Chapter 2.

In Chapter 3 we focus on the structural and electronic properties of Auinduced nanowires. Furthermore, we compare two different methods for preparing Au-induced nanowires. Au can be deposited on a cold surface followed by a subsequent annealing step, or directly onto a hot surface. In both cases the surface will be covered with Au-induced nanowires. STM measurements indicate that the Au-induced nanowires are several atoms high and are $1.6 \mathrm{~nm}$ spaced apart. The top of these nanowires is comprised of dimers that have their bond aligned in a direction perpendicular to the nanowire. These dimers are buckled and some of the dimers show dynamics. Spectroscopy 
measurements indicate that the troughs are slightly more metallic than the nanowires.

The dynamic dimers observed in Chapter 3 are further examined in Chapter 4. Neighbouring dimers on top of the Au-induced nanowires buckle in an opposite direction, leading to rows with a zigzag appearance. At phase boundaries we find dimers that continuously flip back and forth between the two buckled states. This flip-flop motion is fully thermally activated.

In the second part of this Chapter we discuss the adsorption of Cu-phthalocyanine molecules on the Au-modified Ge(001) surface. Six different adsorption configurations have been observed. In four of these configurations the molecule adsorps in a 'molecular bridge' configuration, in which the molecule bridges two adjacent nanowires. Furthermore, rotation and diffusion events were observed at setpoint biases of $>1 \mathrm{~V}$.

When we deposit less than a monolayer of Co on a $\mathrm{Ge}(111)$ substrate we find that the surface reconstructs into $(\sqrt{13} \times \sqrt{13}) \mathrm{R} 13.9^{\circ}$ and $(2 \times 2)$ reconstructed nano islands, depending on the annealing temperature. In Chapter 5 we examine both the exact atomic structure of the islands and the transition from one to the other. At a coverage of 4 monolayers we only find large $(2 \times 2)$ nano islands. On these islands we observe several different domain boundaries and a novel $(6 \times 2)$ reconstruction.

In Chapter 6 we investigate the formation of Co-induced nanocrystals on the $\mathrm{Ge}(001)$ and $\mathrm{Ge}(111)$ surfaces. When several monolayers of Co are deposited onto a $\mathrm{Ge}(001)$ surface we find that strain starts to affect the surface morphology. To some extent the surface is similar to the $\mathrm{Co} / \mathrm{Si}(001)$ system, but we find several differences. In this chapter we observe that in the case of $\mathrm{Co}$ on $\mathrm{Ge}(001)$ there exist two types of nanocrystals that are either flattopped or peaked. On $\mathrm{Ge}(111)$ we find elongated and compact nanocrystals. Furthermore, in the case of $\mathrm{Co}$ on $\mathrm{Ge}(111)$ we find that these nanocrystals prefer to nucleate either on domain boundaries or step edges.

And finally in Chapter 7 we study Ir nanowires on a Ge(001) surface. In these metallic wires, that consist of double rows of Ir atoms, we are able to visualize electron standing wave patterns. The conducting electrons (i.e. the electrons close to the Fermi level) are scattered at both ends of the wire. The interference of these Friedel oscillations leads to the standing wave patterns 
and the quantization of nanowires lengths. In this chapter we show that the growth of Ir nanowires on a Ge(001) surface is stabilized by an electronic effect. 



\section{Samenvatting}

Dit proefschrift beschrijft de depositie van drie verschillende metalen, namelijk $\mathrm{Au}$, Co en Ir, op een atomair schoon gemaakt Ge substraat. Het behandelt een enkel onderwerp: één-dimensionale structuren. Dankzij depositie van zeer kleine hoeveelheden (tot maar enkele monolagen) metaal op een $\mathrm{Ge}$ substraat waarna een verhittingsstap volgt zien we dat de fysische en electronische eigenschappen van het resulterende oppervlak enorm verschillen van het schone oppervlak en het gedeponeerde metaal in zijn pure vorm. In het geval van depositie van de $5 d$-overgangsmetalen Au en Ir op het Ge(001) oppervlak zien we dat het oppervlak reconstrueert in zeer smalle nanodraden van twee tot slechts enkele atomen breed. De depositie van Co op $\mathrm{Ge}(001)$ en $\mathrm{Ge}(111)$ leidt echter tot de vorming van nano-eilanden en nanokristallen.

Het vermogen van een scanning tunneling microscoop (STM) om metaalgeïnduceerde nanostructuren weer te geven met atomaire resolutie maakt het tot een perfecte meetmethode voor het bepalen van de oppervlaktemorfologie. De spectroscopische mogelijkheden van de STM zijn bovendien een zeer nuttig instrument als het gaat om het bepalen van de lokale elektronische en dynamische eigenschappen. De experimentele opstelling en de preparatiemethode van het substraat worden besproken in Hoofdstuk 2 .

In Hoofdstuk 3 focussen we op de structurele en elektronische eigenschappen van Au-geïnduceerde nanodraden. Daarnaast vergelijken we twee verschillende methoden voor het maken van Au-geïnduceerde nanodraden. Au atomen worden opgedampt op een Ge(001) oppervlak bij kamertemperatuur waarna het substraat wordt verhit, of direct op een verwarmd oppervlak. Echter, het blijkt dat in beide gevallen de methode resulteert in een oppervlak dat netjes bedekt is met nanodraden. STM metingen indiceren dat 
de Au-geïnduceerde nanodraden verscheidene atoomlagen hoog zijn en een tussenruimte van $1.6 \mathrm{~nm}$ hebben. De top van deze nanodraden bestaat uit dimeren die hun binding loodrecht op de draadrichting hebben staan. Deze dimeren zijn gekanteld en sommige van deze dimeren zijn zeer dynamisch. Spectroscopie metingen tonen aan dat de geulen tussen de draden in iets metallischer zijn dan de draden zelf.

De in Hoofdstuk 3 geobserveerde dynamische dimeren worden verder bestudeerd in Hoofdstuk 4. Aaneengrenzende dimeren bovenop de Au-geïnduceerde nanodraden kantelen in een tegenovergestelde richting wat leidt tot een zigzag uiterlijk. Bij fasegrenzen vinden we dimeren die continu schakelen tussen de twee mogelijke kantelconfiguraties. Deze flip-flop beweging is volledig thermisch geactiveerd.

In het tweede deel van dit hoofdstuk beschrijven we de adsorptie van $\mathrm{Cu}$ phtalocyanine moleculen op een Au-gemodificeerd Ge(001) oppervlak. Er zijn zes verschillende adsorptie configuraties geobserveerd. In vier van deze configuraties adsorbeert het molecuul in een 'moleculaire brug' configuratie, waarbij het molecuul een brug vormt tussen twee aangrenzende nanodraden. Ook werden er rotatie en diffusie gevallen waargenomen bij een gap-spanning $\operatorname{van}>1 \mathrm{~V}$.

Wanneer we cobalt atomen verdampen op een Ge(111) oppervlak met een bedekkingsgraad van minder dan een monolaag zien we dat het oppervlak recontrueert. Afhankelijk van de temperatuur waarop we het substraat verhitten vinden we $(\sqrt{13} \times \sqrt{13}) \mathrm{R} 13.9^{\circ}$ en $(2 \times 2)$ gereconstrueerde nano-eilanden. In Hoofdstuk 5 onderzoeken we de exacte atomaire structuur van beide reconstructies en hoe de overgang van de ene naar de andere plaatsvindt. Bij een bedekking van 4 monolagen vinden we alleen grote $(2 \times 2)$ nano-eilanden. Op deze eilanden vinden we drie verschillende types domeingrenzen en een nieuwe $(6 \times 2)$ reconstructie.

In Hoofdstuk 6 onderzoeken we de formatie van Co-geïnduceerde nanocrystallen op $\mathrm{Ge}(001)$ en $\mathrm{Ge}(111)$ oppervlakken. Wanneer verscheidene monolagen Co worden verdampt op een $\mathrm{Ge}(001)$ oppervlak zien we dat spanning een invloed begint te hebben op de oppervlakte morfologie. Tot op zekere hoogte lijkt het $\mathrm{Co} / \mathrm{Ge}(001)$ systeem erg op het $\mathrm{Co} / \mathrm{Si}(001)$ systeem, maar ook zijn er een aantal verschillen. In dit hoofdstuk zien we dat in het geval van Co op Ge(001) twee verschillende types nanokristallen ontstaan. Deze hebben 
ofwel een afgevlakte top, of een puntige. Op Ge(111) vinden we compacte en langwerpige nanokristallen. In het $\mathrm{Co}$ op $\mathrm{Ge}(111)$ systeem vinden we ook dat de nanokristallen voornamelijk nucleëren op domeingrenzen en stapranden.

Tot slot, in Hoofdstuk 7 bestuderen we Ir nanodraden op een Ge(001) oppervlak. In deze metallische nanodraden, die bestaan uit dubbele rijen van Ir atomen, kunnen wij staande golf patronen van elektronen visualiseren. De geleidingselektronen (i.e. de elektronen dicht bij het Fermi niveau) worden gevangen tussen de twee uiteinden van de draad. De interferentie van Friedel oscillaties leidt tot de staande golf patronen en de kwantisatie van nanodraad lengtes. In dit hoofdstuk laten we zien dat de groei van Ir nanodraden op een $\mathrm{Ge}(001)$ oppervlak wordt gestabiliseerd door een elektronisch effect. 



\section{Publications}

- D. Kockmann, T.F. Mocking, A. van Houselt, B. Poelsema, H.J.W. Zandvliet, 'Structural and Electronic Properties of Au Induced Nanowires on Ge(001)', J. Phys. Chem. C 113, 17156-17159 (2009)

- A. van Houselt, D. Kockmann, T.F. Mocking, B. Poelsema, H.J.W. Zandvliet, 'Comment on 'New Model System for a One-Dimensional Electron Liquid: Self-Organized Atomic Gold Chains on Ge(001)", Phys. Rev. Lett 103, 209701 (2009)

- T.F. Mocking, D. Stam, B. Poelsema, H.J.W. Zandvliet, 'Dynamics of Au-induced nanowires on Ge(001)', Surf Sci 604, 2021-2023 (2010)

- R.P. Berkelaar, H. Söde, T.F. Mocking, A. Kumar, B. Poelsema, and H.J.W. Zandvliet, 'Molecular Bridges', J. Phys. Chem. C 115, 2268-2272 (2011)

- T.F. Mocking, A. Kumar, R.P. Berkelaar, 'Moleculaire bruggen, dynamica en massatransport op nanoschaal', Nevacblad 49, 7-12 (2011)

- T.F. Mocking, G. Hlawacek, H.J.W. Zandvliet, 'Cobalt induced nanocrystals on Ge(001)', Surf. Sci. 606, 924 (2012)

- G. Hlawacek, V. Veligura, S. lorbek, T.F. Mocking, A. George, R. van Gastel, H.J.W. Zandvliet, and B. Poelsema, 'Exploiting channeling in helium ion microscopy', Beilstein J. Nanotechnol. 3, 507 (2012)

- T.F. Mocking, B. Poelsema, H.J.W. Zandvliet, 'Cobalt containing nano-islands on Ge(111)-c(2×8)', Surf. Sci., 610, 59 (2013) 
- T.F. Mocking, P. Bampoulis, N. Oncel, B. Poelsema and H.J.W. Zandvliet, 'Electronically stabilized nanowire growth', Accepted for publication in Nature Communications (2013) 


\section{Dankwoord}

Het maken van een proefschrift is een proces waar 4 jaar overheen gaan. In die periode van 4 jaar hebben een flink aantal mensen een belangrijk aandeel in dit werk gehad. Daarom wilde ik van deze mogelijkheid gebruik maken om verscheidene personen te danken voor hun hulp en steun.

Bovenal wil ik mijn promotor Harold bedanken voor zijn energie, vrolijkheid, en niet onbelangrijk: zijn uitstekende dagelijkse begeleiding. Niet alleen was het geen probleem om vele natuurkundige vragen met engelengeduld te beantwoorden, maar ook was er die positieve instelling, nimmeraflatende enthousiasme, de motiverende one-liners en ook de gezelligheid aan de koffietafel. Harold, bedankt voor het mij bijbrengen van een hoop kennis en expertise. Hopelijk weet ik je in de toekomst nog eens te verslaan met handjedrukken. Verder wil ik ook graag Bene bedanken voor goede discussies, maar ook voor het uitgebreide gepuzzel met atoompjes.

Mijn dank gaat ook zeer sterk uit naar de drie masterstudenten die mij flink geholpen hebben om verscheidene hoofdstukken in dit thesis mogelijk te maken. Of ze uit Nederland, Duitsland of Griekenland kwamen, de motivatie en het enthousiasme waren voor alledrie erg hoog. Daan, Hajo en Pantelis, ik dank jullie voor een prettige en voor mij ook leerzame samenwerking en tijd bij de PIN-groep.

Daarnaast zijn er vele collega's geweest waarvan sommigen tijdens deze 4 jaar hun PhD of MSc al afrondden, maar die toch hebben bijgedragen aan een zeer fijne en aangename tijd bij de PIN groep. Hen en ook de huidige collega's wil ik graag bedanken. Een aantal namen wil ik toch graag in het bijzonder noemen: Frank, Robbin en Amir, we hebben fijn gerocked samen 
als Quantum of Sound! Avijit, Robin en René, jullie waren fantastische kantoormaatjes. We hadden een hele goede sfeer in het kantoor en konden praten over alles: werk-, maar ook niet werkgerelateerd. Ook waren de tijden in de USA, Parijs, Würzburg en ook München natuurlijk ronduit legendarisch!

Tijdens het uitvoeren van experimenten kom je vanzelfsprekend ook talloze problemen en technische mankementen van de opstelling tegen. Deze werden echter snel en op daadkrachtige wijze verholpen door Hans en Herman, waarvoor dank. Simone en Rianne, bedankt voor het regelen van alle admistratieve zaken.

Kai, Patrick, Erik, Hairong, Maciej, Daniel, Vasilisa, Ali, Stefan, Raoul, Herbert en de rest van de PIN groep: heel erg bedankt voor de goede sfeer in de groep, in de kroeg en aan de koffietafel.

Uiteraard verdient de lunchclub ook een bedankje. Het was even spannend, maar gelukkig wist iedereen aan het campusvirus te ontkomen. Koert, TO, Theo en Jasper bedankt voor alle goede tijden. Koert, jij mag mij als paranimf nu eindelijk eens terugbetalen voor al die keren dat ik je 's ochtends vroeg uit bed en naar college heb gesleept.

Zonder mijn familie was ik natuurlijk ook niet zover gekomen als ik nu ben. Dus: Tilly, Gerard en ook Ceriel, bedankt voor jullie voortdurende steun en vertrouwen ondanks al jullie tegenslagen. Tot slot wil ik de belangrijkste persoon in mijn leven nog graag noemen: Eliane, jij bent er altijd voor mij en bij jou kan ik helemaal mezelf zijn. Met jou ben ik ontzettend gelukkig! 

